\title{
Rastreamento de objetos baseado em reconhecimento estrutural de padrões
}

\author{
Ana Beatriz Vicentim Graciano \\ DISSERTAÇÃO APRESENTADA \\ $\mathrm{AO}$ \\ INSTITUTO DE MATEMÁTICA E ESTATÍSTICA \\ DA \\ UNIVERSIDADE DE SÃO PAULO \\ PARA \\ OBTENÇÃO DO TÍTULO DE MESTRE \\ EM \\ CIÊNCIAS

\begin{abstract}
Área de Concentração: Ciência da Computação Orientador: Prof. Dr. Roberto Marcondes Cesar Jr.
\end{abstract}

Durante a elaboração deste trabalho, a autora recebeu auxílio financeiro do CNPq.

- São Paulo, março de 2007. - 



\title{
Rastreamento de objetos baseado em reconhecimento estrutural de padrões
}

\author{
Este exemplar corresponde à redação \\ final da dissertação devidamente corrigida \\ e defendida por Ana Beatriz Vicentim Graciano \\ e aprovada pela Comissão Julgadora.
}

São Paulo, março de 2007.

Banca Examinadora:

Prof. Dr. Roberto Marcondes Cesar Jr. (orientador) - IME/USP

Prof $^{a}$. Dr ${ }^{a}$. Nina Sumiko Tomita Hirata - IME/USP

Prof $^{\mathrm{a}}$. Dr ${ }^{\mathrm{a}}$. Maria Cristina Ferreira de Oliveira - ICMC/USP 
Ana Beatriz Vicentim Graciano: Rastreamento de objetos baseado em reconhecimento estrutural de padrões , Dissertação de Mestrado, (C) 2007 
A meus pais, Moacir e Maria Aparecida, pelo amparo e incentivo constantes em minha vida. 



\section{RESUMO}

Diversos problemas práticos envolvendo sistemas de visão computacional, tais como vigilância automatizada, pesquisas de conteúdo específico em bancos de dados multimídias ou edição de vídeo, requerem a localização e o reconhecimento de objetos dentro de seqüências de imagens ou vídeos digitais.

Mais formalmente, denomina-se rastreamento o processo de determinação da posição de certo(s) objeto(s) ao longo do tempo numa seqüência de imagens. Já a tarefa de reconhecimento caracteriza-se pela classificação desses objetos de acordo com algum rótulo pré-estabelecido ou apoiada em conhecimento prévio tipicamente introduzido através de um modelo dos objetos de interesse.

No entanto, rastrear e classificar objetos em vídeo digital são tarefas desafiadoras, tanto pelas dificuldades inerentes a esse tipo de elemento pictórico, quanto pelo variável grau de complexidade que os quadros sob análise podem apresentar.

Este documento apresenta uma metodologia baseada em modelo para rastrear e reconhecer objetos em vídeo digital através de uma representação por grafos relacionais com atributos (ARGs). Tais estruturas surgiram dentro do paradigma de reconhecimento estrutural de padrões e têm se mostrado bastante flexíveis e poderosas para modelar problemas diversos, pois podem transmitir dados quantitativos, relacionais, estruturais e simbólicos.

Como modelo e entrada são descritos através desses grafos, a questão de reconhecimento é interpretada como um problema de casamento inexato entre grafos, que consiste em mapear os vértices do ARG de entrada nos vértices do ARG modelo. Em seguida, é realizado o rastreamento dos objetos de acordo com uma transformação afim derivada de parâmetros obtidos da etapa de reconhecimento. Para validar a metodologia proposta, resultados sobre seqüências de imagens digitais, sintéticas e reais, são apresentados e discutidos. 



\section{ABSTRACT}

Several practical problems involving computer vision systems, such as automated surveillance, content-based queries in multimedia databases or video editing require the location and recognition of objects within image sequences or digital video.

More formally, the process of determining the position of certain objects in an image sequence throughout time is called tracking, whereas the recognition task is characterized by the classification of such objects according to pre-defined labels or a priori knowledge, tipically introduced by means of a model of the target objects.

However, tracking and recognition of objects in digital video are not simple tasks, either because of the inherent difficulties of such a pictorial element, or due to the variable level of complexity that the frames under consideration might present.

This document presents a model-based methodology for tracking and recognizing objects represented by attributed relational graphs (ARGs) in digital video. These structures have arisen from the paradigm of structural pattern recognition and have proven to be very flexible and powerful for modelling various problems, as they can hold many sorts of data (e.g: quantitative, relational, structural and symbolic).

Since both model and input data are described through these graphs, the recognition matter may be interpreted as an inexact graph matching problem, which consists in finding a correspondence between the set of vertices of the input ARG and that of the model ARG. In the next step, object tracking is performed according to an affine transform derived from parameters extracted from the recognition phase. To validate the proposed methodology, results obtained from real and synthetic digital image sequences are presented and discussed. 



\section{AGRADECIMENTOS}

No esporte, a vitória é sempre de um time, seja esse composto por uma grande equipe ou um único atleta e seu treinador. Da mesma forma, a conclusão de meu mestrado é fruto dos esforços de um time: orientador, colaboradores, família e amigos. Assim, registro aqui minha gratidão a todos os que me acompanharam nessa trajetória...

...A Deus, pelo dom gratuito da vida e pelas inúmeras bençãos e oportunidades concedidas no meu viver, sem as quais este trabalho jamais poderia ter sido realizado.

Aos meus pais muito amados, Moacir e Maria Aparecida, pela formação que me proporcionaram, pelo amor e dedicação que me dispensam, pelo apoio constante, pela amizade, pelas orientações e pelos incentivos.

Ao meu orientador, Prof. Dr. Roberto Marcondes Cesar Jr., pelo voto de confiança depositado em mim desde a proposta de um projeto de iniciação científica, permitindo que eu trabalhasse na área que me levou a escolher Ciência da Computação como carreira a seguir. Sua acessibilidade e sua humildade no compartilhamento do conhecimento, amizade e compreensão, tanto nas questões técnicas como pessoais, fazem dele mais do que um cientista verdadeiro, mas um ser humano exemplar.

À professora Isabelle Bloch, da École Nationale Supérieure des Télécommunications de Paris, por todas as discussões relativas ao projeto e à metodologia quando de suas visitas ao Brasil, as quais permitiram tomar decisões importantes para $\mathrm{o}$ andamento do mestrado, além da disponibilidade para elaborar artigos em diferentes fases do projeto, sempre de maneira amigável e interessada, contribuindo para a melhoria da qualidade técnica do trabalho.

Aos professores Carlos Hitoshi Morimoto e Nina S. T. Hirata, pelas críticas e sugestões feitas em meu exame de qualificação, as quais permitiram a elaboração de um texto mais completo e a realização de testes diversos para validação da metodologia. Igualmente, aos membros integrantes de minha banca de mestrado, professoras Maria Cristina F. de Oliveira e, novamente, Nina S. T. Hirata, cujas valiosas contribuições serão de extrema importância na exploração dos novos tópicos de pesquisa que surgiram deste trabalho.

Aos professores Roberto Hirata Jr., Ana Cristina Vieira de Melo e Zara Issa Abud, 
pela amizade e pelos conselhos diversos sobre a vida acadêmica.

A todos os familiares e amigos muito queridos que contribuíram com seu apoio e carinho. Em particular, a Luis Augusto Hiroshi Yamada, pelo companheirismo, incentivo e suporte técnico na elaboração de vídeos criados para esta pesquisa (equipamentos e story-board).

A todos os amigos do grupo Creativision e dos laboratórios Bioinfo I e II, pela presença nas prévias, na qualificação, ou na defesa, pelas sugestões e discussões diversas sobre a metodologia, pelos auxílios quanto a questões práticas e ferramentais dos laboratórios, e por tornarem o nosso ambiente de trabalho um local agradável e de companheirismo.

A todos da Comissão de Pós-Graduação que se empenharam na resolução de problemas burocráticos diversos e aos funcionários do setor de Audiovisual, pela eficiência e simpatia na reserva e instalação de equipamentos.

Finalmente, ao $\mathrm{CNPq}$, pelo auxílio financeiro concedido, com o qual pude me dedicar exclusivamente à pesquisa relativa a este mestrado. 


\section{SUMÁRIO}

$1 \quad$ INTRODUÇÃO

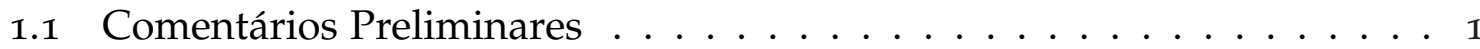

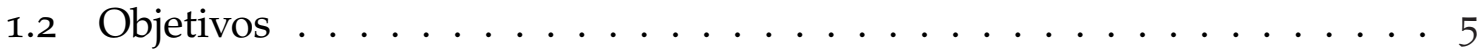

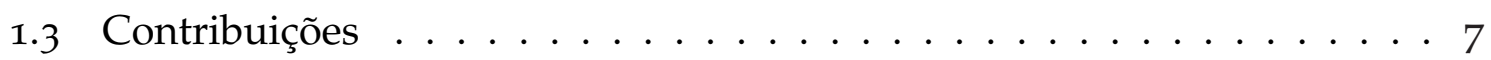

1.4 Organização do Texto . . . . . . . . . . . . . . . 8

2 REVISÃO BIbLIOGRÁfica 9

2.1 Grafos como Ferramentas de Representação de Imagens . . . . . . . . . I1

2.1.1 Conceitos, Definições e Propriedades . . . . . . . . . . . I1

2.1.2 Imagens Digitais e Representação de Objetos . . . . . . . . . . . . I3

2.1.3 Tipos de Grafos e Implementação . . . . . . . . . . . . . . . . . 15

2.1.4 Grafos e Algoritmo de Watershed . . . . . . . . . . . . . . 18

2.2 Grafos e Reconhecimento de Padrões . . . . . . . . . . . . . . . . . . 20

2.2.1 Um Resumo sobre Reconhecimento de Padrões . . . . . . . . . . 20

2.2.2 Reconhecimento Estrutural de Padrões e Grafos Relacionais . . . 22

2.2.3 Casamento Exato entre Grafos . . . . . . . . . . . . . . . 24

2.2.4 Casamento Inexato entre Grafos . . . . . . . . . . . . . . 26

2.3 Grafos e Sistemas de Visão Computacional . . . . . . . . . . . . . . . . 28

3 MEtodologia 33

3.1 Perspectiva Geral . . . . . . . . . . . . . . . . . . 34

3.2 Considerações sobre Modelo e Vídeo Digital . . . . . . . . . . . . . 38

3.2.1 Seqüências de Imagens . . . . . . . . . . . . . . . . 38

3.2.2 Imagem de Referência . . . . . . . . . . . . . . . . 39

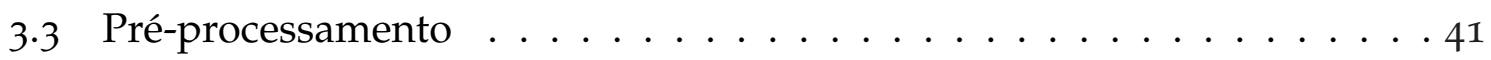

3.4 Segmentação . . . . . . . . . . . . . . . . . . . . . 42

3.5 Representação das Imagens . . . . . . . . . . . . . . . . . . 45

$3.5 .1 \quad$ ARG Intra-quadros . . . . . . . . . . . . . . . . . . 45

3.5 .2 Construção de ARGs-intra . . . . . . . . . . . . . . . . . . . . . . . . . . . . .

3.5 .3 ARG Inter-quadros . . . . . . . . . . . . . . . . 52

3.5 .4 Construção de um ARG-inter . . . . . . . . . . . . . 53

3.6 Reconhecimento dos Objetos . . . . . . . . . . . . . . . . . . 
3.6.1 Homomorfismo entre Grafos . . . . . . . . . . . . . . 56

3.6.2 Casamento Inexato entre Grafos: Busca Heurística . . . . . . . 57

3.6.3 Função Custo . . . . . . . . . . . . . . . . . . . .63

3.7 Processo de Rastreamento . . . . . . . . . . . . . . . . 65

4 Resultados experimentais $\quad 69$

4.1 Seqüências Sintéticas . . . . . . . . . . . . . 70

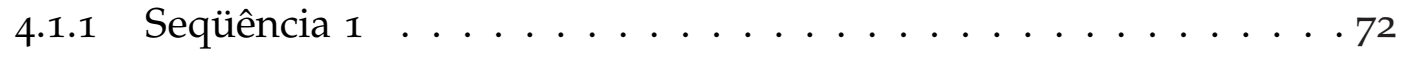

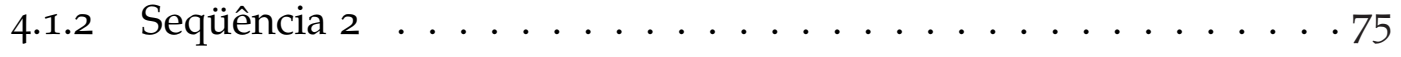

4.2 Seqüências Reais . . . . . . . . . . . . . . . . . . .79

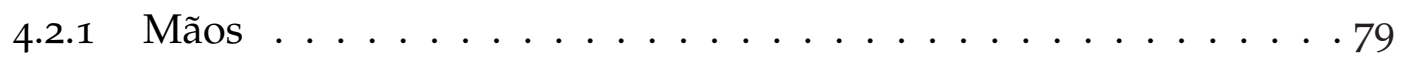

4.2.2 Brinquedo de corda . . . . . . . . . . . . . . 87

4.3 Comentários Adicionais $\ldots \ldots \ldots . \ldots \ldots 2$

5 CONClusão 95

5.1 Considerações Finais . . . . . . . . . . . . . . . . . . . 95

5.2 Contribuições . . . . . . . . . . . . . . . . .966

5.3 Trabalhos Futuros . . . . . . . . . . . . . . . . . . . .97

Índice Remissivo 101

$\begin{array}{ll}\text { REFERÊNCIAS BIBLIOGRÁFICAS } & 103\end{array}$

$\begin{array}{ll}\text { I ANEXOS } & 109\end{array}$

Artigo SIBGRAPI $2003 \quad 111$

$\begin{array}{ll}\text { Artigo CIARP } 2003 & 115\end{array}$ 


\section{LISTA DE FIGURAS}

Figura $1 \quad$ Reconhecimento de objetos - exemplo. . . . . . . . . 2

Figura 2 Reconhecimento de Objetos: diagrama de etapas. . . . . . . 3

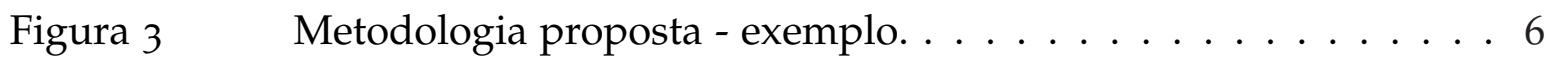

Figura 4 Representação de imagens por grafos. . . . . . . . . . . . 14

Figura 5 Grafos derivados do diagrama de Voronoi. . . . . . . . . . . 17

Figura 6 Exemplo de ARG de uma imagem. . . . . . . . . . . . 35

Figura $7 \quad$ Fluxograma simplificado da metodologia. . . . . . . . 38

Figura 8 Imagens de referência e máscaras modelos. . . . . . . . . . 40

Figura 9 Exemplos de imagens segmentadas. . . . . . . . . . . . . . . 44

Figura 10 Exemplos de ARG-intra derivados de quadros de seqüências. . . 48

Figura 11 Exemplos de ARGs modelos. . . . . . . . . . . . . . 48

Figura 12 Exemplo de ARG inter-quadros. . . . . . . . . . . . . . . 53

Figura 13 Representação gráfica do problema de casamento entre grafos. . 56

Figura 14

Figura 15

Algoritmo de busca em árvore. . . . . . . . . . . . . . .60

Figura 16

Rastreamento - ilustração da transformação afim . . . . . . . . 66

Figura 17

Seqüência sintética - modelo. . . . . . . . . . . 70

Figura 18

Seqüência sintética 1 - testes sem atributos temporais. . . . . .73

Figura 19

Figura 20

Figura 21

Figura 22

Seqüência sintética 1 - testes com atributos temporais. . . . . . 74

Figura 23

Figura 24

Figura 25

Seqüência sintética 2 - testes sem atributos temporais. . . . . 76

Figura 26

Seqüência sintética 2 - testes com atributos temporais. . . . . 77

Seqüência sintética 2 - mais testes com atributos temporais. . 78

Seqüência real 1 - modelo. . . . . . . . . . . . . 80

Seqüência real 1 - testes sem atributos temporais. . . . . . . . 83

Seqüência real 1 - testes com atributos temporais. . . . . . . . 84

Figura 27

Seqüência real 1 - mais testes com atributos temporais. . . . . . 85

Coerência espacial-temporal. . . . . . . . . . . . . . 86

Figura 28

Figura 29

Figura 30

Seqüência real 2 - modelo. . . . . . . . . . . . . . . 87

Seqüência real 2 - testes sem atributos temporais. . . . . . . . . 89

Seqüência real 2 - testes com atributos temporais. . . . . . . . 990

Seqüência real 2 - mais testes com atributos temporais. . . . . . 91 
Figura 31 Reconhecimento baseado em atributos individuais. . . . . . . 993

Figura 32 Particionamento e Reconhecimento. . . . . . . . . . . . . 993

LISTA DE TABELAS

Tabela 1 Grafos, Visão Computacional e Reconhecimento de Padrões . . . 10

Tabela 2 Seqüência sintética: pesos e atributos. . . . . . . . . . 71

Tabela 3 Seqüência real 1 : pesos e atributos. . . . . . . . . . 81

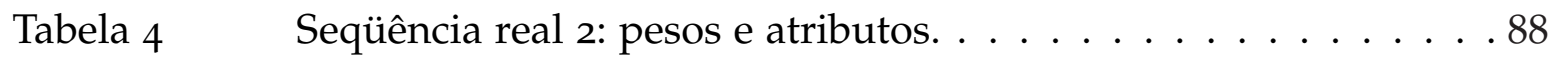

SIGLAS

ARG grafo relacional com atributos

GA algoritmo genético

EDA algoritmo de estimativa de distribuição 


\section{INTRODUÇÃO}

Ver é uma experiência (...)

São as pessoas que vêem, e não seus olhos (...) A visão não envolve apenas o que se enxerga.

- N. R. Hanson, Patterns of Discovery, 1958

\section{I.I COMENTÁRIOS PRELIMINARES}

O processo cognitivo-visual humano é um assunto extremamente complexo [27, 46]. A facilidade com que um ser humano perfeitamente dotado de sua capacidade visual utiliza esse canal de comunicação com o mundo é inversamente proporcional à de estudo do funcionamento de tal sentido. A visão não se resume à formação de uma imagem do ambiente que nos rodeia, mas envolve, também, análise, categorização e reconhecimento dos componentes que constituem tal imagem, bem como interações com outras funções cognitivas (emoções, linguagem, memória, etc.).

A simulação por meio de computador do processo supracitado caracteriza os chamados sistemas de visão computacional, cuja aplicabilidade permeia problemas diversos como visão robótica, interfaces homem-máquina inteligentes, recuperação de informação em bancos de dados multimídia, análise de imagens médicas, sistemas digitais de identificação de pessoas, segurança e vigilância automatizadas, sensoriamento remoto, dentre outros.

Embora os sistemas atuais de visão computacional sejam extremamente limitados em relação ao sistema visual humano, seu projeto e seu funcionamento também apresentam um elevado grau de complexidade, englobando diversas etapas, desde a aquisição da imagem, passando pelo armazenamento, processamento, pela seg- 
mentação, e extração de informações relevantes, até a aplicação de tais dados a propósitos específicos.

Uma das tarefas possíveis de se realizar através de um sistema de visão computacional é reconhecer objetos automaticamente. No entanto, essa tarefa não é trivial, principalmente no tratamento de cenas complexas, com variações de iluminação, posição, ângulo, escala, textura, sombras, deformações, oclusões e outras características. Para abordar essas questões, são unidos esforços não apenas de processamento de imagens e visão computacional, mas também de domínios como reconhecimento de padrões, inteligência artificial, psicofísica e ciências cognitivas [23].

Sistemas de Reconhecimento de objetos. De forma mais específica, um sistema para reconhecimento de objetos visa classificar objetos do mundo real a partir de uma imagem do mundo. Imagine, por exemplo, uma aplicação cujo objetivo é detectar faces humanas numa imagem para posterior utilização num sistema de identificação de pessoas. Dada uma imagem como a da figura $1(a)$, o sistema de reconhecimento de objetos deveria classificar a região circunscrita pela linha vermelha (fig. 1 (b)) como o objeto procurado, ou seja, uma face humana, descartando os demais componentes da cena.

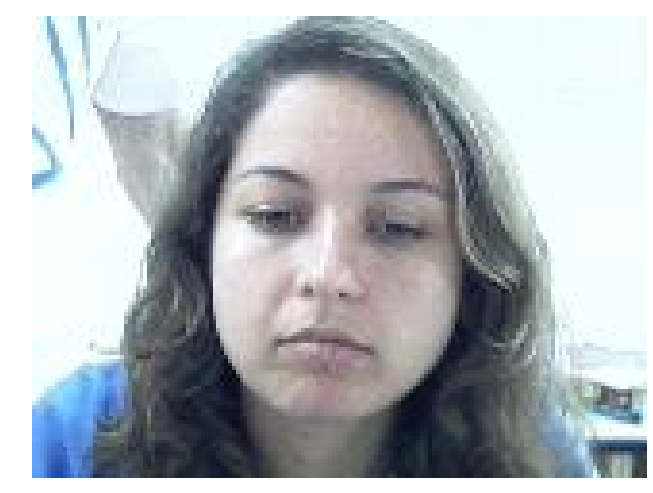

(a)

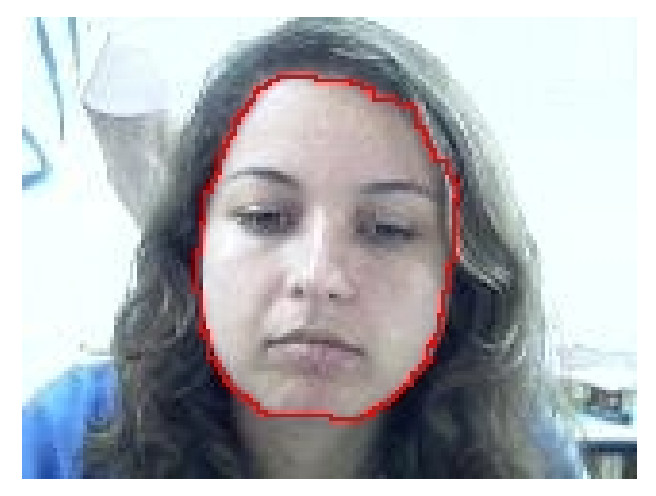

(b)

Figura 1. Imagem de entrada de um sistema de reconhecimento de objetos e possível resultado esperado.

Para melhor compreender o processo automático de reconhecimento de objetos, o diagrama apresentado na figura 2 ilustra as etapas principais que compõem tal processo em geral. 


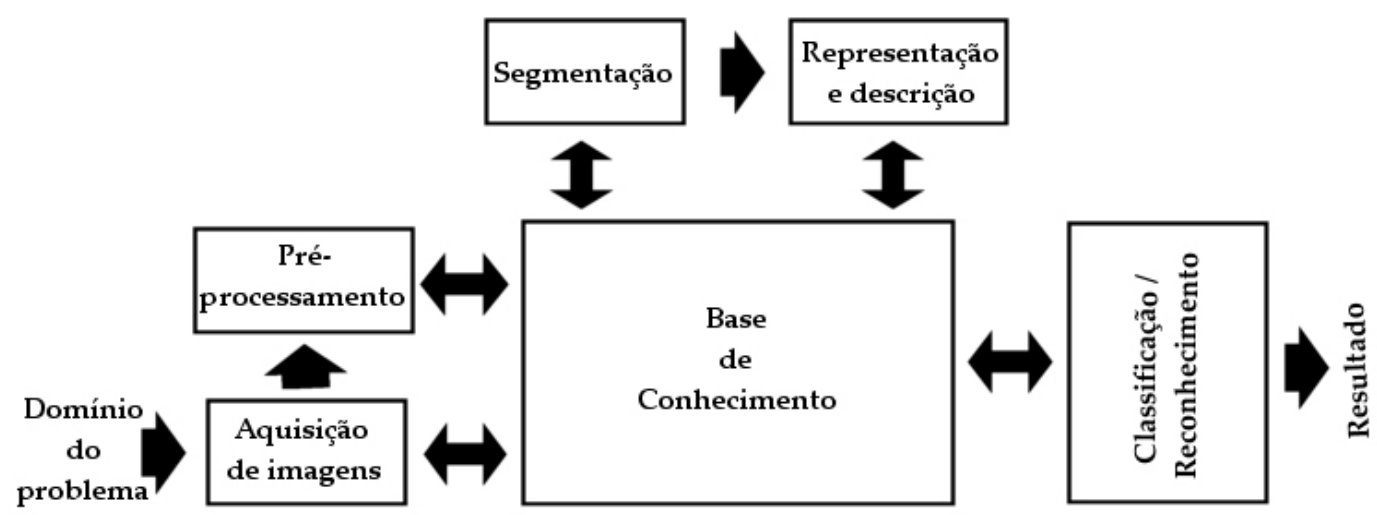

Figura 2. Diagrama de etapas de um sistema de reconhecimento de objetos (adaptado de Gonzalez e Woods 17, cap. 9).

Em primeiro lugar, é necessário adquirir as imagens a serem analisadas dentro do domínio do problema, colocando-as num formato adequado para o processamento via computador (ex: matriz numérica). A seguir, são aplicadas técnicas de processamento de imagens para pré-processar a entrada, realçando aspectos específicos (ex: bordas) e reduzindo ruídos.

Logo após essas etapas, realiza-se a segmentação das imagens em componentes ou regiões de acordo com algum critério (ex: uniformidade de cor, texturas) e, com base nessas partições obtidas, é possível medir características geométricas, de formas, entre outras, e gerar descrições dos elementos segmentados. Tais descrições visam caracterizar os elementos segmentados de acordo com propriedades que auxiliem as etapas posteriores na decisão de classificação.

Finalmente, são realizados os processos associados a um maior grau de abstração e de inteligência artificial: classificação e reconhecimento dos componentes obtidos na etapa anterior. É importante ressaltar que as fases de segmentação e de reconhecimento de objetos interagem de forma que o resultado de uma segmentação pode ser melhorado através de informações provenientes do reconhecimento, assim como o reconhecimento depende das descrições das regiões obtidas na segmentação.

Todas as etapas constituintes de um sistema de reconhecimento de objetos podem ser guiadas por informações conhecidas a respeito do domínio do problema, as quais definem uma base de conhecimento. Retomando o exemplo de reconhecimento de faces introduzido anteriormente, se sabemos que as imagens adquiridas são afetadas 
por iluminação não-uniforme, o pré-processamento pode se encarregar de reduzir esse efeito através de filtragens apropriadas como um operador open top-hat [14].

reconhecimento de objetos baseado em modelo. Particularmente, quando existe conhecimento prévio a respeito dos objetos a serem buscados nas imagens, é possível criar um modelo para instruir o sistema quanto aos alvos que deverá classificar. Nesse caso, o problema de reconhecimento de objetos pode ser definido como o de rotulação baseado em um ou mais modelos de objetos conhecidos a priori, ou seja, dada uma imagem contendo um ou mais objetos de interesse dispostos numa cena e um conjunto de rótulos correspondentes a modelos conhecidos dentro do problema em questão, o sistema de reconhecimento deve ser capaz de atribuir um rótulo correto a cada região ou conjunto de regiões da imagem. Tal abordagem é conhecida como reconhecimento de objetos baseado em modelo.

Os modelos de objetos adotados são um aspecto fundamental do sistema, pois devem concentrar todas as informações relevantes do problema e evitar redundâncias, além de organizar esses dados num formato facilmente manipulável pelas etapas do processo de reconhecimento. Em especial, esses modelos podem ser descritos através de partes componentes dos objetos e suas relações. A definição de parte, no entanto, pode variar dependendo do problema de reconhecimento de objetos em questão.

RECONHECIMENTO E SEQÜÊNCIAS DE IMAgens. Um sistema de reconhecimento de objetos pode tratar tanto imagens estáticas quanto seqüências de imagens (ou vídeo digital), elementos constituídos por imagens (ou quadros) adquiridas ao longo do tempo, tipicamente representadas por um conjunto de imagens estáticas bidimensionais ordenadas seqüencialmente. Devido às peculiaridades dessa última modalidade, novas questões e dificuldades são introduzidas.

O grande volume de informações contido em seqüências de imagens requer máquinas e algoritmos eficientes para analisá-las. Assim, redundâncias presentes nos quadros podem ser reduzidas e/ou exploradas por um sistema de reconhecimento de objetos.

No entanto, ao longo do tempo, o conteúdo dos quadros poderá sofrer deslocamentos, deformações, oclusões, dentre outras modificações, aspectos que dificultam a obtenção de um reconhecimento correto e coerente de um mesmo objeto ou parte em diferentes instantes. Essa constatação relaciona-se ao problema da manutenção 
da coerência espaço-temporal no reconhecimento de objetos, caracterizado pelo interesse em se atribuir rótulos de modo consistente a regiões que correspondam a um mesmo objeto ou a uma mesma parte em quadros distintos.

Para lidar com o dinamismo de seqüências de imagens, o problema de reconhecimento associa-se a outras duas importantes tarefas: detecção de movimento e rastreamento de objetos. Detecção de movimento consiste em identificar regiões da imagem representantes de movimento físico. Já o conceito de rastreamento de um objeto consiste na obtenção do posicionamento de um dado alvo ao longo do tempo.

\subsection{OBJETIVOS}

Dentro do contexto exposto acima, este trabalho de mestrado aborda as questões de reconhecimento e rastreamento de objetos em seqüências de imagens, propondo uma metodologia dentro do paradigma baseado em modelos de objetos descritos por partes.

A partir de um modelo retratando objeto(s) de interesse subdividido(s) em suas partes constituintes (fig. 3(a)) e de uma seqüência de imagens (fig. 3(b) e 3(c)), desejase realizar o processo de reconhecimento em cada quadro do vídeo, resultando numa classificação dos objetos detectados e no rastreamento de cada uma das partes do modelo ao longo do tempo (fig. 3(d) e $3(\mathrm{e})$ ).

Na metodologia desenvolvida, partes são definidas como unidades representantes de função ou detentoras de semântica relevante para o problema em questão. Por exemplo, na aplicação de faces, o modelo poderia ser caracterizado pelo rosto, lábios, olhos e nariz. No caso da figura 3, as partes do modelo representam o bico, a cabeça, o pescoço, a asa, o corpo e as patas do animal. 


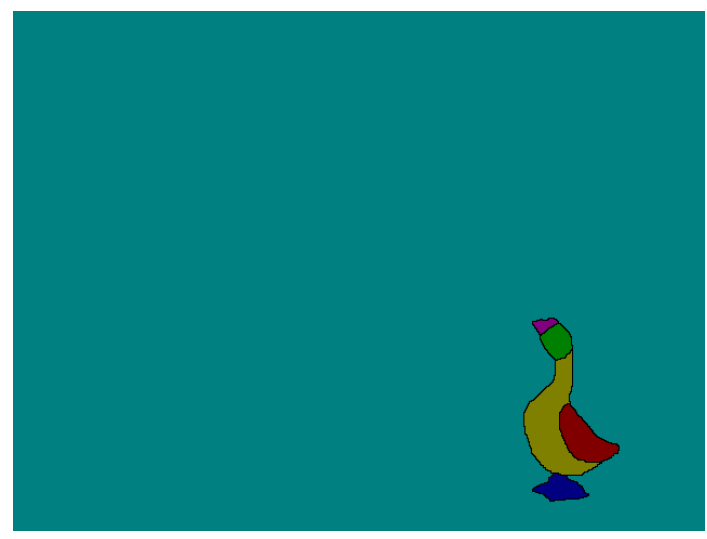

(a)

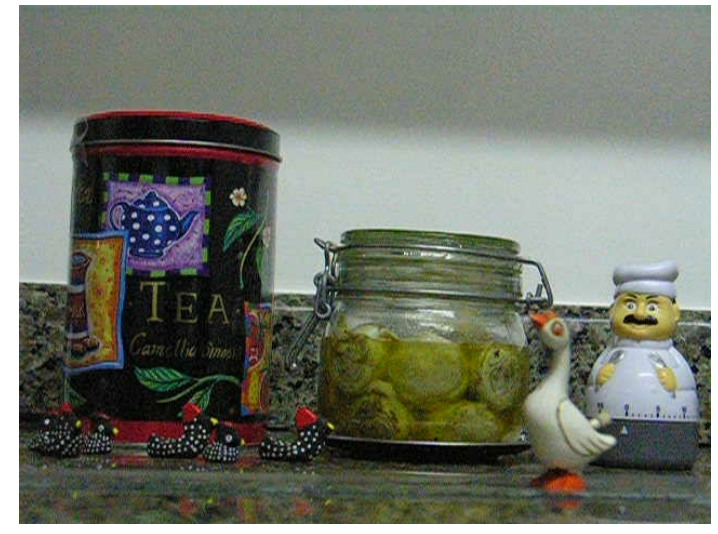

(b)

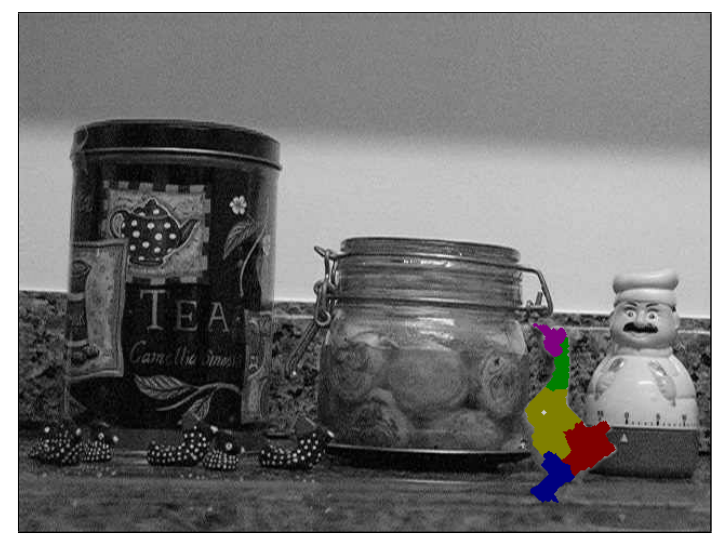

(d)

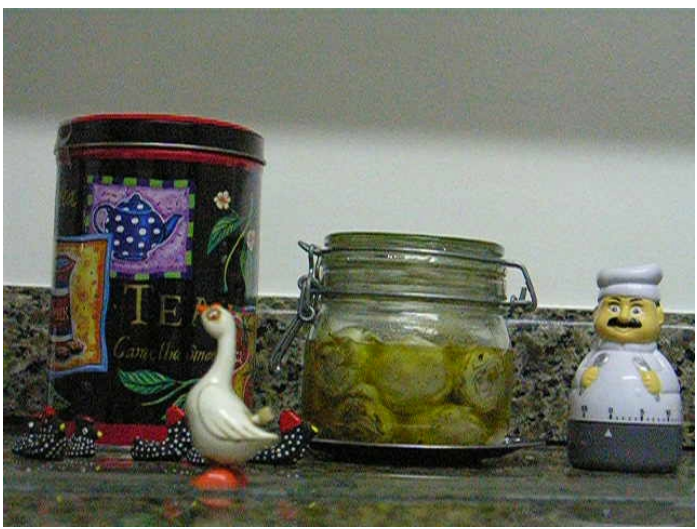

(c)

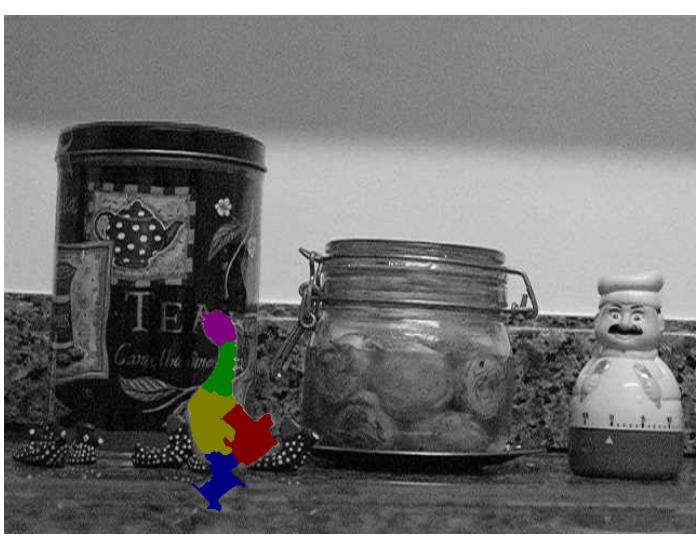

(e)

Figura 3. (a): modelo e rótulos (cores) associados às partes (bico, cabeça, corpo, asa e patas da gansa); (b) e (c): amostras de quadros extraídos do vídeo em momentos distintos; (d) e (e): classificações das partes nos quadros amostrados. 


\subsection{CONTRIBUIÇÕES}

De acordo com a discussão anterior a respeito de sistemas de reconhecimento de objetos, torna-se clara a importância de se adotar uma descrição de objetos apropriada e robusta, bem como um modelo cuja descrição seja bastante abrangente e, ao mesmo tempo, precisa e sem redundâncias. No tratamento de seqüências de imagens digitais, esses aspectos não são menos relevantes, agregando-se aos demais desafios próprios de vídeo digital.

Para tratar esses dois fatores, a metodologia aqui desenvolvida propõe as seguintes soluções:

- modelo de objeto descrito por partes, para facilitar o reconhecimento de formas complexas a partir de componentes primitivos mais simples;

- representação dos objetos dada por grafo relacional com atributos (ARG), permitindo que modelo e entrada contenham informações estrutural, temporal e quantitativa dos objetos;

- realização da tarefa de reconhecimento através de casamento inexato entre grafos, para considerar imprecisões entre modelo e entrada.

Um ARG, do inglês attributed relational graph, consiste num grafo cujos vértices representam objetos, enquanto arestas denotam relações entre os mesmos. Objetos podem ser caracterizados por um número finito de atributos (numéricos ou simbólicos), tais como área, perímetro, cor, forma, dentre outros. Já as relações entre os objetos correspondem, em geral, a algum tipo de medida de distância ou (dis)similaridade entre os mesmos. Na estrutura do ARG, essas informações são expressas através de um vetor de atributos associado a cada vértice e outro vetor de atributos associado a cada aresta, os quais são denominados, respectivamente, vetor de atributos de objeto e vetor de atributos relacional. Tal formulação descreve uma estrutura de dados bastante poderosa e flexível em termos de representação.

Duas espécies de grafos relacionais com atributos são introduzidas neste trabalho: ARG intra-quadros, ou ARG-intra, e ARG inter-quadros, ou ARG-inter. Conceitualmente, o papel desempenhado por um ARG-intra é modelar informações relacionais e propriedades dos objetos presentes num dado quadro de uma seqüência de imagens, enquanto um ARG-inter introduz as mesmas informações e propriedades acrescidas 
de informação temporal a respeito de objetos presentes num subconjunto de quadros consecutivos do vídeo.

Através dessas estruturas, pretende-se introduzir diferentes tipos de informações da base de conhecimento proveniente da entrada, bem como tratar problemas intrínsecos de vídeo digital como coerência espaço-temporal, deslocamentos, deformações e variações quantitativas das imagens quadro-a-quadro.

A partir da representação do conteúdo das imagens por grafos relacionais com atributos, a questão do reconhecimento de objetos pode ser tratada como um problema de casamento entre grafos, que consiste na determinação de um mapeamento do conjunto de vértices de um ARG no conjunto de vértices de outro. Na metodologia desenvolvida, esse mapeamento é realizado entre ARGs-inter obtidos do vídeo sob análise e um ARG-intra modelo pré-definido.

Técnicas de casamento entre grafos têm sido recentemente redescobertas e aplicadas a vários problemas de reconhecimento de padrões e visão computacional, graças ao avanço tecnológico em termos de recursos computacionais (memória, processamento), que tornou a utilização de algoritmos em grafos mais plausível.

\subsection{ORGANIZAÇÃO DO TEXTO}

Neste capítulo, foram discutidos o cenário, os objetivos e as contribuições da metodologia desenvolvida para reconhecimento e rastreamento de objetos em seqüências de imagens. Uma revisão bibliográfica abrangendo trabalhos correlatos e uma discussão sobre o uso de grafos em processamento de imagens, visão computacional e reconhecimento de padrões é apresentada no capítulo 2. Em seguida, o capítulo 3 consagra-se à descrição detalhada de todos os passos da metodologia, apresentando aspectos teóricos e práticos. Resultados experimentais são exibidos e comentados no capítulo 4 e, finalmente, conclusões e trabalhos futuros constituem o tópico do capítulo 5 . 


\section{2}

REVISÃO BIBLIOGRÁFICA

Wonka: Suponho que todos saibam como a televisão comum funciona.

Mike: Claro que sim. Você fotografa algo, e então a fotografia é quebrada em milhões de pedacinhos que são transmitidos pelo ar até sua $T V$, onde são reunidos na ordem correta.

— Diálogo de A Fantástica Fábrica de Chocolates, 1971

Um grafo é uma estrutura de dados que pode ser descrita informalmente como um conjunto de vértices (ou nós) conectados através de arestas (ou arcos). Suas propriedades e questões inerentes são o tema de estudo da Teoria dos Grafos.

O interesse em grafos está intrinsecamente relacionado a sua aplicabilidade a diversos fenômenos, pois vários problemas práticos de interesse podem ser formulados de acordo com sua teoria e sua estrutura pode assumir inúmeros significados, apresentando um grande poder de representação. Exemplos de aplicações que usam modelagem através de grafos e suas propriedades são análise de redes (sociais, de transporte, internet), representação estrutural molecular em física e química, projeto de circuitos eletrônicos, entre outras.

Em processamento de imagens, visão computacional e reconhecimento de padrões, a utilização de grafos também é bastante expressiva, como indica a tabela 1 . O relativo sucesso de tal estrutura nessas áreas deve-se, em grande parte, a sua capacidade de disponibilizar informações de naturezas distintas de forma compacta.

Desse modo, a adoção de grafos para modelar objetos num sistema automático de reconhecimento de objetos é bastante adequada, já que a representação e a descrição 


\begin{tabular}{|c|c|c|}
\hline ALGORITMOS & APLICAÇÕES & OBSERVAÇÕES \\
\hline \multirow[t]{3}{*}{$\begin{array}{l}\text { Buscas em largura e pro- } \\
\text { fundidade }\end{array}$} & Funções distância [40] & $\begin{array}{l}\text { Algoritmos rápidos e sim- } \\
\text { ples }\end{array}$ \\
\hline & Conectividade [40] & $\begin{array}{l}\text { Implementações através } \\
\text { de filas ou pilhas }\end{array}$ \\
\hline & $\begin{array}{l}\text { Cálculo do número de Eu- } \\
\text { ler como descritor de for- } \\
\text { mas [26] }\end{array}$ & Função distância restrita \\
\hline Dijkstra & $\begin{array}{l}\text { Distâncias euclidianas e } \\
\text { geodésicas [36] }\end{array}$ & Relativa simplicidade \\
\hline Programação Dinâmica & $\begin{array}{l}\text { Segmentação e reconheci- } \\
\text { mento de objetos 2D [16] }\end{array}$ & Flexibilidade \\
\hline \multirow[t]{3}{*}{ Cortes mínimos } & Segmentação [44] & $\begin{array}{l}\text { Algoritmos razoavel- } \\
\text { mente complexos }\end{array}$ \\
\hline & $\begin{array}{l}\text { Agrupamento de caracte- } \\
\text { rísticas [44] }\end{array}$ & Algoritmos lentos \\
\hline & Superfícies minimais [44] & $\begin{array}{l}\text { Nicho de pesquisa em ex- } \\
\text { pansão }\end{array}$ \\
\hline \multirow[t]{3}{*}{$\begin{array}{l}\text { Árvores / Florestas gera- } \\
\text { doras ótimas }\end{array}$} & Watersheds [41] & $\begin{array}{l}\text { Algoritmos gulosos (Prio- } \\
\text { rity First Search) }\end{array}$ \\
\hline & $\begin{array}{l}\text { Crescimento de regiões a } \\
\text { partir de semente [40] }\end{array}$ & $\begin{array}{l}\text { Simples, porém podem } \\
\text { não resultar na melhor so- } \\
\text { lução, sendo sensíveis a } \\
\text { erros e ruídos }\end{array}$ \\
\hline & Segmentação [45] & \\
\hline \multirow[t]{2}{*}{$\begin{array}{l}\text { Casamento Exato e Ine- } \\
\text { xato entre Grafos }\end{array}$} & $\begin{array}{l}\text { Reconhecimento de obje- } \\
\text { tos em geral }[4,9,13]\end{array}$ & $\begin{array}{l}\text { Algoritmos computacio- } \\
\text { nalmente custosos em cer- } \\
\text { tos casos. }\end{array}$ \\
\hline & & $\begin{array}{l}\text { Modelagem poderosa (re- } \\
\text { lações e propriedades in- } \\
\text { trínsecas) }\end{array}$ \\
\hline
\end{tabular}

Tabela 1. Grafos e suas aplicações em Visão Computacional e Reconhecimento de Padrões. 
dos objetos têm grande importância, pois são responsáveis pela transmissão de informações que os caracterizam e que são utilizadas para classificá-los ou reconhecêlos.

Na metodologia para reconhecimento e rastreamento de objetos proposta nesta dissertação, um tipo especial de grafo é adotado na modelagem de objetos e do modelo descrito por partes: grafo relacional com atributos. A origem dessa estrutura encontra-se na subárea de reconhecimento estrutural de padrões e sua escolha afeta não somente o aspecto de representação, mas induz também o processo de reconhecimento a um problema de casamento entre grafos.

Para fundamentar a escolha dessa representação no tratamento dos problemas de reconhecimento e rastreamento, o presente capítulo apresenta uma revisão teórica relacionada a grafos, necessária para melhor compreender o funcionamento da metodologia.

Em primeiro lugar, são discutidos os aspectos de grafos como representação do conteúdo de imagens digitais. Em seguida, a relação de tal estrutura com a área de reconhecimento de padrões é introduzida. Por fim, uma descrição de trabalhos correlatos e observações sobre o estado da arte no estudo de grafos em sistemas de visão computacional são apresentados.

\section{I GRAFOS COMO FERRAMENTAS DE REPRESENTAÇÃO DE IMAGENS}

\subsubsection{Conceitos, Definições e Propriedades}

Nesta subseção, são definidos alguns conceitos e notações a respeito de grafos, os quais serão adotados ao longo de toda a dissertação.

Um grafo $G=(V, E)$ dirigido é uma estrutura definida por um conjunto não vazio de vértices (ou nós) $\mathrm{V}$ e por um conjunto de arestas (ou arcos) $\mathrm{E} \subseteq \mathrm{V} \times \mathrm{V}$. Quando $V$ e $E$ são conjuntos finitos, $G$ constitui um grafo finito. As notações $|V|$ e $|E|$ serão adotadas para indicar a cardinalidade dos conjuntos $V$ e $E$ respectivamente.

Um grafo é representado graficamente por pontos, representando vértices, enquanto uma linha é traçada ligando dois vértices se os mesmos são extremos de uma aresta. Se é possível desenhar um grafo $\mathrm{G}$ de modo que nenhuma de suas arestas se interceptem, a menos de um vértice em comum, tal grafo é considerado planar.

Cada aresta de $\mathrm{G}$ está associada a um par de vértices do grafo e é denotada por 
$a=(v, w): v$ representa a ponta inicial da aresta, enquanto $w$ representa a ponta final. Quando $v$ e $w$ são coincidentes, a aresta é denominada laço.

$\mathrm{G}$ é dito simétrico se, para cada aresta da forma $(v, w)$, existe uma aresta da forma $(w, v), v, w \in V$. Um caso particular de grafo simétrico de grande importância é o grafo não-dirigido.

Na metodologia descrita nesta dissertação, os grafos utilizados são dirigidos e finitos, a menos de exceções devidamente documentadas.

Dois vértices $v$ e $w$ são adjacentes, ou vizinhos, se, e somente se, constituem vértices extremos de uma aresta de $G$, ou seja, se $(v, w) \in E$ ou $(w, v) \in E$. Para grafos não-dirigidos, tal relação é simétrica, pois $(v, w) \in E$ e $(w, v) \in E$. O conjunto $N_{E}$ de vértices adjacentes ou vizinhos a um vértice $v \in V$ é definido como $N_{E}(v)=\left\{w_{i} \in\right.$ $V:\left(v, w_{i}\right) \in E$ ou $\left.\left(w_{i}, v\right) \in E\right\}$. Se os vértices de $G$ são dois a dois adjacentes, então $G$ é um grafo completo.

Um caminho num grafo é uma seqüência finita e não vazia de vértices distintos e arestas $P_{G}=\left(v_{0}, a_{1}, v_{1}, a_{2}, \ldots, a_{k}, v_{k}\right)$, em que $a_{i}=\left(v_{i-1}, v_{i}\right) \in E, \forall i=1, \ldots, k$, e seu respectivo comprimento é $k$. Um caminho entre dois vértices $v$ e $w$ é dito mínimo se não existe outro caminho entre os mesmos vértices cujo comprimento é menor. Se existe $a=\left(v_{k}, v_{0}\right) \in E$, então $P_{G}$ somado a a constitui um ciclo de $G$.

Um grafo $G$ é conexo se, para cada par de vértices distintos $v, w \in V$, existe um caminho ligando $v$ a $w$. Se esta condição não for observada, $G$ é considerado desconexo.

Um grafo é acíclico se não apresenta ciclos em sua estrutura. Nesse caso, é também chamado floresta. Uma floresta conexa é denominada árvore.

A distância d entre dois vértices $v$ e $w$, denotada $\mathrm{d}_{\mathrm{G}}(v, w)$, é definida como o comprimento do caminho mínimo existente entre ambos. Há também a noção de vizinhos de ordem- $k$ de um vértice $v \in V$, os quais formam o conjunto de vértices $w_{i}$ que distam $k$ arcos de $v$, ou seja, $d_{G}\left(v, w_{i}\right)=k$. Se não existe caminho entre $v$ e $w$, pode-se dizer que a distância entre ambos é infinita.

Um subgrafo $\mathrm{G}^{\prime}=\left(\mathrm{V}^{\prime}, \mathrm{E}^{\prime}\right)$ de $\mathrm{G}=(\mathrm{V}, \mathrm{E})$, ou $\mathrm{G}^{\prime} \subseteq \mathrm{G}$, é um grafo tal que $\mathrm{V}^{\prime} \subseteq \mathrm{V}$ e $E^{\prime} \subseteq E$ e, para cada aresta $a \in E^{\prime}$, seus extremos em $V^{\prime}$ são também extremos em $V$. Um clique é um subgrafo em que cada vértice está ligado por uma aresta a cada um dos outros vértices. Um clique maximal é tal que nenhum outro clique o inclui.

Em especial, uma componente é um subgrafo conexo maximal de G, ou seja, a inclusão de outros vértices ou arestas em tal subgrafo viola a condição de conectividade 
do mesmo.

Enfim, o grafo de associação $\tilde{\mathrm{G}}_{\mathrm{A}}$ entre dois grafos $\mathrm{G}_{1}=\left(\mathrm{V}_{1}, \mathrm{E}_{1}\right)$ e $\mathrm{G}_{2}=\left(\mathrm{V}_{2}, \mathrm{E}_{2}\right)$ é definido como o grafo completo $\tilde{G}_{A}=\left(V_{A}, E_{A}\right)$, em que $V_{A}=V_{1} \times V_{2}$.

\subsubsection{Imagens Digitais e Representação de Objetos}

A aquisição de imagens digitais envolve a conversão do sinal produzido por um sensor de imageamento, como câmera ou filmadora, numa representação que possa ser interpretada por um computador, caracterizando um processo de digitalização.

Como uma função contínua (ex: coordenadas de posição no espaço contínuo 3D ou quantidade de energia eletromagnética carregada por um raio luminoso) não pode ser perfeitamente representada num computador, a digitalização implica na discretização do sinal da imagem, originando dois processos: amostragem e quantização.

O primeiro constitui a discretização espacial da imagem sobre uma grade tipicamente regular, cujas unidades constituintes são denominadas pixels (de picture element). Já o segundo consiste na discretização das intensidades contínuas médias de luz capturadas em cada unidade da grade.

Assim, a representação digital de uma imagem num computador assume a forma de uma matriz cujos índices de linhas e colunas identificam um ponto da imagem, enquanto o valor correspondente a tal elemento da matriz exprime o nível de cinza ou intensidade naquele ponto.

овJеtos E FORMAS. A representação de imagens no formato digital permite realizar inúmeras operações sobre a mesma com objetivos diversos. Em problemas de reconhecimento automático de objetos, por exemplo, deseja-se isolar objetos ou formas específicos contidos numa imagem para que esses possam ser identificados e reconhecidos dentre outros elementos. Para isso, é necessário interpretar os pixels constituintes da imagem digital, para posterior utilização na descrição de tais objetos.

Numa primeira etapa, é preciso localizar, na matriz da imagem, os pixels que constituem os objetos de interesse e segmentá-los, desconsiderando demais elementos. Assim, uma nova imagem é obtida, na qual pixels válidos estão diretamente relacionados ao conteúdo desejado. De posse dessa segmentação, a descrição de um objeto pode ser extraída segundo diferentes abordagens.

Objetos podem ser caracterizados de acordo com propriedades de diferentes 
naturezas, como contorno, cor, textura e forma [6]. Embora medidas relativas a esses conceitos sejam derivadas da representação digital de imagens por matrizes, nem sempre a manipulação dessa representação é conveniente. Particularmente, em problemas expressos em termos de regiões da imagem ou do relacionamento entre regiões, o uso de uma matriz de pixels pode ser computacionalmente custoso, pouco representativo e pouco compacto.

Nesse cenário, grafos surgem como alternativa poderosa para a representação de objetos e conteúdo de imagens, pois podem modelar tanto características próprias de pixels ou regiões, quanto as inter-relações apresentadas por esses elementos. Tipicamente, as informações associadas aos vértices referem-se a propriedades das regiões a que correspondem na imagem, podendo ser univaloradas ou multivaloradas, enquanto as arestas retratam tais inter-relações (vide fig. 4).

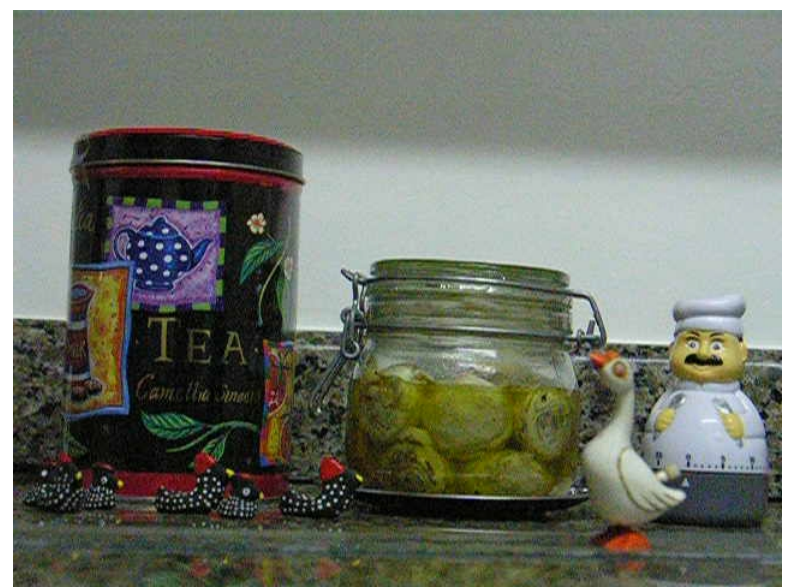

(a)

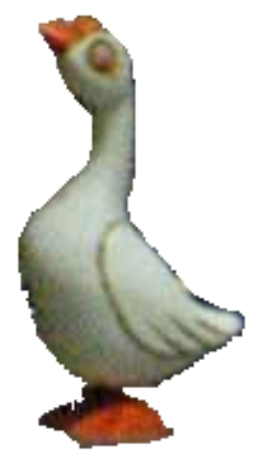

(b)

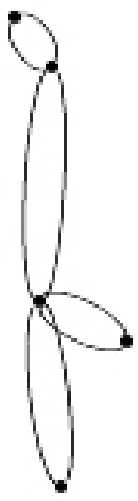

(c)

Figura 4. Representação por grafo de objetos contidos numa imagem: (a) imagem original; (b) um objeto da imagem segmentado e uma representação através de grafo derivada do mesmo (c).

Uma dessas relações possíveis refere-se à configuração de vizinhança de uma região, segundo a qual derivam grafos com topologias distintas a partir de uma mesma imagem. Os grafos que expressam esse tipo de relação são denominados grafos de vizinhança $[36,43,47]$ e serão discutidos na próxima subseção. 


\subsubsection{Tipos de Grafos e Implementação}

Seja $G=(V, E)$ um grafo finito extraído de uma imagem digital particionada em $n$ regiões caracterizadas por conjuntos conexos de pixels e disjuntos entre si. Seu conjunto $V$ é composto de $n$ vértices representantes de tais regiões, as quais são definidas em termos das coordenadas de seus respectivos centros de massa, ou centróides. Referências ao centróide de uma região associada a um vértice $v \in V$ serão feitas através da notação $p(v)$, enquanto o conjunto de centróides relativos às regiões da imagem é denotado $P$.

Já o conjunto E de arestas pode ser determinado de formas diferentes [40, 41, 47], de acordo com funções de distância medidas sobre os elementos do conjunto P, as quais definem uma relação de vizinhança em $G$. Nesta discussão, as distâncias utilizadas, considerando-se dois pontos $p=\left(x_{1}, y_{1}\right)$ e $q=\left(x_{2}, y_{2}\right)$, são as seguintes:

A. Euclidiana: $\mathrm{d}_{e}(\mathrm{p}, \mathrm{q})=\sqrt{\left(\mathrm{x}_{1}-\mathrm{x}_{2}\right)^{2}+\left(\mathrm{y}_{1}-\mathrm{y}_{2}\right)^{2}}$

B. City-block: $\mathrm{d}_{1}(\mathrm{p}, \mathrm{q})=\left|\mathrm{x}_{1}-\mathrm{x}_{2}\right|+\left|\mathrm{y}_{1}-\mathrm{y}_{2}\right|$

c. Chessboard: $d_{\infty}(p, q)=\max \left\{\left|x_{1}-x_{2}\right|,\left|y_{1}-y_{2}\right|\right\}$

Em primeiro lugar, vamos introduzir um conjunto de relações de vizinhança que induzem a formação de grafos não necessariamente conexos ou planares.

\section{k-VIZINHOS MAIS PRÓXIMOS}

Considere um vértice $v \in V$ e uma seqüência crescente das distâncias calculadas $\left(d_{e}, d_{1}\right.$ ou $\left.d_{\infty}\right)$ entre $p(v)$ e $p(w), \forall w \in V \backslash\{v\}$. Se a distância entre $p(v)$ e $p(w)$ é uma das $k$ menores distâncias da seqüência, então $w$ é um dos $k$ vizinhos mais próximos de $v$ e uma aresta é criada em $E$ conectando esses dois vértices.

\section{DISTÂNCIA MÁXIMA}

Dado um valor $d$, uma aresta é criada entre um vértice $v$ e cada um dos demais vértices de $G$ que obedecem a relação $d_{e}(p(v), p(w)) \leqslant d$. Assim, existe uma aresta conectando um par de vértices do grafo apenas se a distância entre os centróides das regiões a que correspondem não é maior do que d.

\section{VIZINHOS DO BARICENTRO}

Seja o fecho convexo de um conjunto de pontos Q no plano o menor conjunto 
convexo que contém $\mathrm{Q}$ [2]. Dado um vértice $v \in \mathrm{V}$ e um conjunto de vértices $w_{i} \in V \backslash\{v\}, i=1 \ldots k$, uma aresta é criada ligando $v$ a cada $w_{i}$ se $p(v)$ está contido no fecho convexo definido pelos centróides associados a cada $w_{i}$. Esta construção, no entanto, não garante a unicidade do grafo [40].

Embora os grafos induzidos pelas relações de vizinhança supracitadas sejam pertinentes, há um outro conjunto de grafos derivados do conceito de diagrama de Voronoi que se mostram mais robustos e interessantes, pois não dependem de parâmetros como nos casos anteriores, além de serem planares e conexos. Antes de discutí-los, no entanto, é preciso definir o conceito de Diagrama de Voronoi de um conjunto de pontos $\mathrm{P}$.

DIAGRAMA DE VORONOI. O diagrama de Voronoi correspondente a um conjunto $P$ finito de pontos no plano é dado pela união dos lugares geométricos de influência de cada um dos pontos de P:

$$
\bigcup_{p}\left\{Z(p)=\left\{m \in \mathfrak{R}^{2}, \forall q \in P \backslash\{p\}, d_{e}(m, p)<d_{e}(m, q)\right\}\right\} .
$$

No caso geral, $P=\left\{C_{1}, \ldots, C_{n}\right\}$, onde cada $C_{i}$ é um conjunto finito e disjunto dos demais, e as definições de distância envolvidas são aquelas aplicáveis a conjuntos. Podemos notar que tal diagrama define uma partição sobre o domínio analisado.

triangulação de delaunay. Também conhecido como grafo dual do diagrama de Voronoi, este grafo planar é constituído por todos os pares de pontos $(p, q)$ cujos polígonos de Voronoi associados $(Z(p)$ e $Z(q))$ são adjacentes. Assim, arestas em $G$ denotam adjacências entre regiões.

GRAFO DE GABRIEL. As arestas deste grafo são geradas se, para um par de pontos $(p, q) \in P^{2}=P \times P$, a seguinte relação é satisfeita:

$$
\forall \mathrm{m} \in \mathrm{P} \backslash\{\mathrm{p}, \mathrm{q}\}, \mathrm{d}_{e}(\mathrm{~m}, \mathrm{p})^{2}+\mathrm{d}_{e}(\mathrm{~m}, \mathrm{q})^{2}>\mathrm{d}_{e}(\mathrm{p}, \mathrm{q})^{2} .
$$

GRAFO DE VIZINHANÇA RELATIVA. As arestas geradas para este grafo são tais que, para um par de pontos $(p, q) \in P^{2}=P \times P$, vale: 


$$
\forall \mathrm{m} \in \mathrm{P} \backslash\{\mathrm{p}, \mathrm{q}\}, \mathrm{d}_{e}(\mathrm{p}, \mathrm{q})<\left\{\begin{array}{l}
\mathrm{d}_{\mathrm{e}}(\mathrm{m}, \mathrm{p}) \\
\mathrm{ou} \\
\mathrm{d}_{e}(\mathrm{~m}, \mathrm{q})
\end{array}\right.
$$

ÁrVORE GERAdORA mínima. Um grafo $\mathrm{G}=(\mathrm{V}, \mathrm{E})$ é uma árvore geradora mínima se a soma das distâncias euclidianas entre os centróides associados aos extremos das arestas de $\mathrm{E}$ é mínima e se, para quaisquer dois vértices $v, w \in \mathrm{V}$, um caminho ligando esses mesmos vértices existe e é único.
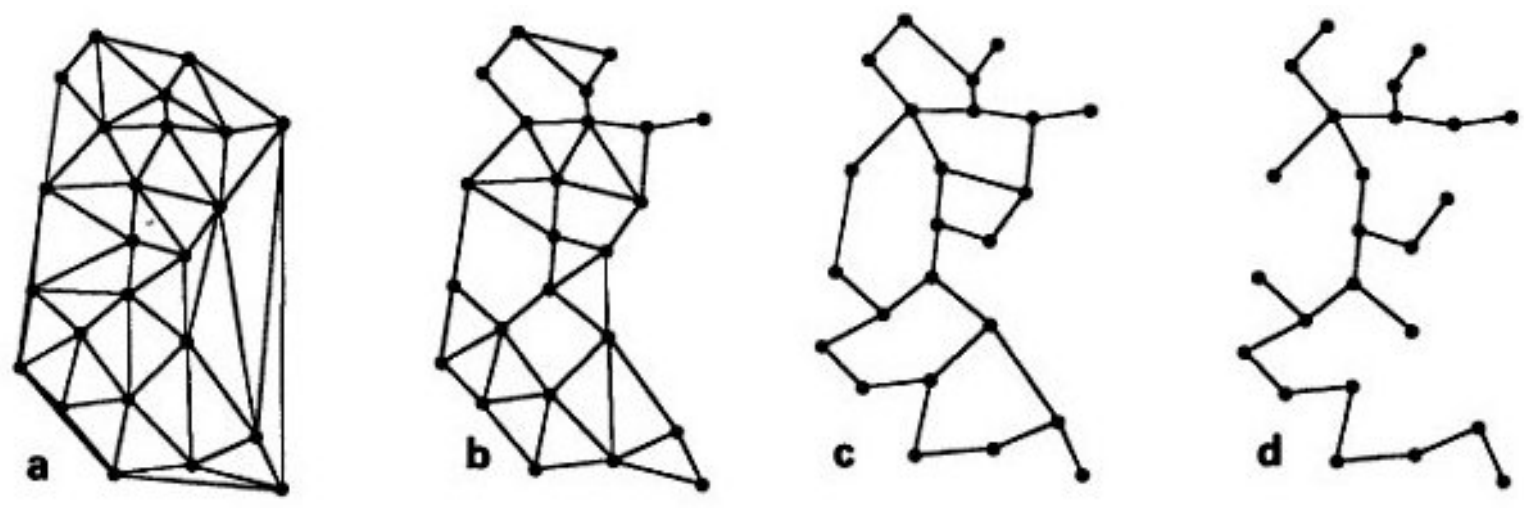

Figura 5. Grafos derivados do diagrama de Voronoi: (a) Triangulação de Delaunay; (b) Grafo de Gabriel; (c) Grafo de Vizinhança Relativa; (d) Árvore Geradora Mínima (adaptado de Vincent, 1989 [40]).

I MPLEMENTAÇÃo. Seja $n$ o número de pixels da imagem. Implementações do algoritmo para gerar o diagrama de Voronoi são amplamente encontradas na literatura de geometria computacional [2] e possuem complexidade $O(n \log n)$. Já a derivação dos grafos a partir do diagrama consome tempo proporcional a $\mathrm{O}(\mathrm{n})$. 


\subsubsection{Grafos e Algoritmo de Watershed}

O algoritmo de watershed, ou linha de partição de águas, é uma ferramenta morfológica amplamente conhecida e de grande aplicabilidade a problemas de segmentação de imagens ou detecção de bordas e contornos.

Em comparação com outras abordagens clássicas para detecção de bordas, tais como limiarização, a técnica de watershed mostra-se mais robusta e produz contornos mais precisos.

Desde sua proposição como ferramenta de segmentação de imagens, diversas implementações do algoritmo foram desenvolvidas, sendo a introduzida por Vincent e Soille [42] uma das mais eficientes e difundidas, bem como a versão do algoritmo baseada em marcadores proposta por Beucher e Meyer em [1]. Um estudo comparativo das implementações existentes, tanto por abordagens seqüenciais quanto paralelas, é apresentado em [31].

De modo geral, no entanto, a idéia da técnica de watershed pode ser compreendida através de uma analogia com a simulação de uma inundação num relevo. Uma imagem I em níveis de cinza pode ser vista como uma superfície topográfica, sendo o valor do nível de cinza associado a cada pixel equivalente à altura desse ponto em relação à base da superfície.

O processo de "inundação" é iniciado a partir dos mínimos locais da imagem. A topografia é, então, inundada a partir desses mínimos, aumentando-se gradualmente o nível de água que preenche a superfície. Quando as águas provenientes da inundação de diferentes mínimos estiverem prestes a se encontrarem, um "dique" é construído para evitar a fusão das mesmas. Quando toda a superfície tiver sido inundada, deixando visíveis apenas os topos dos diques, as linhas de partição de águas, ou watershed, terão sido determinadas. Por sua vez, as regiões de água entre os diques denotam as bacias de captação associadas aos mínimos locais iniciais.

De forma simplificada, computacionalmente, esse processo equivale à atribuição de rótulos aos mínimos locais de I, os quais são simultaneamente propagados até que rótulos distintos estejam prestes a serem atribuídos a um mesmo pixel. Nesse caso, o pixel pertencerá a uma linha de partição de águas. Quando todos os pixels tiverem sido examinados e nenhum rótulo for modificável, obtém-se a segmentação de I pelo algoritmo de watershed. Convém observar que, na versão do algoritmo proposta por Beucher e Meyer, os mínimos locais são substituídos por um conjunto de marcadores, 
ou seja, pixels selecionados previamente e a partir dos quais o processo de inundação é realizado.

Em geral, o algoritmo de watershed não é aplicado sobre uma imagem isenta de pré-processamentos. É comum utilizá-lo sobre o gradiente morfológico da imagem, pois tal operação realça bordas e transições ali presentes. Porém, o gradiente pode ser muito sensível a ruídos e, por conseqüência, levar a um fenômeno conhecido como supersegmentação da imagem resultante do algoritmo de watershed. Na prática, esse problema é verificado pelo grande número de bacias de captação produzidas.

Outra imagem que pode ser processada pelo algoritmo de watershed com implicações importantes é a negação da transformada da distância relativa a uma imagem binária. O conjunto de linhas de partições de águas obtido para essa imagem particular é equivalente ao esqueleto por zonas de influência de I (ou SKIZ), enquanto as bacias de captação equivalem às regiões do diagrama de Voronoi de I. Assim, usando algoritmo de watershed, é possível extrair o diagrama de Voronoi de uma imagem e, conseqüentemente, também os outros grafos citados na subseção 2.1.3.

Para a metodologia proposta nesta dissertação, o interesse particular no algoritmo de watershed está relacionado ao uso do particionamento originado por essa técnica na criação de grafos representantes do conteúdo de imagens, especialmente grafos relacionais com atributos [8], ou ainda grafos de adjacência de regiões [24, 33, 37]. Para esse propósito, cada região gerada pelo watershed dá origem a um vértice do grafo, enquanto uma dada relação de vizinhança entre regiões é expressa através das arestas.

Nesse caso, além das construções de arestas definidas pelas relações de vizinhança abordadas na subseção anterior, é possível também derivar arestas a partir do conceito de vizinhança de um pixel.

Seja $p$ um pixel de coordenadas $(x, y)$ numa matriz representante de uma imagem. Seus vizinhos horizontais e verticais são expressos pelas coordenadas $(x+1, y)$, $(x-1, y),(x, y+1),(x, y-1)$ e definem a vizinhança de 4 de $p$, ou $N_{4}(p)$. Já seus vizinhos diagonais encontram-se nas posições $(x-1, y-1),(x+1, y-1),(x-1, y+$ $1),(x+1, y+1)$ e, unidos aos pontos de $N_{4}(p)$, definem a vizinhança de 8 de $p$, ou $\mathrm{N}_{8}(\mathrm{p})$.

Assim, considerando um grafo $G=(V, E)$ extraído da imagem resultante do algoritmo de watershed, uma aresta é criada entre dois vértices $v$ e $w$ se as regiões associadas a cada um deles apresentam pixels que compõem a vizinhança $\left(\mathrm{N}_{4} \mathrm{Ou}\right.$ 
$\mathrm{N}_{8}$ ) de pelo menos um mesmo pixel pertencente ao conjunto de linhas de partição de águas.

\subsection{GRAFOS E RECONHECIMENTO DE PADRÕES}

\subsubsection{Um Resumo sobre Reconhecimento de Padrões}

Reconhecimento de padrões é o processo de classificação de dados de observação baseado ora em conhecimento prévio a respeito das categorias esperadas, ora em informações estatísticas e descritivas extraídas de amostras-padrões. O conceito de reconhecimento de padrões é bastante genérico, sendo reconhecimento de objetos uma aplicação de tal conceito sobre imagens.

Um sistema completo para reconhecimento de padrões é semelhante àquele para reconhecimento de objetos (seção 1.1), consistindo basicamente em:

- aquisição e representação dos dados de observação a serem classificados e/ou descritos;

- um mecanismo de extração e seleção de características para cômputo de informações numéricas ou simbólicas a respeito dos dados;

- um esquema de classificação, descrição ou aprendizagem dos dados a partir das características extraídas

O esquema de classificação ou descrição dos dados usualmente apóia-se na disponibilidade de um conjunto de amostras-padrões já classificadas ou descritas. Esse conjunto de amostras-padrões é comumente chamado de conjunto de treinamento, e a estratégia de classificação adotada é denominada supervisionada, pois baseia-se nas medidas extraídas de tal conjunto. Outra estratégia possível é a classificação não-supervisionada, a qual estabelece classes ou agrupamentos de dados de acordo com as regularidades derivadas das medidas extraídas dos padrões.

As abordagens usuais para a etapa de classificação podem ser categorizadas da seguinte forma:

- Abordagem estatística $[15,35,22]$ :

Possivelmente a mais difundida das técnicas de reconhecimento de padrões, 
apóia-se em modelagens estatísticas para realizar classificações. Classificadores estatísticos resultam do desenvolvimento de estratégias de decisão ou classificação baseadas em hipóteses probabilísticas conhecidas e medidas, denominadas características, definidas e extraídas das amostras. As classes possíveis e de interesse para o domínio do problema são chamadas de estados da natureza, sendo caracterizados por uma distribuição de probabilidade que rege a expressão das características medidas dos padrões.

Embora esse paradigma apresente um método formal e preciso para o problema de classificação, a escolha de características adequadas e a geração de hipóteses probabilísticas nem sempre são triviais.

- Abordagem estrutural ou sintática [30, 18, 35]:

Este paradigma de reconhecimento de padrões pode ser usado para classificar ou descrever padrões, partindo do pressuposto que informações estruturais, ou, mais genericamente, relacionais, são extremamente relevantes e significativas para a caracterização de um padrão. Tais informações costumam ser difíceis de se quantificar na forma de um vetor de características, como se faz em reconhecimento estatístico de padrões.

Assim, a abordagem estrutural propõe a quantificação das informações estruturais e relacionais de duas formas: através de gramáticas formais e de descritores relacionais (tipicamente grafos). A esses métodos de quantificação estão associados procedimentos de reconhecimento sintático, sendo estes, respectivamente, parsing e casamento de grafos relacionais.

A capacidade de representação de gramáticas formais é relativamente limitada, principalmente devido a dificuldades intrínsecas de parsing. No entanto, os métodos baseados em descritores relacionais, ou ainda, descrições gráficas de estrutura, têm sido amplamente usados, principalmente em aplicações de visão baseadas em modelos e inteligência artificial.

- Abordagem através de Redes Neurais [15, 21, 35]:

Sistemas biológicos realizam a tarefa de reconhecimento de padrões através de interconexões e trocas de mensagens entre células físicas especializadas: os neurônios. Inspiradas nesse modelo biológico e numa tentativa de replicá-lo computacionalmente, foram introduzidas as redes neurais, as quais constituem um paradigma de reconhecimento de padrões cujo estudo e desenvolvimento 
se estendem por aproximadamente 50 anos, e cuja aplicação na resolução de diversos problemas recebeu grande atenção na última década.

Tipicamente, uma rede neural é composta por unidades, ou neurônios, e interconexões entre esses elementos, definindo a topologia da rede. Uma rede neural é um sistema dinâmico, cujas entradas e respostas associadas podem mudar ao longo do tempo, de acordo com o conhecimento e o treinamento aos quais o sistema é exposto, por exemplo, novos padrões de treinamento, reajustes no comportamento de associação dos neurônios, entre outros.

Um dos problemas relativos ao uso de redes neurais é conhecido por regularização, sendo caracterizado pela seleção e pelo ajuste da complexidade da rede e dos parâmetros que a regem. Além disso, redes neurais funcionam como uma "caixa-preta" e, embora apresentem resultados de classificação satisfatórios, não oferecem necessariamente informações precisas e transparentes sobre o funcionamento interno do sistema.

A decisão sobre qual abordagem adotar depende da adequação da mesma ao problema a ser solucionado. Dentro da proposta da metodologia descrita neste documento, foi adotado o paradigma de reconhecimento estrutural de padrões através de grafos relacionais com atributos, o qual será explicado em detalhes na próxima subseção.

\subsubsection{Reconhecimento Estrutural de Padrões e Grafos Relacionais}

Como dito anteriormente neste capítulo, a representação através de grafos é mais compacta em diversas situações e apresenta a vantagem de se reaproveitar algoritmos já conhecidos da Teoria dos Grafos dentro do contexto dessas áreas. Em particular, a abordagem estrutural para reconhecimento de padrões [30, 35] faz uso de tal estrutura e de seu potencial tanto para representar padrões quanto para classificálos.

GRAFOS RELACIONAIS. O primeiro conceito essencial a ser introduzido é o de grafos relacionais. Grafos relacionais são grafos cujos vértices denotam subpadrões e primitivas e cujas arestas denotam relações entre tais subpadrões e primitivas. Se as relações em questão são simétricas, tais grafos são não-dirigidos; caso contrário, são 
grafos dirigidos.

Para ilustrar esse conceito, considere os componentes de uma face humana (olhos, lábios, narinas, sobrancelhas, etc.) e uma relação que descreva o arranjo espacial dos mesmos através de noções como estar ao lado de, estar acima ou abaixo de e estar contido em. Um grafo relacional para modelar esse esquema seria constituído por vértices representantes dos elementos da face e por arestas conectando vértices que observassem alguma dessas noções.

GRAFOS RELACIONAIS COM ATRIBUtos (ARgS). Embora grafos relacionais atendam o propósito de aplicações diversas, sua capacidade de representação é limitada. Isso se deve, em grande parte, à importância dispensada à estrutura como informação relevante de um problema. No entanto, outros tipos de informação também podem ser significativas e nem sempre facilmente mapeáveis num conjunto de vértices e arestas como, por exemplo, características simbólicas (cor, textura, etc.) ou numéricas contínuas.

Para suprir essas deficiências do conceito de grafo relacional, foi proposta uma extensão que agrega tanto as características estruturais do padrão quanto informações numéricas e simbólicas. Tal conceito estendido é denominado grafo relacional com atributos, ou ARG (do inglês attributed relational graph).

Formalmente, um ARG é definido como uma 4-tupla $G=(V, E, \mu, v)$, em que $V$ representa o conjunto de vértices de $G$, enquanto $E \subseteq V \times V$ representa seu conjunto de arestas. Nessa estrutura, cada vértice e aresta de $G$ possui um vetor de atributos associado, os quais são representados por $\mu: V \rightarrow L_{V}$, ou vetor de atributos de vértices, e $v: E \rightarrow L_{E}$, ou vetor de atributos de arestas.

Como atributos são propriedades estruturais, simbólicas e numéricas, esses vetores são responsáveis pela inclusão de dados relevantes e mais abrangentes para o problema na estrutura do grafo.

CASAmento entre grafos. Para que um padrão seja reconhecido usando-se a abordagem de grafos, basta que cada classe de padrões estruturais de interesse seja representada por um grafo prototípico. Dessa forma, padrões desconhecidos podem ser convertidos para a representação por grafos e então comparados aos protótipos das classes. Como raramente os dados a serem classificados alinham-se perfeitamente com os protótipos, é preciso definir medidas adequadas de similaridade 
para comparação dos grafos

Com base em tais medidas de similaridade, é possível derivar uma correspondência entre os vértices e arestas de um par de grafos, a qual deve satisfazer restrições que garantam um mapeamento correto de subestruturas de um grafo para subestruturas similares no outro. Esse processo de busca por correspondências é chamado casamento entre grafos [9, 10] e divide-se em duas categorias: casamento exato e casamento inexato entre grafos. Nas próximas subseções, serão discutidas as características de cada uma dessas abordagens.

\subsubsection{Casamento Exato entre Grafos}

Considere dois grafos finitos $G_{1}=\left(V_{1}, E_{1}\right)$ e $G_{2}=\left(V_{2}, E_{2}\right)$, com $\left|V_{1}\right|$ e $\left|V_{2}\right|$ não necessariamente iguais. Casamento exato entre grafos é o problema de se encontrar um mapeamento $f$ entre $V_{1}$ e $V_{2}$ tal que a existência de arestas seja preservada. Assim, se $v_{1}, w_{1} \in V_{1}$ e $\left(v_{1}, w_{1}\right) \in E_{1}$, então $\left(f\left(v_{1}\right), f\left(w_{1}\right)\right) \in E_{2}$. Diversas classes de mapeamentos, tipicamente funções, satisfazem tal condição e são, portanto, interessantes para o problema de casamento exato entre grafos.

ISOMORFISMO ENTRE GRAFOS. A forma mais rigorosa de casamento exato baseia-se na condição de isomorfismo entre grafos, a qual pode ser definida como uma bijeção $f: V_{1} \rightarrow V_{2}$ tal que, se $\left(v_{1}, w_{1}\right) \in E_{1}$, então $\left(f\left(v_{1}\right), f\left(w_{1}\right)\right) \in E_{2}$ e a recíproca também é válida.

A determinação de um isomorfismo entre dois grafos é computacionalmente custosa. Algoritmos para teste de isomorfismo requerem, para casos genéricos, tempo exponencial ou fatorial no pior caso. Embora, na prática, os grafos observados não sejam instâncias do pior caso e o custo de tempo de processamento seja aceitável, isomorfismos não são mapeamentos desejáveis para a maior parte dos problemas de reconhecimento de padrões, pois não permitem considerar deformações estruturais entre padrões observados e modelos, nem a presença de ruídos e outros efeitos resultantes da extração do padrão.

Numa tentativa de flexibilizar as restrições impostas pelo conceito de isomorfismo, são propostas algumas variações baseadas em conceitos menos rigorosos, mas que preservam a condição que caracteriza casamento exato.

- Isomorfismo entre subgrafos: dois grafos $\mathrm{G}_{1}$ e $\mathrm{G}_{2}$ são ditos subisomorfos se $\mathrm{G}_{1}$ é 
isomorfo a um subgrafo de $G_{2}$. A determinação de subisomorfismo também é computacionalmente custosa.

- Monomorfismo entre grafos: um monomorfismo entre dois grafos $\mathrm{G}_{1}$ e $\mathrm{G}_{2}$ requer que cada vértice de $V_{1}$ seja mapeado num vértice distinto de $V_{2}$, enquanto cada aresta de $E_{1}$ deve possuir uma aresta correspondente em $E_{2}$.

- Máximo Subgrafo Comum: consiste no maior subgrafo existente em $\mathrm{G}_{1}$ que seja isomorfo a um subgrafo de $G_{2}$. Esse problema é equivalente à determinação de um clique máximo num grafo de associação gerado a partir dos grafos iniciais.

- Homomorfismo entre grafos: um homomorfismo permite um mapeamento entre diversos vértices de $V_{1}$ num mesmo vértice de $V_{2}$, desde que se mantenha a condição de preservação de arestas.

A maior parte dos algoritmos de casamento exato entre grafos baseia-se em alguma variação de um algoritmo de busca em árvore [28, 32] com backtracking, cuja idéia geral é discutida a seguir.

algoritmos baseados em busca em árvore. A idéia principal em que se baseiam esses algoritmos é partir de um casamento inicialmente vazio e expandí-lo através da inclusão iterativa de pares de vértices correspondentes, desde que as restrições impostas pelo conceito utilizado (isomorfismo, homomorfismo, etc.) sejam obedecidas e verificadas.

Tal expansão é feita até que todos os vértices de um grafo tenham sido mapeados nos do outro, ou até que não seja mais possível incluir vértices sem infringir as regras. Se essa última situação for encontrada, o algoritmo pode desfazer a escolha das últimas atribuições entre os vértices, até que encontre uma solução viável, passo conhecido como backtracking. Se nenhuma solução é possível, o algoritmo é abortado.

A partir dessa idéia central, os diversos algoritmos diferenciam-se pela ordem de percurso das soluções parciais investigadas. Em particular, são bastante explorados os algoritmos de busca em profundidade, também conhecidos como algoritmos branch and bound. Tal subclasse de algoritmos é razoavelmente simples e requer uma menor complexidade computacional de espaço na busca por uma solução. Além disso, comporta facilmente a inclusão e consideração de atributos de vértices e arestas nas restrições de um casamento, o que é bastante desejável em aplicações de reconhecimento de padrões. 


\subsubsection{Casamento Inexato entre Grafos}

Como mencionado anteriormente, os grafos obtidos em diversas aplicações estão sujeitos a deformações e imprecisões resultantes de razões diversas: variabilidade inerente aos padrões, ruídos derivados do processo de aquisição, oclusões, dentre outros. Por esses motivos, nem sempre é possível utilizar casamento exato para mapear os vértices de um dado grafo no conjunto de vértices de outro. Além disso, ainda que um tal casamento seja adequado, há também a limitação do custo de tempo computacional das técnicas que implementam casamento exato.

Para tentar contornar essas dificuldades, foi proposto o conceito de casamento inexato entre grafos [3,4], ou ainda, casamento tolerante a erro. Nessa categoria de casamento, mapeamentos entre vértices que violam a condição de preservação de arestas não são proibidos. Ao contrário, são associados custos a cada correspondência entre vértices, sendo que tais custos consideram tanto a estrutura, quanto os atributos de vértices e arestas (quando esses estiverem disponíveis). Desse modo, a escolha de um mapeamento adequado depende da minimização do custo de um casamento.

A abordagem por casamento inexato entre grafos não garante que a melhor solução será encontrada. No entanto, ela permite que se encontre uma boa aproximação do mapeamento ideal e, em geral, em tempo aceitável. Pode-se ainda dividir os algoritmos em duas sub-categorias:

\section{ALgORITMOS ÓtIMOS:}

Tais técnicas resultam numa solução cujo custo é o mínimo global. Esses algoritmos podem ser vistos como uma generalização dos de casamento exato. Assim, se uma solução exata para o problema em questão existir, os algoritmos ótimos podem encontrá-la. No entanto, o tempo de processamento nem sempre é reduzido.

\section{ALgORITMOS SUBÓtimos OU APROXIMADOS:}

Produzem apenas uma solução cujo custo é um mínimo local. Embora forneçam apenas uma aproximação da solução ideal, o ganho em tempo de processamento é considerável, tornando vários desses algoritmos polinomiais. Quando uma aproximação for aceitável como solução de um problema, essa abordagem torna-se bastante interessante.

Há também muitas implementações para casamento inexato. Dentre as mais 
comuns e estudadas, encontram-se as apresentadas a seguir.

Algoritmos baseados em busca em árvore. Como no caso exato, algoritmos de busca em árvore com backtracking são aplicáveis para efetuar casamento inexato $[9,10]$. No entanto, o percurso que define as soluções parciais já não é a característica discriminante. A busca por um casamento passa a ser guiada pelos custos associados às soluções parciais obtidas até o momento e por uma heurística que indique qual seria o melhor caminho a expandir e explorar até atingir uma situação terminal.

Algoritmos baseados em otimização contínua. Nesta categoria, a questão de casamento entre grafos é vista como um problema de otimização não-linear contínua [9, 10]. Tal formulação deriva implementações com custo computacional reduzido. Outra vantagem é o aprimoramento gradual de uma solução inicial fraca até que se obtenha uma solução mais robusta e precisa, por meio de estimativas de probabilidade ajustáveis. Porém, essa técnica não garante atingir a solução ótima para um problema e requer conversões entre os domínios discreto e contínuo, o que nem sempre é trivial e pode ainda incluir um novo grau de aproximação nos resultados.

algoritmos baseados em métodos espectrais. Métodos espectrais [9, 10] são uma categoria de algoritmos de casamento inexato limitada à busca por isomorfismos. Baseiam-se no fato de que os autovalores e os autovetores da matriz de adjacências de um grafo são invariantes a permutações de vértices e na percepção de que se dois grafos são isomórficos, então seus autovalores e autovetores serão iguais. Como a detecção dessas características é feita em tempo polinomial, há o interesse no uso dessa abordagem para casamento. Porém, ela é exclusivamente estrutural, não comportando o uso de atributos de vértices e arestas.

Algoritmos genéticos (GAS). Algoritmos genéticos [8] são uma categoria de algoritmos de busca inspirados em fenômenos de evolução biológicos como mutações, heranças, seleção natural e recombinações. A execução de tais algoritmos é, portanto, uma simulação do comportamento evolutivo de uma população de indivíduos ao longo de gerações de acordo com os fenônemos citados previamente. 
A escolha dos indivíduos que serão perpetuados ou modificados através das gerações é baseada numa função de adequação da população e regras de mutação e recombinação.

Para o problema de casamento, uma população representa inicialmente uma solução aleatória. Tal solução será iterativamente avaliada em termos da função de adequação estipulada e certos indivíduos (rótulos) serão escolhidos segundo algum critério e sofrerão alterações para formarem uma nova população, a qual será considerada na etapa seguinte do algoritmo. Esse processo é repetido até que uma solução satisfatória seja atingida.

algoritmos de estimativa de distribuição (edas). Assim como os algoritmos genéticos, essa classe de algoritmos $[7,8]$ enquadra-se na abordagem evolutiva, em que diferentes indivíduos ou soluções são gerados a cada etapa de execução até a obtenção de um resultado desejável. Porém, enquanto o comportamento de GAs depende de uma certa perícia na escolha dos parâmetros que regem as regras de mutação e recombinação, EDAs são independentes desses processos e parâmetros, o que facilita seu uso.

O processo de evolução de uma geração para a seguinte é feito estimando-se a distribuição de probabilidade relativa a uma seleção de indivíduos, originando, assim, um modelo gráfico probabilístico. A partir desse modelo probabilístico, são sorteadas novas amostras, das quais resulta uma nova geração de indivíduos a ser analisada na próxima etapa do algoritmo. Um caso particular de extrema importância ocorre quando os indivíduos são, na verdade, instâncias de valores discretos, pois o modelo probabilístico criado nessa situação assume a forma de uma rede Bayesiana.

\subsection{GRAFOS E SISTEMAS DE VISÃO COMPUTACIONAL}

A associação entre a representação de objetos a partir de grafos e procedimentos de classificação formulados como um problema de casamento entre grafos foi explorada em inúmeras situações encontradas na literatura.

Por exemplo, em Saxena et al. [34], é proposta uma técnica para detectar, em imagens complexas, objetos descritos por um template composto de informações geométricas e de cor. Grafos relacionais com atributos são adotados na representação da imagem e do template, enquanto a busca pelos objetos de interesse é realizada 
através da determinação de um clique no grafo de associação derivado de ambos os ARGs.

Já o artigo de Carvalho e Lotufo [5] propõe o mapeamento de regiões correspondentes em quadros consecutivos de uma seqüência de imagens. Tais regiões são obtidas através de um algoritmo de watershed hierárquico, e são representadas por grafos. Neste caso, também, o mapeamento desejado é equivalente a um clique no grafo de associação relativo aos grafos. O método foi aplicado experimentalmente sobre seqüências de imagens de ressonância magnética representativas do ventrículo esquerdo.

Ainda, uma outra aplicação dos conceitos de grafos e casamento entre grafos é evidenciada em Kim et al. [25]. Os autores expõem a importância do uso de um descritor de características perceptíveis de objetos 3D em soluções de recuperação de dados pictóricos baseada em conteúdo. Tais descritores transmitem informações tanto de formas, quanto de funcionalidade e estrutura, de acordo com uma representação dos objetos decompostos em partes.

ARGs são estruturas bastante adequadas e eficientes para modelar essas informações e foram usados na composição do descritor de características perceptíveis de formas 3D (Perceptual 3D Shape, $\mathrm{P}_{3} \mathrm{DS}$ ) adotado como padrão internacional em codificação MPEG-7. Diante desse fato, o artigo compara o desempenho de alguns métodos para casamento entre grafos, visando orientar a escolha de soluções de recuperação de dados efetuadas sobre esse descritor.

O trabalho realizado em Cesar-Jr et al. [8] objetivava o reconhecimento de características faciais (ex: lábios, narinas, pupilas, etc.) em imagens estáticas de faces disponíveis em bancos de imagens públicos e outras imagens próprias adquiridas através de uma câmera digital. Simultaneamente, foram comparadas diversas técnicas para solução do problema casamento inexato entre grafos.

Um modelo pré-definido manualmente e uma imagem de entrada supersegmentada originaram, respectivamente, um ARG modelo e um ARG de entrada, ambos grafos completos. Com essa representação, o processo de reconhecimento foi realizado segundo três classes de implementações de casamento inexato entre grafos: algoritmos genéticos, de estimativa de distribuição e baseados em busca em árvore.

Em todos esses casos, a classificação das características faciais resultou da minimização de uma determinada função custo responsável pela avaliação das soluções encontradas pelos algoritmos, penalizando casamentos possivelmente ruins entre en- 
trada e modelo de acordo com medidas de dissimilaridade extraídas da comparação dos atributos dos ARGs.

A partir das diferentes implementações, foi possível analisar os resultados obtidos para o reconhecimento sobre um conjunto de faces-testes e comparar o desempenho de cada algoritmo segundo critérios como custo computacional e taxa de erros das classificações. As conclusões do artigo apontaram o algoritmo baseado em busca em árvore como a implementação de melhor custo-benefício, pois apresentou o menor tempo de processamento em relação aos demais e dele derivaram resultados com baixas taxas de erro.

Particularmente, da discussão teórica e dos resultados apresentados nesse último artigo, surgiu o interesse em se aplicar ARGs e a solução de reconhecimento por casamento inexato entre grafos implementado por um algoritmo de busca em árvore ao problema de reconhecimento de objetos em vídeo digital, o que resultou na metodologia desenvolvida neste mestrado.

Essa idéia foi apresentada no próprio artigo como potencial trabalho futuro e foi sustentada pelas tendências de representação em reconhecimento de padrões e técnicas estruturais, como reportado por Lev Goldfarb em apresentação realizada na Conferência Internacional de Reconhecimento de Padrões, ICPR, em 2004:

As principais dificuldades estão associadas, e continuarão a estar, à necessidade de se introduzir informação temporal numa representação estrutural, ou seja, ao conceito de histórico de formação ou evolução de um objeto.

No entanto, como imagens estáticas e vídeo possuem características distintas, as mesmas devem ser observadas. Assim, a manipulação de seqüências de imagens introduziu uma série de mudanças na proposta relatada no artigo, dentre as quais destacam-se:

- adoção de ARGs cuja topologia segue o padrão de grafos de adjacência de regiões, para reduzir os recursos necessários na manutenção dos grafos em memória;

- formulação de um novo tipo de grafo relacional com atributos, o chamado ARG inter-quadros, para acomodar atributos de caráter espacial-temporal típicos de vídeo digital; 
- adaptação da função custo e do funcionamento do algoritmo de busca em árvore proposto no artigo, para que refletissem as alterações feitas na representação por grafos relacionais com atributos.

No próximo capítulo, todos os tópicos supracitados serão abordados detalhadamente. 



\section{METODOLOGIA}

Eu me enquadro entre aqueles que vêem grande beleza na ciência. Um cientista em seu laboratório não é apenas um técnico: ele também é uma criança colocada em frente a fenômenos naturais que a impressionam como um conto de fadas.

- Marie Curie

As idéias introduzidas nos capítulos precedentes evidenciaram a importância de se representar adequadamente o conteúdo de uma imagem digital, particularmente, para descrever objetos. Além disso, tornou-se claro que a escolha de uma certa representação influencia também os procedimentos que serão adotados ao longo do fluxo de um sistema de reconhecimento de objetos, como a etapa de classificação.

Dentre diversas representações existentes na literatura, foi destacada a importância de grafos como descritores de objetos, especialmente, grafos relacionais com atributos (ARG), cujo inerente poder de representação permite agregar, de forma compacta, informações de diferentes naturezas sobre os elementos a que se referem.

As questões de representação e reconhecimento de objetos aparecem também na análise de vídeo digital, pois tal elemento é, na verdade, composto por um conjunto de imagens digitais seqüenciais adquiridas ao longo do tempo, as quais são chamadas quadros. Porém, essa característica temporal de vídeo o torna um elemento pictórico singular, pois o capacita a capturar transformações dos objetos no transcorrer dos quadros.

Dessa última observação decorrem novos problemas a serem resolvidos no tratamento de vídeo. Rastreamento de objetos é um exemplar desses problemas e pode 
ser descrito como a determinação da posição de um objeto específico em cada quadro. Como a identificação de um objeto está envolvida nesse procedimento, existe uma conexão entre os processos de rastreamento e reconhecimento.

Precisamente, neste capítulo, será apresentada a proposta de uma metodologia para reconhecer e rastrear objetos em vídeo digital através de uma representação baseada em grafos relacionais com atributos e casamento inexato entre grafos, cujo funcionamento é discutido a seguir.

\subsection{PERSPECTIVA GERAL}

Seja $T\left(I_{t}, t\right), t=1, \ldots, n$, uma seqüência de imagens digitais, ou vídeo digital, composta por $n$ imagens digitais $I_{t} 2 D$ ordenadas seqüencialmente no tempo, também chamadas quadros.

Em cada quadro $I_{t}$ de um vídeo, deseja-se rastrear e reconhecer determinado(s) objeto(s), para posterior utilização a finalidades diversas. Por exemplo, é possível localizar e identificar um determinado artista nos quadros que compõem um filme digital, ou então o ventrículo esquerdo num diagnóstico realizado por imageamento médico do sistema cardiorespiratório de um paciente.

Mais formalmente, um objeto contido num certo quadro de uma seqüência de imagens pode ser definido da seguinte forma [38, 39]:

Definição 3.1.1 Um objeto $\mathrm{O}$ é uma dupla $(\mathrm{S}, \mathrm{f})$, em que $\mathrm{S} \subset \mathfrak{R}^{2}$ representa o suporte geométrico de $\mathrm{O}$, o qual define a topologia e a geometria do objeto, enquanto $\mathrm{f}: \mathrm{S} \rightarrow \mathfrak{R}^{\mathrm{n}} e^{\prime}$ uma função que mapeia esse suporte em seu respectivo conjunto de descritores quantitativos, qualitativos e relacionais, também chamados de atributos.

O suporte geométrico de um objeto pode ser interpretado como o conjunto de pixels (região) relacionados a esse mesmo objeto, contidos num quadro ou numa imagem. Ainda, um objeto pode ser decomposto em outros objetos do ponto de vista semântico, ou seja, uma região da imagem pode conter sub-regiões também de interesse para a aplicação em questão, as quais são denominadas partes.

Por exemplo, o conjunto de pixels relativos a uma face numa imagem pode ser considerado um objeto, bem como os subconjuntos de pixels relativos aos olhos, boca e nariz, cujas propriedades visuais locais também são relevantes para a descrição do objeto em sua totalidade. 
Retomando as definições da seção 2.2.2, um grafo relacional com atributos consiste num grafo em que vértices representam objetos (ou partes) de uma imagem, enquanto arestas denotam relações diversas entre os mesmos.

Cada vértice de um ARG possui um vetor de atributos de objeto associado, cujos elementos formam um conjunto finito de características (numéricas ou simbólicas) medidas em relação a tal objeto. De modo similar, cada aresta associa-se a um vetor de atributos relacionais composto por elementos correspondentes a algum tipo de medida de relação estrutural entre os extremos da aresta, como uma relação espacial (ex. distância), uma medida de simetria ou de (dis)similaridade.

Considere, por exemplo, a figura 6(a). Um possível ARG derivado dessa imagem é exibido na figura $6(\mathrm{~b})$, o qual é constituído de vértices representantes do rosto, dos olhos esquerdo e direito e da boca, além das arestas, que indicam relação de adjacência entre regiões. Os vetores de atributos de objetos poderiam conter dados sobre o nível de cinza médio e centróide de cada região, enquanto os vetores de atributos relacionais indicariam vetores geométricos entre regiões.

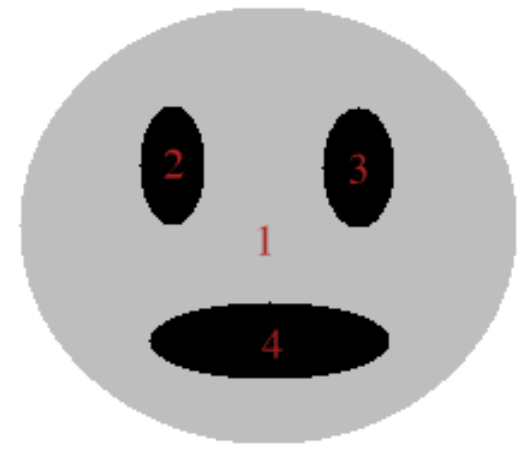

(a) Imagem.

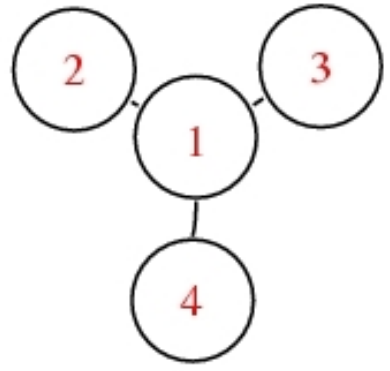

(b) Respectivo ARG.

Figura 6. Exemplo de ARG de uma imagem.

RePRESENTAÇÃo Dos objetos. Para tratar os quadros componentes de uma seqüência de imagens e, simultaneamente, considerar o seu aspecto temporal intrínseco, foram introduzidas duas espécies de grafos relacionais com atributos na 
metodologia proposta: $A R G$ intra-quadros, ou $A R G$-intra, e $A R G$ inter-quadros, ou ARG-inter.

O primeiro consiste exatamente no conceito de ARG descrito anteriormente, extraído de um único quadro da seqüência de imagens. Já o segundo é formado pela união de diversos ARGs-intra, obtidos de n quadros consecutivos da seqüência, numa tentativa de modelar as correspondências entre objetos ou partes em quadros distintos ao longo do tempo.

O conjunto de arestas de um ARG-inter é composto por arestas relacionais, idênticas às arestas de um ARG-intra, e arestas temporais, as quais conectam vértices do ARG-inter provenientes de diferentes ARGs-intra.

O objetivo do uso de arestas temporais é introduzir informação espaço-temporal na estrutura do ARG-inter, representando ligações entre regiões correlacionadas espacialmente e possivelmente relacionadas a um mesmo objeto ou uma mesma parte em diferentes instantes de tempo.

Posteriormente, tal informação é considerada na etapa de reconhecimento, visando obter uma classificação mais coerente de um certo objeto ou de uma certa parte em quadros consecutivos ou próximos do vídeo.

É importante notar que um ARG-intra é, na verdade, um caso particular de ARG-inter em que $n=1$ e o conjunto de arestas temporais é vazio.

RECONHECIMENTO. Uma vez representados através de grafos relacionais com atributos, os quadros do vídeo devem ser submetidos ao processo de reconhecimento, expresso em termos do problema de casamento inexato entre grafos discutido na seção 2.2.4.

Para instruir o sistema em relação a quais objetos deverão ser identificados, um ARG-intra modelo é criado a partir de uma imagem de referência e uma máscara modelo subdividida em partes de interesse. Cada vértice desse grafo recebe um rótulo único que identificará seu objeto associado durante o processamento de todo o vídeo.

Assim, é preciso determinar um mapeamento, tipicamente uma função, do conjunto de vértices de um ARG-inter extraído da seqüência no conjunto de vértices de tal ARG-intra modelo. Ao longo deste texto, os termos reconhecimento e classificação designarão a associação entre um dado vértice do ARG-intra modelo e um vértice do ARG-inter. 
Funcionamento. Para ilustrar o funcionamento da metodologia, a figura 7 exibe um fluxograma simplificado da mesma.

Considere uma seqüência de imagens composta de $\mathrm{N}$ quadros. Em primeiro lugar, um ARG-intra modelo é gerado uma única vez a partir de uma imagem de referência e uma máscara modelo contendo os objetos de interesse a serem reconhecidos. A seguir, $n$ quadros consecutivos da seqüência, $n \ll N$ fixado previamente, são pré-processados e segmentados, originando n ARGs-intra e 1 ARG-inter.

O processo de reconhecimento é então realizado, resultando em vértices do ARGinter rotulados de acordo com os vértices do ARG-intra modelo a que foram associados. Quanto aos quadros da seqüência, as regiões relativas aos objetos de interesse recebem também os rótulos designados a seus respectivos vértices no ARG-inter.

Finalmente, resta determinar a nova localização dos objetos para que se possa rastreá-los na continuidade da seqüência. Com base nas classificações obtidas para os vértices do ARG-inter, pode-se calcular uma nova posição para cada conjunto de vértices associados a um mesmo rótulo. Dessa forma, as posições dos objetos representados pelo ARG-intra modelo podem ser mapeadas nessas novas posições encontradas, mantendo-se atualizadas e refletindo com maior fidelidade o dinamismo dos objetos.

Essas etapas são repetidas ao longo de toda a seqüência, resultando em classificação e rastreamento dos objetos para todos os quadros.

Nas próximas seções, os passos da metodologia serão detalhados seguindo a ordem da seqüência de etapas típicas para reconhecimento de objetos apresentada no capítulo 1: aquisição (seção 3.2), pré-processamento (seção 3.3) e segmentação (seção 3.4) das imagens, seguidos da representação (seção 3.5), do reconhecimento (seção 3.6) e do rastreamento (seção 3.7) dos objetos. 


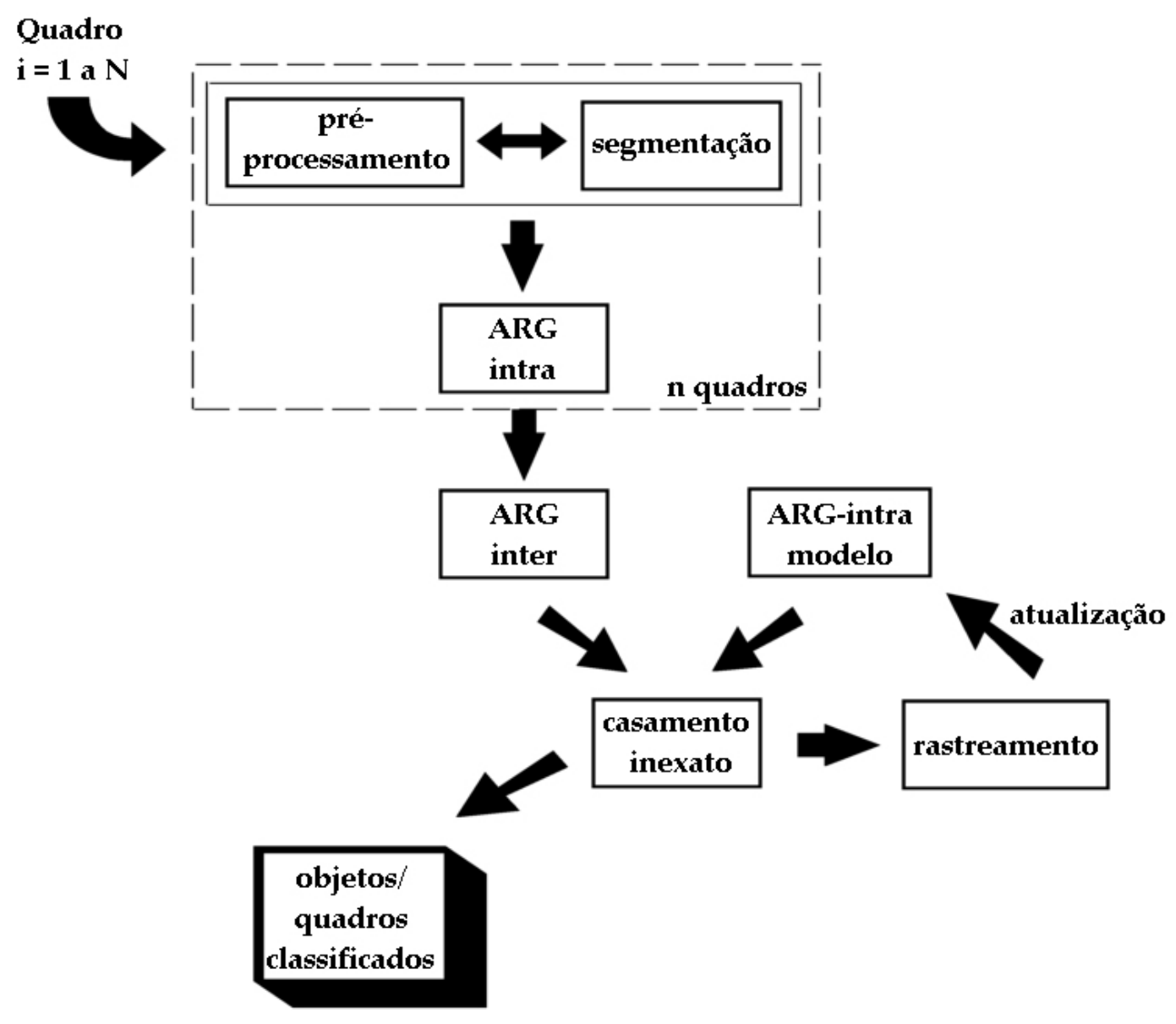

Figura 7. Fluxograma simplificado das etapas componentes da metodologia.

\subsection{CONSIDERAÇÕES SOBRE MODELO E VÍdEO DIGITAL}

\subsubsection{Seqüências de Imagens}

De modo geral, assume-se que a metodologia será aplicada sobre seqüências de imagens, coloridas ou não, adquiridas por câmeras (fotográficas ou webcams) e filmadoras digitais, as quais projetam um cenário 3D numa janela retangular do plano de imagem 2D. Uma outra modalidade de seqüências de imagens possível de ser tratada é aquela obtida através de computação gráfica, a partir da ordenação seqüencial de imagens 2D estáticas geradas sinteticamente.

Para efetuar a segmentação, o reconhecimento e o rastreamento de objetos em 
todos os quadros, foram assumidas algumas restrições baseadas na natureza dos objetos e de seus movimentos.

Devido à inércia, o movimento de uma certa entidade física não se modifica instantaneamente. Assim, se uma seqüência de quadros for adquirida de forma que mudanças bruscas não ocorram entre quadros consecutivos, então também não serão observadas, em geral, mudanças abruptas no movimento da maior parte dos objetos físicos presentes.

Logo, as seguintes hipóteses devem ser verificadas em relação às seqüências a que esta metodologia se aplica:

- a posição de um dado ponto permanecerá relativamente inalterada entre quadros consecutivos;

- a velocidade escalar de um dado ponto permanecerá relativamente inalterada entre quadros consecutivos;

- a direção de movimento de um dado ponto permanecerá relativamente inalterada entre quadros consecutivos.

Em termos práticos, é desejável que a taxa de aquisição dos quadros seja razoável, por exemplo, acima de 24 quadros por segundo.

\subsubsection{Imagem de Referência}

Numa técnica baseada em modelo, a entrada sob análise deverá ser classificada de acordo com a observação de semelhanças e diferenças entre a mesma e um dado modelo. Portanto, o propósito do modelo é especificar características de alvos ideais a serem procurados e possivelmente detectados na entrada, introduzindo informação a priori no processo de reconhecimento.

Dada uma seqüência de imagens, estamos interessados em rastrear e reconhecer determinados objetos em todos os seus quadros componentes. Como nesta metodologia os objetos contidos num certo quadro são representados através de grafos relacionais com atributos, é preciso criar um ARG representante dos objetos-alvos, grafo este denominado ARG-intra modelo.

No entanto, a criação de um tal ARG deve se basear numa imagem de referência que indique quais são os objetos de interesse e que permita calcular os vetores de 
atributos de objeto e relacional referentes a cada um deles. Tipicamente, para os fins da metodologia desenvolvida, toma-se como imagem de referência o primeiro quadro da seqüência de imagens a ser analisada em que os objetos de interesse estejam presentes.

Embora essa imagem permita extrair os atributos relativos aos objetos, uma imagem binária auxiliar, chamada de máscara modelo, é manualmente gerada para proporcionar uma divisão da imagem de referência em regiões que selecionem os objetos de interesse. Cada região dessa máscara recebe um rótulo distinto e esse esquema de rótulos é utilizado posteriormente para identificar os vértices do ARGintra modelo também. Tal rotulação da máscara é feita automaticamente através de um algoritmo de crescimento de regiões $[6,17]$.

A figura 8 exemplifica algumas imagens de referência e suas respectivas máscaras modelos nas versões binária e rotulada. É importante esclarecer que, embora as imagens de referência e mesmo as seqüências de vídeo possam ser coloridas, para fins de processamento, todas as imagens e quadros são convertidos para níveis de cinza.
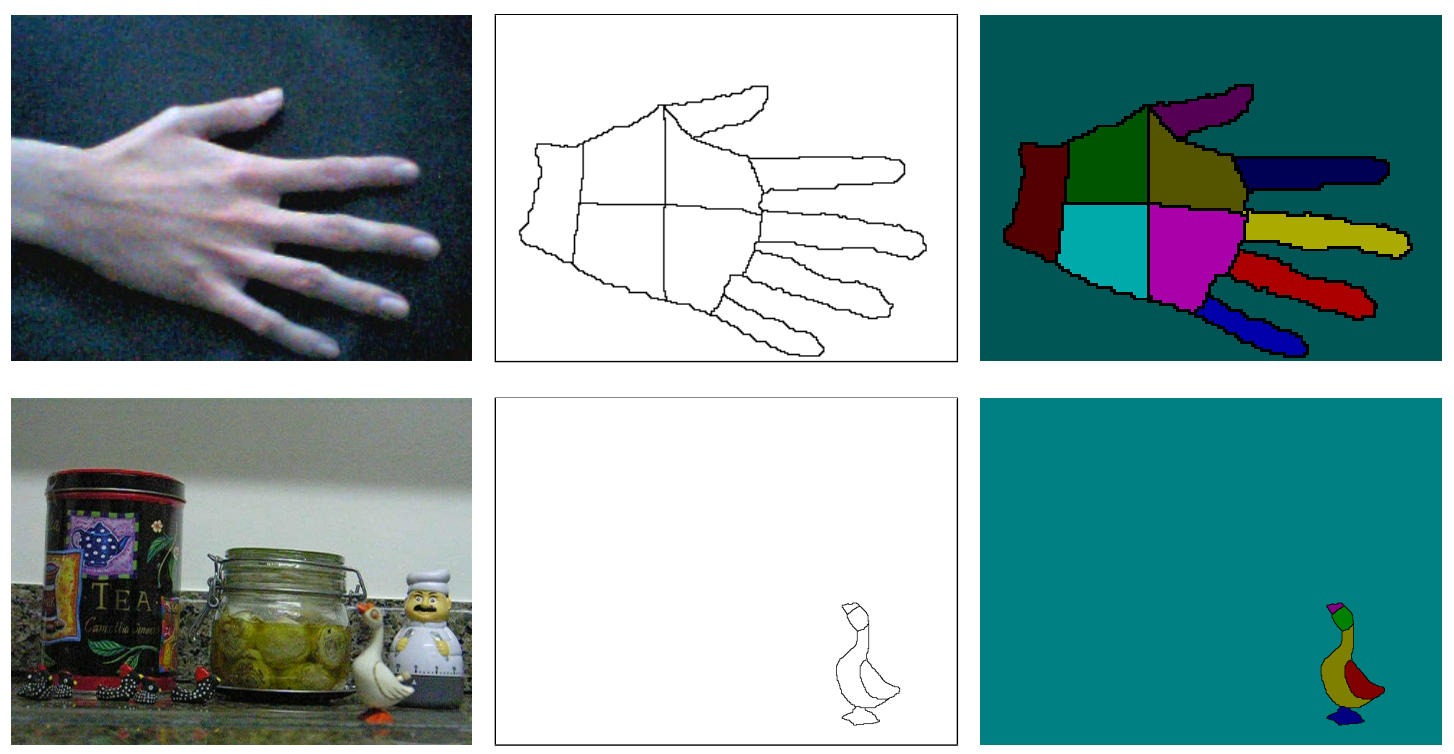

Figura 8. Imagens de referência (à esquerda), máscaras modelos binárias (centro) e rotuladas (à direita). Nas imagens superiores, os objetos de interesse são regiões das costas da mão e dedos. Já nas imagens inferiores, os alvos seriam bico, cabeça, corpo, asa e patas da gansa. 


\subsection{PRÉ-PROCESSAMENTO}

Juntamente com a aquisição das imagens, um passo inicial importante dentro do fluxo para reconhecimento de objetos é o pré-processamento das imagens. Uma imagem digital tal qual é adquirida pode não ser diretamente utilizável numa dada aplicação. Por exemplo, a presença de ruídos pode interferir na extração de informações importantes da imagem. Noutros casos, a qualidade da imagem é satisfatória, mas se faz necessário realçar características específicas da mesma, tais como bordas, regiões específicas (blobs), texturas, entre outras.

Para adequar a imagem aos requisitos do domínio de aplicação a que ela se destina, podem ser utilizadas inúmeras técnicas de processamento de imagens. Particularmente, neste projeto foram utilizadas as seguintes técnicas, de acordo com a necessidade imposta pelas seqüências de imagens utilizadas:

- Suavização por Filtragem Gaussiana [6, 17]

O efeito desse filtro é remover ou suavizar pequenos artifícios (ruídos), provocando uma espécie de "borramento" da imagem. Tal efeito é obtido através da convolução entre uma imagem e uma janela pré-definida que representa discretamente uma função Gaussiana desejada.

O grau de suavização atingido é determinado pelo desvio-padrão dessa função e o resultado da aplicação da mesma é equivalente a uma média ponderada da vizinhança de cada pixel, sendo o maior peso atribuído ao pixel central sob a janela.

Essa característica do filtro permite que a suavização assuma um caráter multiescala, ou seja, o desvio-padrão adotado influencia o borramento da imagem e, conseqüentemente, a persistência de elementos de escalas diferentes na imagem. Quanto maior o desvio-padrão, menor é a presença de pequenos elementos na imagem.

Porém, outros filtros de suavização similares, tais como o da média ou da mediana, poderiam ser aplicados em substituição à filtragem gaussiana.

- Operadores morfológicos [36]:

Operadores morfológicos são definidos no campo da Morfologia Matemática, cuja linguagem, no caso de imagens binárias, é fundamentada na teoria dos 
conjuntos. Intuitivamente, os operadores morfológicos são usados em processamento de imagens para extrair ou modificar componentes de imagens de acordo com a forma que as caracteriza, sendo úteis em diversas aplicações como filtragem de ruído, detecção e decomposição de formas.

No pré-processamento dos quadros do vídeo analisados nesta metodologia, foram utilizados os operadores básicos fundamentais dilatação e erosão, bem como abertura e fechamento, operadores derivados dos dois conceitos anteriores.

- Gradiente Morfológico [36]

Essa operação da morfologia matemática permite ressaltar transições de níveis de cinza consideráveis, o que permite a extração de bordas da imagem. Em particular, o algoritmo de watershed, usado na etapa de segmentação, aplicado sobre a imagem resultante dessa técnica é menos suscetível a ruídos, produzindo resultados de melhor qualidade.

\section{$3 \cdot 4$ SEGMENTAÇÃ O}

Uma etapa importante dentro do fluxo de sistemas automáticos de reconhecimento é a de segmentação dos objetos. Esse processo consiste no isolamento e seleção dos pixels de uma imagem que participam da composição de um objeto. Na metodologia aqui proposta, a tarefa de segmentação permite extrair, em cada quadro de um vídeo, pixels que possam estar relacionados aos objetos definidos previamente pela imagem de referência e a máscara modelo.

Uma grande variedade de técnicas de segmentação existe na literatura de processamento de imagens e visão computacional $[6,17,18,23]$ e quaisquer delas que resultem no suporte geométrico dos objetos de interesse (em sua totalidade, não descritos por partes) em cada quadro do vídeo podem ser adotadas.

Contudo, nos testes realizados (capítulo 4) para validar o funcionamento da metodologia, foram aplicadas as seguintes técnicas de segmentação:

- Algoritmos para remoção de fundo (background) em vídeo digital: Tipicamente, os objetos de interesse numa seqüência de imagens caracterizam o "primeiro plano" (foreground) do cenário em questão, enquanto os demais elementos presentes são considerados fundo, ou background. Logo, um algoritmo 
de remoção de fundo pretende eliminar todos os pixels que não correspondam ao primeiro plano em cada quadro de um vídeo.

Técnicas diversas propõem soluções para esse problema [12], dependendo das propriedades do vídeo a ser analisado, como condições de aquisição (câmera fixa ou em movimento, mudanças de iluminação) ou alterações na geometria do fundo (ex: introdução de novos elementos no cenário).

Em relação aos testes feitos, uma imagem equivalente ao fundo da seqüência de vídeo a ser tratada foi criada automaticamente com base na média dos valores de pixels correspondentes em todos os quadros. Dessa forma, foi possível reconstruir o fundo e subtraí-lo de cada quadro do vídeo, selecionando apenas regiões relativas aos objetos de interesse.

Da imagem originada pela subtração do fundo (fig. 9 (e)), foi gerada uma máscara binária, a qual foi usada para compor uma imagem final em que pixels de fundo tinham valor 0 , enquanto os pixels referentes aos objetos assumiam os respectivos valores de nível de cinza no quadro pré-processado.

Caso fossem detectadas regiões que não correspondessem a objetos de interesse, bastaria descartá-las. Para determinar se uma região pertenceria aos alvos buscados, seriam usadas informações de posição dos objetos transmitidas pelo ARG-intra modelo.

- Limiarização ou Thresholding Global:

A idéia central dessa técnica consiste na seleção de pixels de uma imagem de acordo com a relação dos níveis de cinza dos mesmos e um limiar L prédeterminado. De modo geral, um pixel será considerado pertencente a um objeto se seu nível de cinza for maior do que tal valor L e, caso contrário, será considerado um pixel de fundo.

Existe também uma versão de limiarização adaptativa, cuja regra de inclusão ou não de um pixel no conjunto de interesse não depende apenas do valor de seu nível de cinza, mas também de propriedades locais desse pixel em relação a uma determinada vizinhança.

A imagem originada pela limiarização global (fig. 9 (b)) de um dado quadro pré-processado foi utilizada para compor uma imagem similar à descrita no algoritmo de remoção de fundo, em que pixels de fundo eram representados 
pelo valor 0 , enquanto aqueles referentes aos objetos assumiam os respectivos valores de nível de cinza no quadro pré-processado.

Entretanto, como o modelo utilizado na metodologia é composto por partes, o processo de segmentação só é concluído após o particionamento das imagens encontradas pelas técnicas anteriores. Tal divisão é determinada pela aplicação do algoritmo de watershed [42] sobre o gradiente morfológico dessas imagens resultantes, o qual foi explicado na subseção 2.1.4. Posteriormente, as partições obtidas são usadas como base para a construção dos ARGs-intra que modelam o conteúdo dos quadros do vídeo.

Exemplos de quadros da seqüência de imagens e suas respectivas segmentações finais após a aplicação do algoritmo de watershed sobre o resultado das técnicas de limiarização e remoção de fundo são mostradas nas figuras 9 (c) e 9 (f).

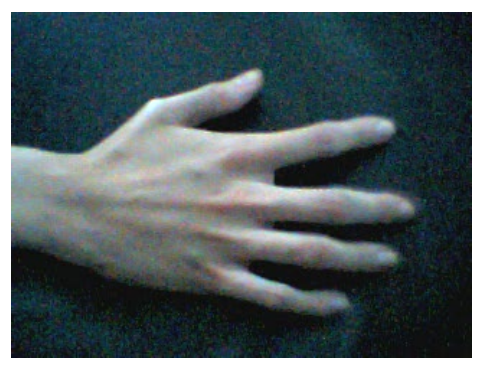

(a)

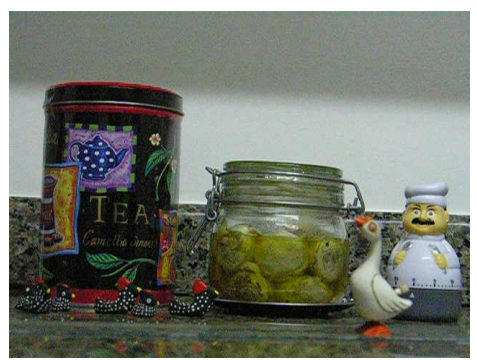

(d)

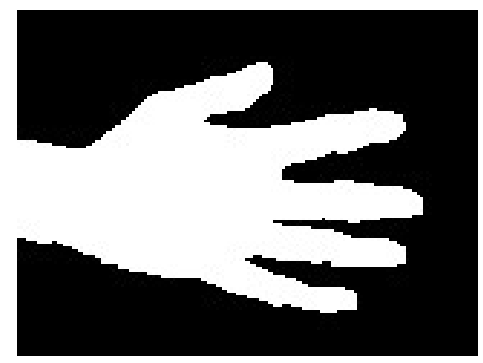

(b)

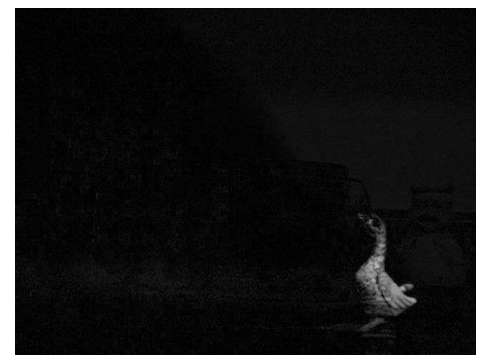

(e)

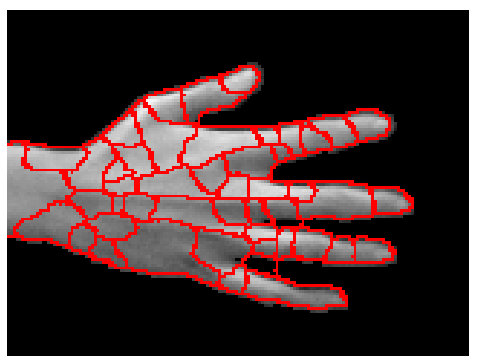

(c)

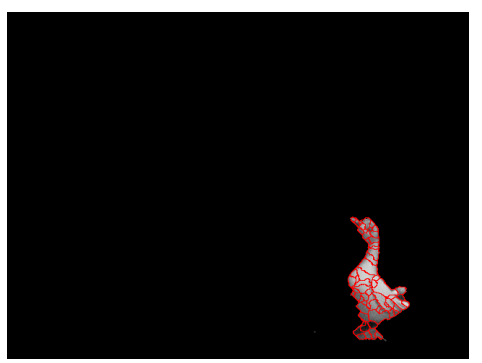

(f)

Figura 9. (a) e (d) - Quadros do vídeo; (b) e (e) - imagens resultantes, respectivamente, da limiarização global e da remoção do fundo; (c) e (f) - linhas de partição resultantes da aplicação do algoritmo de watershed e sobrepostas às imagens geradas a partir do resultado baseado em (b) e (e) respectivamente. 


\subsection{REPRESENTAÇÃO DAS IMAGENS}

Para criar um sistema de reconhecimento de objetos automático, é necessário escolher uma estrutura de dados adequada para representar o conteúdo das imagens digitais. Como visto no capítulo capítulo 2, grafos constituem uma representação apropriada para modelar problemas diversos, sendo bastante utilizados em reconhecimento estrutural de padrões e em processamento de imagens.

grafos Relacionais COM atributos (ARgs). Para o propósito da metodologia aqui discutida, a estrutura de dados utilizada para representar o conteúdo dos quadros da seqüência e da imagem de referência é um grafo relacional com atributos (ARG) (subseção 2.2.2). Em especial, dois tipos de ARGs são introduzidos: ARG intra-quadros e ARG inter-quadros, os quais são explicados nas próximas subseções.

\subsubsection{ARG Intra-quadros}

Um ARG intra-quadros, ou ARG-intra, é um grafo $\mathrm{G}=(\mathrm{V}, \mathrm{E}, \mu, v)$, caracterizado por um conjunto de vértices $V$, em que, $\forall v \in V$, existe um vetor de atributos de objeto $\mu: \mathrm{V} \rightarrow \mathfrak{R}^{p}$ associado, e por um conjunto de arestas $E \subseteq \mathrm{V} \times \mathrm{V}$, em que, $\forall \mathrm{e} \in \mathrm{E}$, associa-se um vetor de atributos relacionais $v: E \rightarrow \Re^{q}$. Os valores $p$ e $q$ indicam o número de atributos de vértices e arestas respectivamente.

Intuitivamente, o conjunto $\mathrm{V}$ representa regiões segmentadas da imagem e possivelmente relativas a objetos de interesse. Os vetores de atributos de objetos, por sua vez, descrevem características dessas regiões como, por exemplo, nível de cinza médio, cor, área, perímetro, centróide.

Já o conjunto E é composto por arestas cuja existência denota relação de adjacência entre as regiões da imagem representadas pelos vértices conectados por elas. Embora a relação de adjacência entre dois dados vértices $v$ e $w$ seja simétrica, os ARGs-intra aqui considerados são dirigidos, já que os atributos relacionais adotados podem quantificar medidas não simétricas entre os mesmos vértices (ex.: vetor entre os centróides de $v$ e $w$ ou $w$ e $v$ ) ou representar outras relações não-simétricas (ex.: estar "à esquerda" ou "à direita" de). 
Atributos. Considere um ARG-intra $G=(V, E, \mu, v)$ e um vértice qualquer $v \in \mathrm{V}$.

$\mathrm{O}$ vetor de atributos de objeto (ou de vértice) $\mu(v)$ é definido como:

$$
\mu(v)=(g(v), c(v), l(v), t(v)) .
$$

O termo $\mathrm{g}(v)$ corresponde ao nível de cinza médio da região da imagem associada ao vértice $v$, normalizado entre 0 e 1 de acordo com o máximo nível de cinza possível, enquanto $\mathrm{c}(v)$ indica as coordenadas do centróide (em pixels) dessa região, que caracterizam a informação posicional que relacionará regiões da entrada com as do modelo.

Quanto mais distantes estiverem as regiões, maior o custo da contribuição para a parcela dos vértices presente na função custo (vide subseção 3.6.3). A adoção desse critério de penalidade se baseia na suposição de que a posição de um mesmo objeto em quadros consecutivos do vídeo sob processamento não varia consideravelmente.

Já o atributo $l(v)$ indica um rótulo único atribuído ao vértice $v$ e utilizado como identificador do mesmo. No caso do ARG-intra modelo, esse rótulo é o mesmo da região da máscara modelo rotulada que originou v. Para ARGs-intra derivados dos quadros, esse atributo só é determinado no processo de classificação dos objetos.

$\mathrm{O}$ último atributo, $t(v)$, corresponde a um índice equivalente ao instante de tempo relativo ao quadro que originou o ARG-intra. Assim, se um ARG-intra corresponde ao i-ésimo quadro de uma seqüência de imagens, então $t(v)=i, \forall v \in V$.

Considere também um outro vértice $w \in V$ tal que $a=(v, w) \in E$ e $a^{\prime}=(w, v) \in E$. $\mathrm{O}$ vetor de atributos relacionais (ou de aresta) $v(v, w)$, é definido como:

$$
v(v, w)=(\vec{v}), \operatorname{com} \vec{v}=\frac{\overrightarrow{(c(w)-c(v))}}{d_{\max }}
$$

Portanto, o vetor de atributos relacionais é composto por um único elemento: um vetor geométrico $\vec{v}$ cujas origem e ponta final coincidem com os centróides das regiões representadas por $v$ e $w$ respectivamente. $\mathrm{O}$ vetor de atributos relacionais referente à aresta $a^{\prime}$ é definido de modo similar, respeitando-se o sentido inverso do vetor resultante entre os centróides.

Assim como na definição de atributos de objeto, os termos $c(v)$ e $c(w)$ indicam as 
coordenadas dos centróides das regiões representadas pelos vértices $v$ e $w$, enquanto o fator de normalização $d_{\max }$ equivale ao módulo do maior vetor calculado entre dois vértices adjacentes do ARG-intra.

Embora os atributos apresentados sejam simples, quaisquer outros atributos numéricos ou vetoriais são comportados pela técnica e poderiam ser escolhidos. Em particular, outras propriedades podem ser úteis em certas aplicações, como, por exemplo, medidas de simetria [29].

\subsubsection{Construção de ARGs-intra}

ARG-INTRA DE entrada. O ARG-intra de entrada é derivado de um quadro do vídeo da seguinte maneira: o particionamento de regiões de um objeto, resultante da aplicação do algoritmo de watershed na etapa de segmentação (seção 3.4) define uma imagem em que cada região possui um rótulo único associado, referente às bacias de captação encontradas pelo algoritmo.

O ARG é então criado a partir dessa imagem resultante do watershed e de sua respectiva imagem original. Para cada região rotulada, um vértice é gerado e seu respectivo vetor de atributos de objeto é calculado.

As arestas são geradas de acordo com a relação de vizinhança desejada para o ARG-intra. Para os fins da metodologia aqui descrita, a topologia de um ARG-intra é definida de acordo com o conceito de vizinhança $\left(\mathrm{N}_{4}\right.$ ou $\left.\mathrm{N}_{8}\right)$ de pixels, conforme explicado na subseção 2.1.4. Logo, uma aresta é adicionada ao grafo se, e somente se, as regiões representadas por dois vértices distintos são adjacentes.

ARG-INTRA mODElo. O ARG-intra modelo é obtido de forma semelhante à descrita para a extração de um ARG-intra de entrada. No entanto, os vértices desse grafo são criados com base nas regiões definidas pela máscara modelo rotulada, e seus atributos são calculados conforme o conteúdo da imagem de referência. Igualmente ao caso de um ARG-intra, arestas são geradas entre dois vértices distintos se existe uma relação de adjacência entre duas regiões, em termos de vizinhança de pixels. 

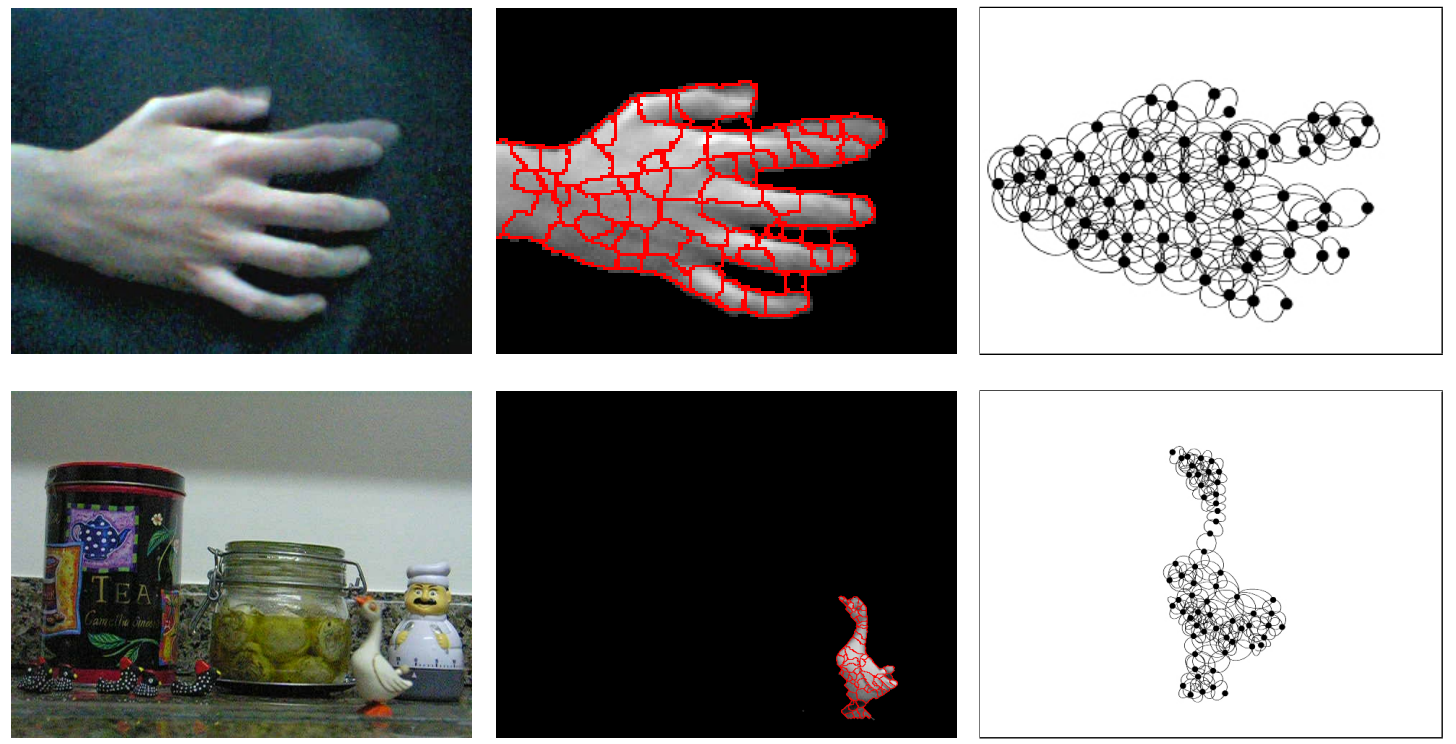

Figura 10. Exemplos de ARG-intra derivados de quadros de seqüências de entrada: quadro original (à esquerda), watershed do quadro original restrito à região de interesse (centro) e respectivo ARG-intra (à direita).
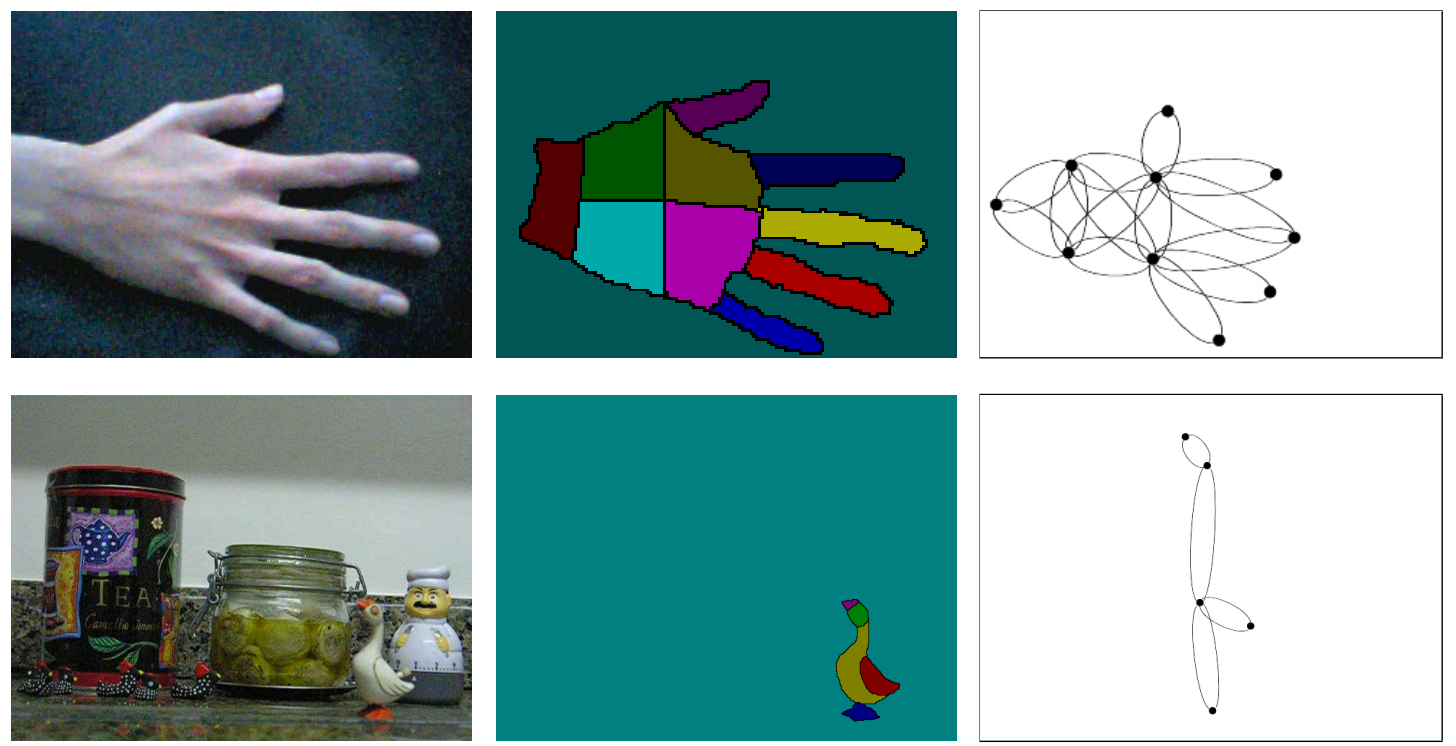

Figura 11. Exemplos de ARGs modelos (à direita) derivados de imagens de referência (à esquerda) e máscaras-modelos rotuladas (centro). 
IMPLEMENTAÇão. O pseudo-código a seguir se refere a um algoritmo para construção de um ARG-intra $G_{\text {intra }}=\left(V_{\text {intra }}, E_{i n t r a}, \mu_{\text {intra }}, v_{\text {intra }}\right)$ com base numa imagem rotulada $L B L$, representante de partições de uma imagem, e numa imagem de referência $I M G$, de tamanhos iguais $M \times N$. Dentro do contexto da metodologia, essas duas imagens equivalem aos seguintes casos:

A. imagem particionada pelo algoritmo de watershed, resultante do processo de segmentação, e seu respectivo quadro pertencente à seqüência de imagens sob análise. Nesse caso, é gerado um ARG-intra de entrada, representante de um certo quadro do vídeo.

в. máscara modelo rotulada e respectiva imagem de referência, dando origem a um ARG-intra denominado ARG-modelo, ou grafo-modelo.

O parâmetro idx equivale ao atributo de objeto $t$, índice que denota o instante de tempo relativo ao quadro sendo processado. Na criação do ARG-modelo, esse índice assume o valor 0 .

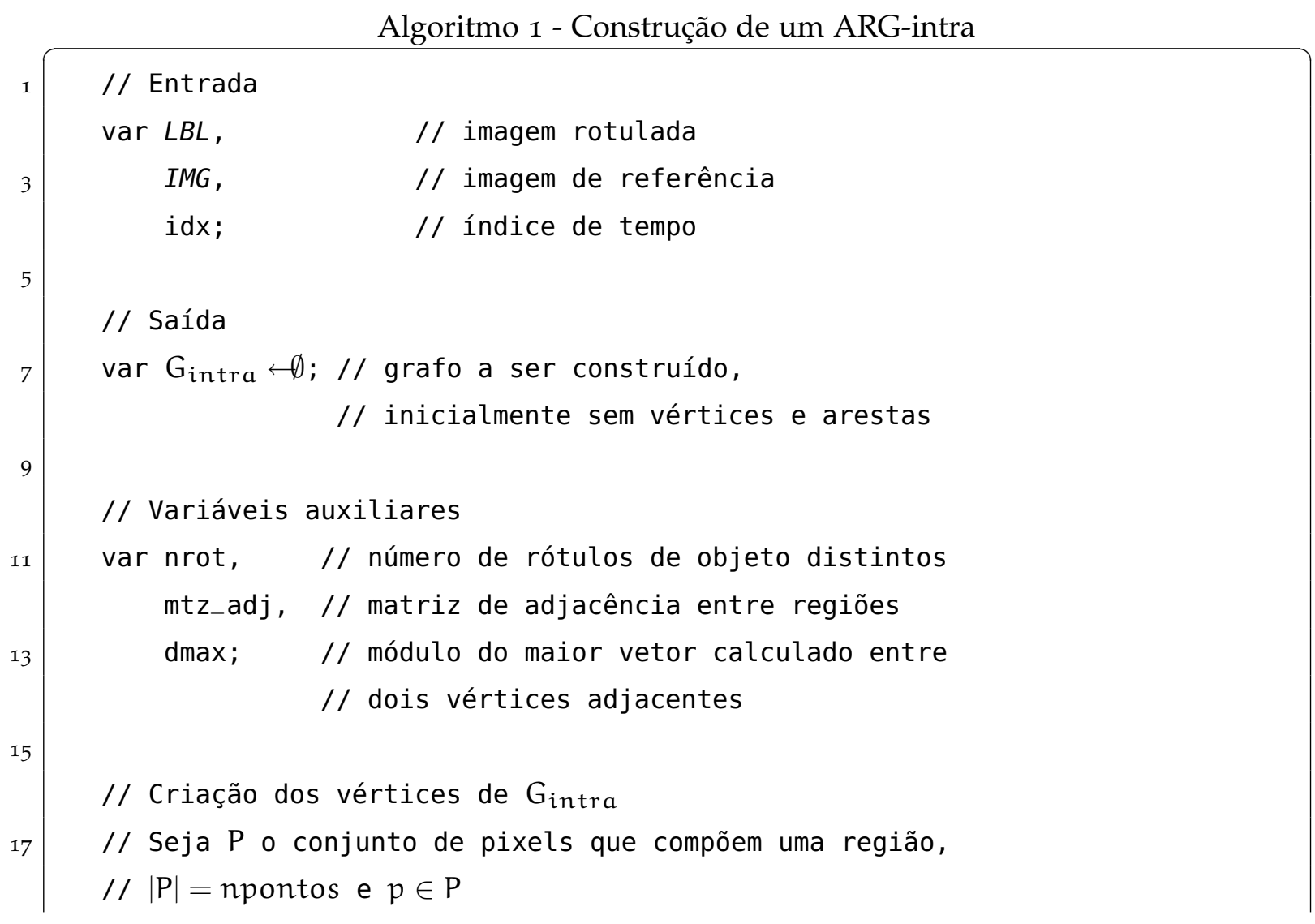




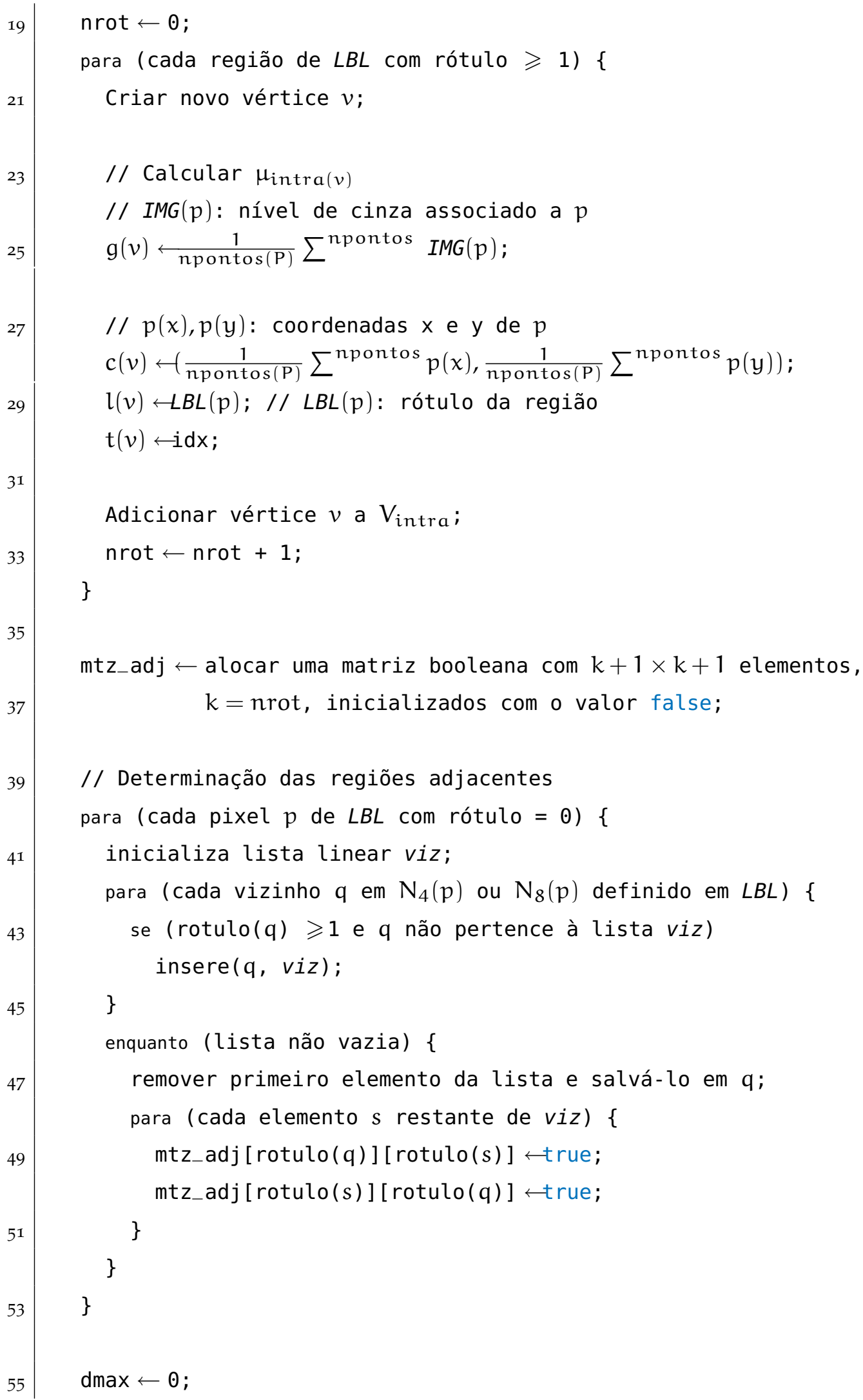


61

89

89

para $(i \leftarrow 1 ; i<$ nrot; $i++)\{$

$v \hookleftarrow$ vértice cujo rótulo correspondente é igual a i;

// Criação de laço de v para v

Criar nova aresta $l=(v, v)$;

// Calcular $v_{\text {intra }}(v, v)$

$\vec{v}(v, v) \leftarrow \overrightarrow{0}$;

Adicionar aresta a $E_{\text {intra }}$;

para $(j \leftarrow i+1 ; j<\operatorname{nrot} ; j++)\{$

// Criação de arestas ligando v e seus vizinhos adjacentes

se $\left(m t z_{-} \operatorname{adj}[i][j]=\right.$ true $)\{$

$w \leftarrow$ vértice cujo rótulo correspondente é igual a $j$;

Criar novas arestas $a=(v, w)$ e $a^{\prime}=(w, v)$;

// Calcular $v_{\text {intra }}(v, w)$ e $v_{\text {intra }}(w, v)$

$\vec{v}(v, w) \overleftrightarrow{((\mathrm{c}(w)-\mathrm{c}(v))} ;$

$\overrightarrow{v^{\prime}}(w, v) \longleftarrow \vec{v}(v, w)$;

se $(\|\overrightarrow{(c(w)-c(v))}\|>\operatorname{dmax})$

$\operatorname{dmax} \leftarrow\|\overrightarrow{(\mathrm{c}(w)-\mathrm{c}(v))}\| ;$

Adicionar arestas a $E_{i n t r a ;}$

\}

\}

\}

// Normalização dos vetores atribuídos às arestas para (cada aresta $e \in E_{\text {intra }}$ ) \{

$\vec{e} \leftarrow \vec{e} / d \max ;$

\}

devolver $G_{\text {intra }}$; 


\subsubsection{ARG Inter-quadros}

Enquanto ARGs intra-quadros são adequados para representar o conteúdo de uma única imagem digital, sua estrutura não comporta o aspecto temporal inerente a seqüências de imagens. Para incorporar a informação de correspondência entre regiões provenientes de quadros consecutivos de uma seqüência, foi criado o conceito de ARG inter-quadros, ou ARG-inter.

Considere um conjunto de ARGs-intra $G_{1}=\left(V_{1}, E_{1}, \mu_{1}, v_{1}\right), \ldots, G_{n}=\left(V_{n}, E_{n}\right.$, $\left.\mu_{n}, v_{n}\right)$ correspondentes a $n$ quadros consecutivos de uma seqüência de imagens $\mathrm{T}=\left(\mathrm{I}_{\mathrm{t}}, \mathrm{t}\right), \mathrm{t}=1, \ldots, \mathrm{N}$.

Um ARG-inter é um grafo $G=\left(V, E, \mu, v, v_{\text {inter }}\right)$, tal que $V=\bigcup_{i=0}^{n} V_{i}$ e $E=$ $\left(\bigcup_{i=0}^{n} E_{i}\right) \cup E_{\text {inter }}, E \subseteq V \times V$, sendo $E_{\text {inter }}$ um conjunto de arestas temporais tais que, se $e_{\text {inter }}=(v, w) \in E_{\text {inter }}$, então $v \in V_{i}, w \in V_{j}, i \neq j$, e $d_{e}(\operatorname{centroide}(v)$, centroide $(w)) \leqslant$ $\varepsilon$.

O elemento $\nu_{\text {inter }}: E_{\text {inter }} \rightarrow \mathfrak{R}^{r}$ é um vetor de atributos temporais associado a cada aresta $e \in \mathrm{E}_{\text {inter }}$, enquanto $\mu \mathrm{e} v$ assumem o mesmo significado que possuíam no caso dos ARGs-intra, associando, portanto, um vetor de objetos a cada vértice em $V$ e um vetor relacional a cada aresta $e \in E \backslash E_{\text {inter }}$.

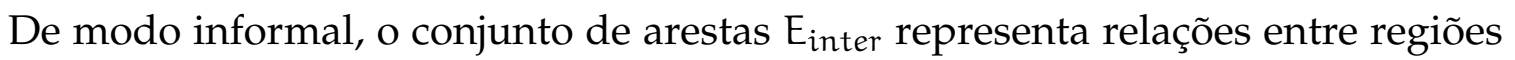
cujos centróides encontram-se a uma distância máxima pré-estipulada e que provêm de quadros distintos da seqüência. Essa formulação pretende associar regiões passíveis de serem as mesmas em diferentes instantes de tempo, porém localizadas em pontos distintos devido ao movimento.

Para ilustrar o conceito supracitado, a figura 12 exibe um ARG-inter resultante da união de ARGs-intra provenientes de 3 quadros consecutivos de uma seqüência, tomados nos tempos $t-1, t, t+1$. Para efeito de visualização, apenas um pequeno subconjunto de arestas temporais é exibido. No entanto, todos os vértices provenientes de quadros distintos podem estar conectados, desde que a condição para existência de arestas temporais não seja violada.

Atributos. Considere um ARG-inter $G_{\text {inter }}=\left(V, E, \mu, v, v_{\text {inter }}\right)$, um vértice qualquer $v \in V$ e uma aresta $a=(v, w)$, com $w \in V$ e $a \in E \backslash E_{\text {inter, }}$ e uma aresta $e \in \mathrm{E}_{\text {inter. }}$.

Tanto o vetor de atributos de objeto $\mu(v)$, quanto o vetor de atributos relacionais 


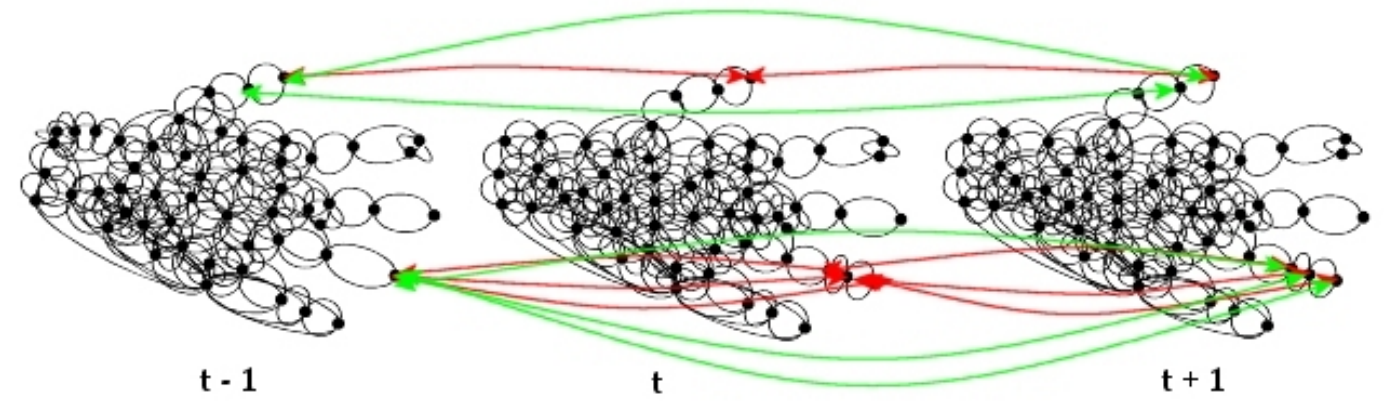

Figura 12. Exemplo de ARG inter-quadros. As arestas em vermelho conectam vértices adjacentes no tempo (distância 1), enquanto arestas verdes indicam vizinhos à distância 2.

$v(v, w)$ são definidos exatamente como descrito na subseção 3.5.1.

Considere agora dois vértices $v_{i}$ e $v_{j}$ pertencentes a $V$ e oriundos de dois ARGsintra $G_{i}$ e $G_{j}, i \neq j$. $O$ vetor de atributos temporais $v_{i n t e r}\left(v_{i}, v_{j}\right)$ é definido como:

$$
v_{\text {inter }}\left(v_{i}, v_{j}\right)=(\vec{v}, \mathrm{dt}), \text { com } \mathrm{dt}=\left|\mathrm{t}\left(v_{\mathrm{i}}\right)-\mathrm{t}\left(v_{\mathrm{j}}\right)\right| \text {. }
$$

O atributo $\vec{v}$ é definido da mesma forma que o vetor geométrico que compõe os atributos relacionais. Já o atributo dt incorporado a $v_{i n t e r}\left(v_{i}, v_{j}\right)$ representa a distância absoluta entre dois vértices do ARG-inter, em termos de quadros. Por exemplo, se $v_{i}$ e $v_{j}$ provêm de quadros consecutivos de um vídeo, então $\mid t\left(v_{i}\right)-$ $\mathrm{t}\left(v_{\mathrm{j}}\right) \mid=1$. Se provêm de ARGs-intra derivados de quadros mais distantes entre si, então $\left|t\left(v_{i}\right)-t\left(v_{j}\right)\right|>1$.

Tais distâncias são utilizadas posteriormente para determinar a influência de uma dada aresta na parcela da função-custo dispensada às arestas, assunto discutido mais à frente.

\subsubsection{Construção de um ARG-inter}

IMPLEMENTAÇÃo. Abaixo, é apresentado um pseudo-código representante de um algoritmo para composição de um ARG-inter $G_{i n t e r}=\left(V, E, \mu, v, v_{\text {inter }}\right)$ a partir de um conjunto de ARGs-intra $G_{1}=\left(V_{1}, E_{1}, \mu_{1}, v_{1}\right), \ldots, G_{n}=\left(V_{n}, E_{n}, \mu_{n}, v_{n}\right)$ 
derivados de $n$ quadros consecutivos de uma seqüência de imagens $T=\left(I_{t}, t\right)$, $t=1, \ldots, N$.

Algoritmo 2 - Construção de um ARG-inter

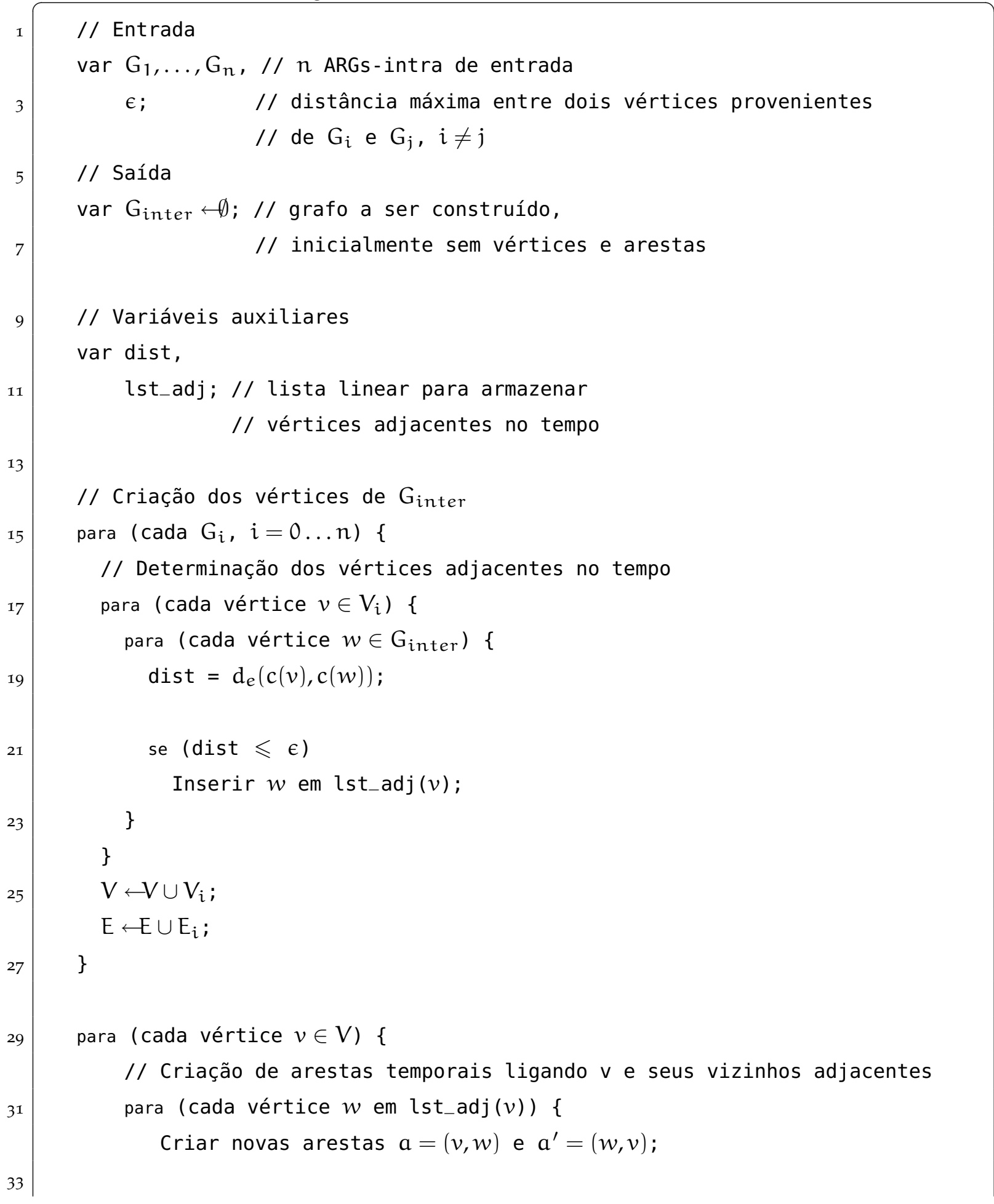




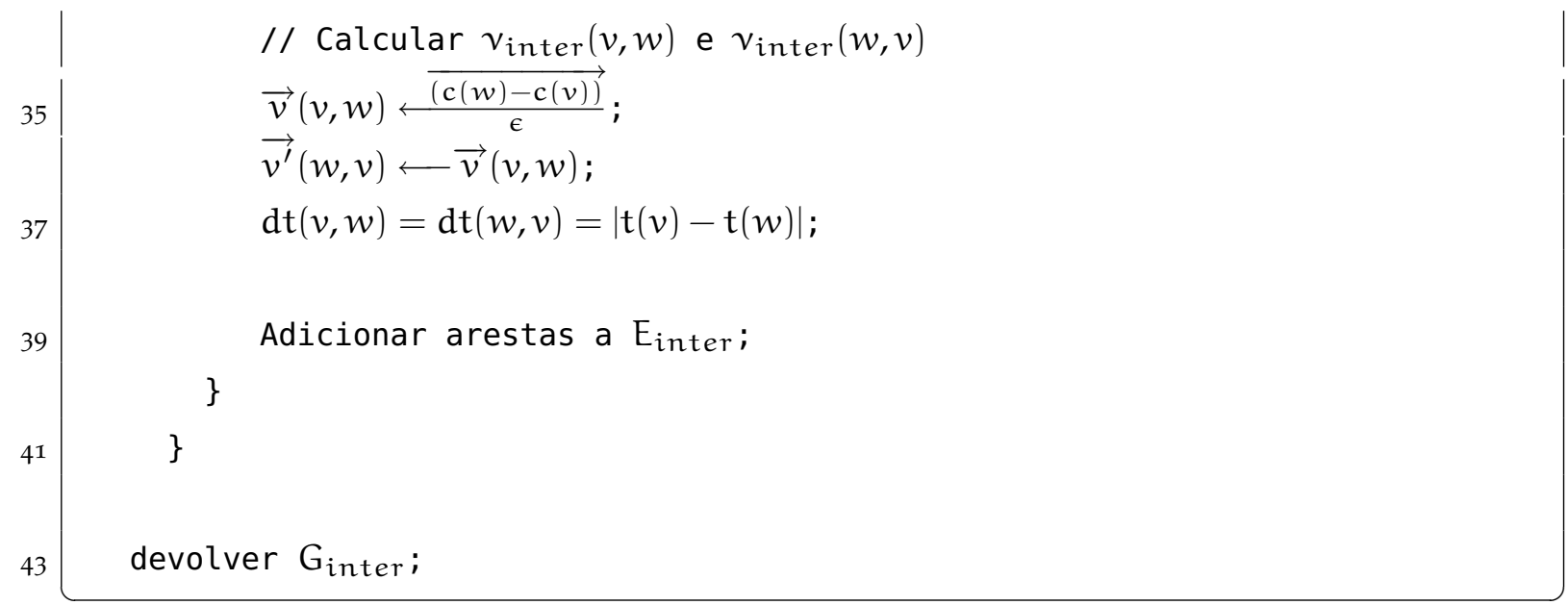

\subsection{RECONHECIMENTO DOS OBJETOS}

A representação de objetos através de grafos induz o processo de reconhecimento ao problema de casamento entre grafos. Como regiões segmentadas de quadros do vídeo correspondem ora a objetos ou partes indicados pela máscara modelo, ora a sub-regiões de tais objetos ou partes, a classificação dessas regiões de acordo com o modelo equivale ao mapeamento dos rótulos do conjunto de vértices de um ARG-inter nos rótulos do conjunto de vértices do ARG-modelo (fig. 13 (a)), constituindo o reconhecimento simultâneo de objetos num subconjunto de quadros.

Em geral, as partições obtidas para cada quadro de uma seqüência de imagens não são idênticas, fato que afeta diretamente a estrutura dos ARGs-intra de entrada gerados e que, uma vez incorporados à estrutura do ARG-inter, serão comparados ao ARG-modelo.

Devido à sensibilidade do algoritmo de watershed que dá origem às partições, ocorre uma supersegmentação dos objetos, ou seja, os mesmos são subdivididos em regiões normalmente muito menores do que aquelas que delimitam as partes do modelo, gerando ARGs-intra com um número maior de vértices do que no ARG-modelo. Além disso, os atributos do ARG-modelo, calculados com base na imagem de referência, podem ser consideravelmente diferentes daqueles calculados para cada quadro do vídeo.

Todos esses aspectos, juntamente com a observação de que um ARG-inter é uma composição de grafos derivados de diferentes quadros, implicam no mapeamento de diferentes vértices do ARG-inter num mesmo vértice do ARG-modelo, o que 
caracteriza uma relação de homomorfismo entre grafos.

Contudo, para acomodar as diferenças entre entrada e modelo, o mapeamento buscado deve ser definido dentro do paradigma de casamento inexato entre grafos (subseção 2.2.4), cuja solução é encontrada na literatura sob a forma de diferentes algoritmos. Particularmente, nesta metodologia, a implementação adotada refere-se a um algoritmo de busca heurística em árvores, a qual resulta numa aproximação de um homomorfismo entre um ARG-inter e o ARG-modelo.

Nas próximas subseções, esses conceitos serão explicados detalhadamente.

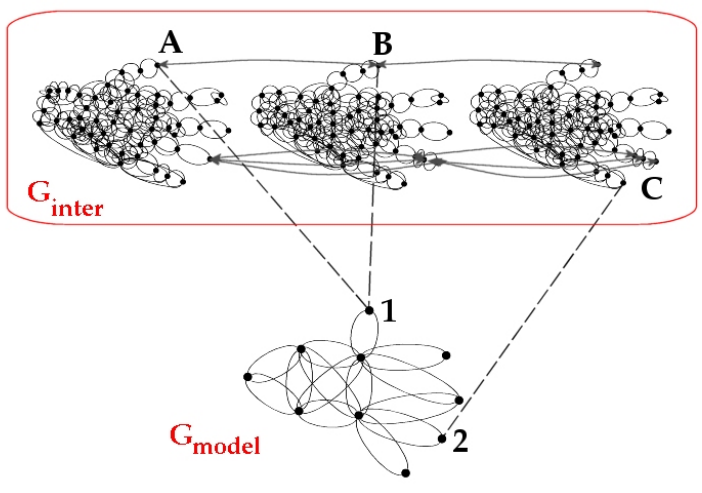

(a)

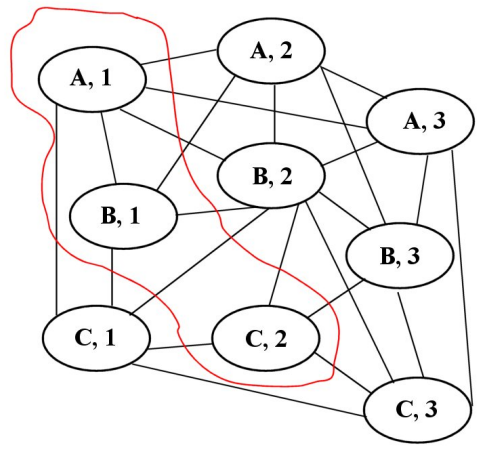

(b)

Figura 13. Representação gráfica do problema de casamento entre grafos: (a) - vértices do ARG-inter associados a vértices do ARG-modelo (linhas tracejadas) e (b) - subconjunto dos vértices do grafo de associação (parcialmente ilustrado), representando o casamento dos vértices ilustrados em (a).

\subsubsection{Homomorfismo entre Grafos}

Considere um ARG-inter $G_{\text {inter }}=\left(V, E, \mu, v, v_{\text {inter }}\right)$ e o ARG-modelo $G_{\text {model }}=$ $\left(V_{\text {model }}, \mathrm{E}_{\text {model }}, \mu_{\text {model }}, v_{\text {model }}\right)$.

Um grafo de associação $\tilde{G}_{A}$ entre $G_{\text {inter }}$ e $G_{\text {model }}$ é definido como o grafo completo $\tilde{G}_{A}=\left(V_{A}, E_{A}\right)$, onde $V_{A}=V \times V_{\text {model }}$ e $E_{A}=E \times E_{\text {model }}$.

Intuitivamente, os vértices de um grafo de associação representam pares de vértices em que um deles provém do ARG-inter e outro, do ARG-modelo. Logo, esses pares simulam a hipotética associação entre uma região extraída de um quadro do vídeo e 
uma região do modelo, como ilustrado na figura 13 (b).

Tanto os vértices quanto as arestas de $\tilde{G}_{A}$ estão associados a custos que exprimem, respectivamente, medidas de (dis)similaridade entre o par de vértices que compõe um elemento de $V_{A}$ e a compatibilidade entre as associações de regiões representadas por dois pares de vértices de $V_{A}$ conectados.

Um homomorfismo $h$ entre $G_{\text {inter }}$ e $G_{\text {model }}$ é um mapeamento $h: V \rightarrow V_{\text {model }}$ tal que $\forall a_{1} \in V, \forall b_{1} \in V, e=\left(a_{1}, b_{1}\right) \in E \Rightarrow e^{\prime}=\left(h\left(a_{1}\right), h\left(b_{1}\right)\right) \in E_{\text {model. Essa }}$ definição presume que todos os vértices de $G_{\text {inter }}$ são mapeados em algum vértice de $\mathrm{G}_{\text {model }}$. Convém também notar que um tal homomorfismo representa um clique de $\tilde{G}_{A}$.

De acordo com a proposta de [8], uma solução para encontrar um homomorfismo entre $G_{i n t e r}$ e $G_{\text {model }}$ pode ser definida como um subgrafo completo $\tilde{G}_{S}=\left(V_{S}, E_{S}\right)$ do grafo de associação $\tilde{G}_{A}$, no qual $V_{S}=\left\{\left(a_{1}, a_{2}\right), a_{1} \in V, a_{2} \in V_{\text {model }}\right\}$ tal que $\forall a_{1} \in$ $V, \exists a_{2} \in V_{\text {model }},\left(a_{1}, a_{2}\right) \in V_{S}$, e $\forall\left(a_{1}, a_{2}\right) \in V_{S}, \forall\left(a_{1}{ }^{\prime}, a_{2}{ }^{\prime}\right) \in V_{S}, a_{1}=a_{1}{ }^{\prime} \Rightarrow a_{2}=a_{2}{ }^{\prime}$. Tal formulação garante que cada vértice do ARG-inter corresponde a exatamente um vértice do ARG-modelo, e $\left|V_{S}\right|=|V|$. Essa solução considera apenas as características estruturais de $G_{\text {inter }}$ e $G_{\text {model}}$, originando diversos homomorfismos possíveis entre ambos os grafos.

Encontrar um homomorfismo entre o ARG-inter e o ARG-modelo é a chave para o processo de reconhecimento de objetos. Sendo $|\mathrm{V}|$ usualmente maior do que $\left|V_{\text {model }}\right|$, um homomomorfismo adequado entre ambos os grafos deve mapear vértices distintos de $G_{\text {inter }}$ num único vértice de $G_{\text {model, }}$ o que corresponde ora à fusão de sub-regiões similares de um objeto supersegmentado a partir de um quadro da entrada, ora à classificação de uma mesma região em diferentes instantes de tempo.

Assim, a tarefa de escolha de um homomorfismo apropriado é realizada através de uma técnica de casamento inexato entre grafos, implementada por um algoritmo baseado em busca em árvores descrito a seguir.

\subsubsection{Casamento Inexato entre Grafos: Busca Heurística}

Casamento inexato entre grafos aplicado a problemas de reconhecimento de padrões foi abordado de várias formas, como visto no capítulo 2.

Nesta metodologia, em especial, o casamento entre grafos é realizado através do 
algoritmo de otimização baseado em busca em árvore proposto em [8] e cuja escolha foi apoiada no estudo comparativo introduzido pelo mesmo artigo. Em relação a algoritmos genéticos e de estimativa de distribuição, esse método apresentou a melhor relação custo-benefício em termos de classificações corretas e tempo de processamento.

A idéia do algoritmo consiste na utilização da estrutura de dados conhecida como árvore n-ária com raiz [11] para simular o grafo de associação entre dois grafos quaisquer e, simultaneamente, determinar uma aproximação de um homomorfismo entre tais grafos.

Nesse contexto, cada nó que compõe a árvore é formado por um par correspondente a vértices de dois grafos distintos, enquanto um caminho da raiz da árvore até um nó terminal representa um determinado mapeamento entre os vértices desses grafos. Naturalmente, a criação de uma árvore cheia representante do grafo de associação inteiro permitiria determinar todos os mapeamentos possíveis, para posterior escolha de um homomorfismo.

Entretanto, a manutenção de uma tal árvore em memória seria bastante dispendiosa e a análise de todos os caminhos possíveis para, finalmente, escolher uma combinação de vértices satisfatória, seria um problema combinatório de complexidade exponencial.

Portanto, ao invés de gerar uma árvore completa, o algoritmo constrói a árvore de modo gradual, incluindo nós apenas em caminhos que apresentem maiores chances de representar uma solução desejável. Em termos práticos, a escolha do caminho que deve ser expandido é feita, a cada iteração, através da análise dos custos associados aos mapeamentos representados pelos caminhos existentes até aquele instante.

Para medir o custo de um caminho, é preciso definir uma heurística, ou função custo (subseção 3.6.3), que permita avaliar o quão apropriado é o mapeamento representado por ele, em termos de dissimilaridades dos vértices e arestas dos grafos que estão sendo casados. Assim, o caminho que minimizar tal função custo é selecionado e expandido na iteração seguinte.

O término do algoritmo é alcançado quando um determinado caminho representar o mapeamento de todos os vértices de um dos grafos nos do outro.

Para compreender a aplicação do algoritmo sobre os grafos de interesse para a metodologia, $G_{\text {inter }}$ e $G_{\text {model }}$, ambos definidos como na subseção anterior, considere uma seqüência de vértices $v_{i} \in V$ indexados de $i=1, \ldots,|V|$, tal que segmentos da 
seqüência representam intercalações de vértices de $G_{\text {inter }}$ provenientes de diferentes ARGs-intra.

Por exemplo, sejam $V=V_{1} \cup V_{2} \ldots \cup V_{n}$ e $v_{i, j} \in V_{i}, i=1, \ldots, n$ e $j=1, \ldots,\left|V_{i}\right|$. Uma seqüência válida teria a forma $v_{1,1}, v_{2,1}, \ldots, v_{n, 1}, v_{1,2}, \ldots, v_{n, 2}, \ldots$ Vértices oriundos de um mesmo ARG-intra poderiam estar localizados em posições consecutivas quando nenhum outro vértice de ARG-intra distinto estivesse disponível.

O algoritmo baseado em busca em árvore cria uma árvore em que cada nó é análogo a um vértice do grafo de associação entre $G_{\text {inter }}$ e $G_{\text {model }}$, ou seja, cada nó representa um par de vértices $(k, l), k \in V$ sorteado de acordo com a seqüência de vértices supracitada, e $l \in V_{\text {model }}$. Um caminho da raiz até um nó-folha da árvore determina uma solução parcial ou total para o problema de casamento entre $G_{\text {inter }}$ e $\mathrm{G}_{\text {model }}$.

Para considerar a expansão de diferentes caminhos (soluções em paralelo) ao longo da execução do algoritmo, os nós-folhas são armazenados numa fila de prioridades implementada como um min-heap, o que permitirá a expansão do caminho de menor custo a cada etapa do algoritmo. $\mathrm{O}$ tamanho da fila de prioridades é limitado a priori, para que sejam considerados apenas os caminhos mais baratos existentes num determinado momento da execução. Quando o limite da fila for atingido, os nós mais caros serão descartados.

Essa abordagem reduz o tempo de convergência do algoritmo para uma solução, bem como o espaço em memória usado para armazenar a árvore, em detrimento da análise de um grande conjunto de caminhos, o que pode levar à perda de uma solução melhor. Porém, na prática, essa limitação não afeta consideravelmente a qualidade da solução encontrada e reduz consideravelmente o tempo de processamento. Para tentar melhorar a solução determinada em termos da função custo, podem ser aplicados procedimentos de backtracking como os descritos em [8].

Simulando a execução do algoritmo, inicialmente o nó-raiz da árvore é rotulado $(0,0)$, representando uma solução vazia, e expandido em $\left|V_{\text {model }}\right|$ nós-filhos rotulados $(1, l), l=1 \ldots\left|V_{\text {model }}\right|$. Nessa etapa do algoritmo, cada caminho equivale a um único nó-folha da árvore e seu custo associado é determinado através da função custo (subseção 3.6.3), considerando apenas a dissimilaridade entre os vértices de $G_{\text {inter }} \mathrm{e}$ $\mathrm{G}_{\text {model }}$ que caracterizam o respectivo nó. A seguir, os nós são inseridos na fila de prioridades de acordo com o valor da função custo calculada para cada um deles.

Na próxima etapa do algoritmo, o nó-folha armazenado no início da fila de priori- 
dades é removido, dando seqüência à expansão da árvore. Novamente, o caminho terminado por esse nó é expandido em $\left|V_{\text {model }}\right|$ nós-filhos rotulados (prox(1), l), em que $l=1 \ldots\left|V_{\text {model }}\right|$ e $\operatorname{prox}(1)$ é o vértice $v \in V$ sucessor de 1 na seqüência de vértices de $G_{\text {inter }}$ explicada anteriormente. Os custos de cada um desses novos nós são calculados, agora considerando tanto dissimilaridades entre objetos quanto estruturais, e inseridos na fila de prioridades. Esse processo é repetido até que um nó-folha $\left(|\mathrm{V}|, l_{\min }\right)$ seja atingido, o que equivale à determinação de um mapeamento de todos os vértices de $G_{\text {inter }}$ nos vértices de $G_{\text {model }}$.

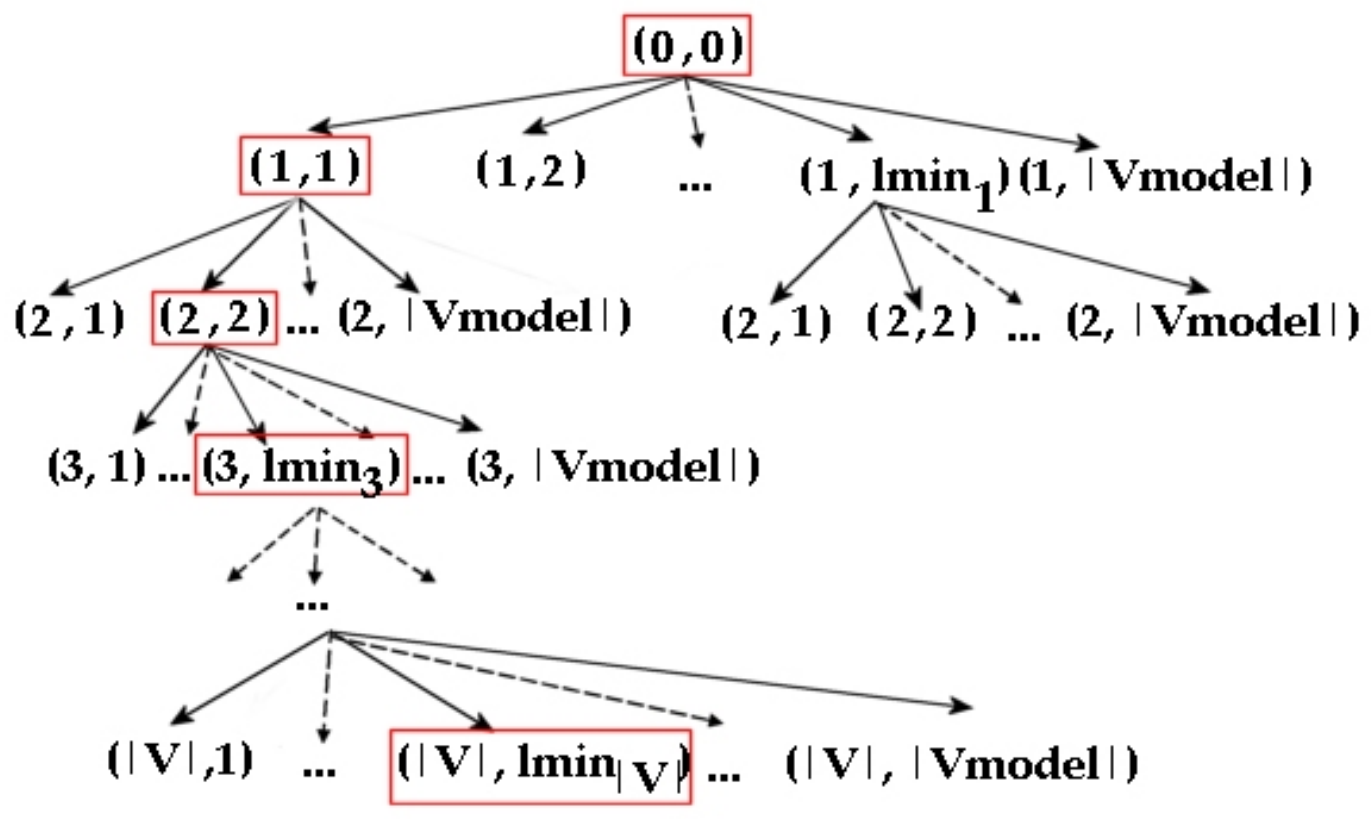

Figura 14. Exemplo de configuração possível numa execução do algoritmo de busca em árvore.

O algoritmo 3 apresenta um pseudo-código simplificado do funcionamento do algoritmo de busca em árvore. Como entrada, são dados os grafos $\mathrm{G}_{\text {inter }} \mathrm{e} \mathrm{G}_{\text {model }}$ e, a partir desses dados, uma árvore n-ária com raiz é criada incrementalmente, para representar as associações de vértices e de arestas entre tais grafos. Uma fila de prioridades pq é utilizada para gerenciar a expansão dos caminhos a cada passo. Ao final bem sucedido do algoritmo, o nó-folha de um caminho que represente a solução completa de menor custo avaliada é devolvido, pressupondo-se que a 
implementação da árvore permita percorrê-la de um nó-folha até a raiz.

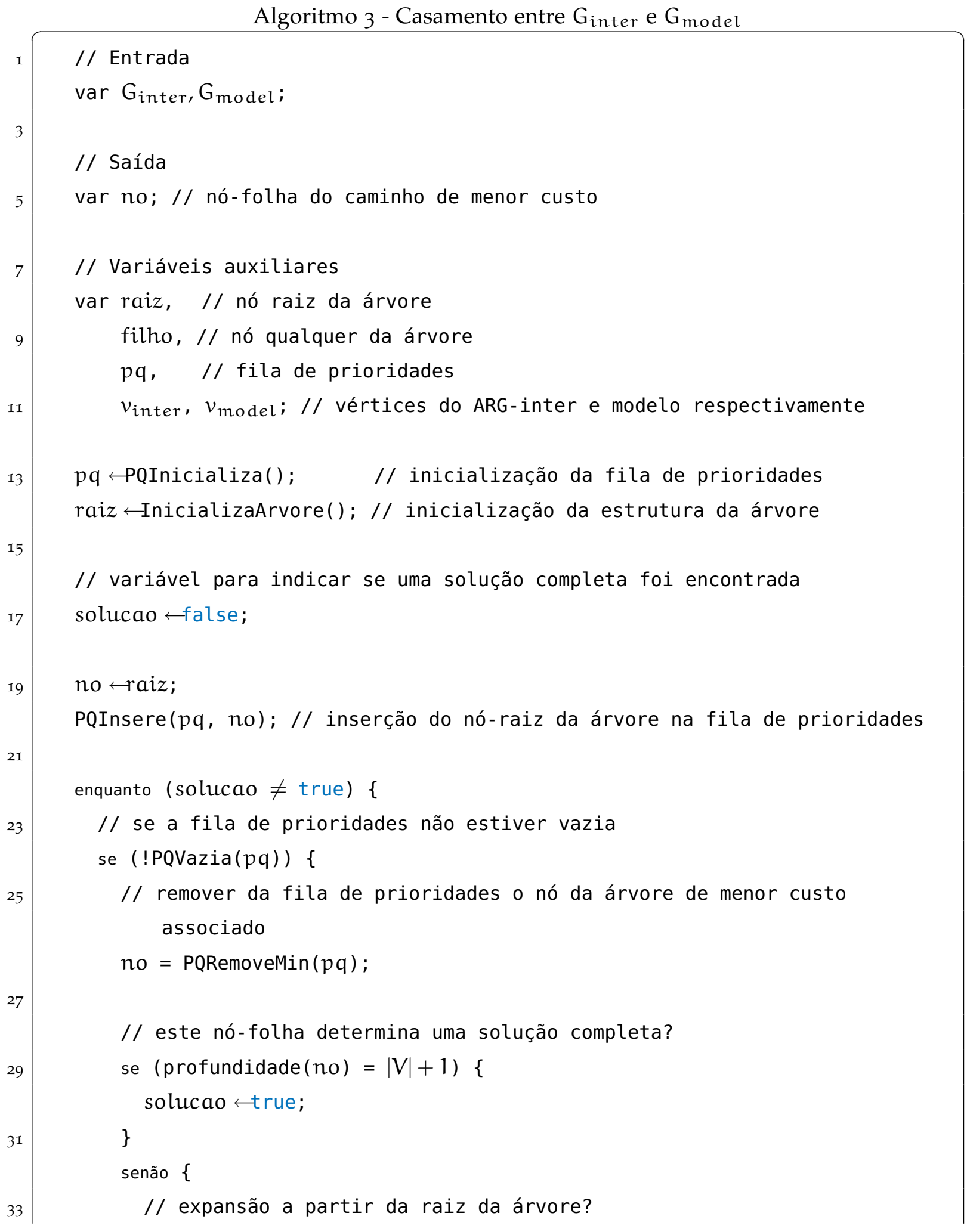

Algoritmo 3 - Casamento entre $G_{\text {inter }}$ e $G_{\text {model }}$ 
se $($ no $=$ raiz $)\{$

// acesso ao primeiro vértice de $G_{i n t e r}$

$v_{\text {inter }} \leftarrow$ BuscaVértice $\left(G_{\text {inter }}, 1\right)$;

\}

senão \{

// acesso ao vértice seguinte de $G_{i n t e r,}$

// na seqüência de vértices intercalados

$v_{\text {inter }} \leftrightarrow$ BuscaVértice $\left(G_{\text {inter }}, \operatorname{prox}\left(v_{\text {inter }}\right)\right)$;

\}

// expansão de um caminho em $\left|V_{\text {model }}\right|$ filhos

para (cada $\left.v_{\text {model }} \in V_{\text {model }}\right)\{$

// criação de novo nó contendo informações sobre o

// par de vértices de $G_{i n t e r}$ e de $G_{\text {model }}$

filho $\leftarrow$ info $\left(v_{\text {inter }}, v_{\text {model }}\right)$;

// inserção do novo nó na árvore, como filho de no InsereNoArvore (no, filho);

// cálculo do custo associado ao nó e ao caminho a

// que pertence, assumindo-se que o valor encontrado

// é armazenado na própria estrutura do nó.

FunçãoCusto (filho) ;

// inserção do novo nó na fila de prioridades de

// acordo com o valor do custo calculado

$P Q$ Insere ( $p q$, filho);

\}

\}

\}

senão \{

solucao $\leftarrow$ true;

no $\leftrightarrow$ NULL;

\}

\} 


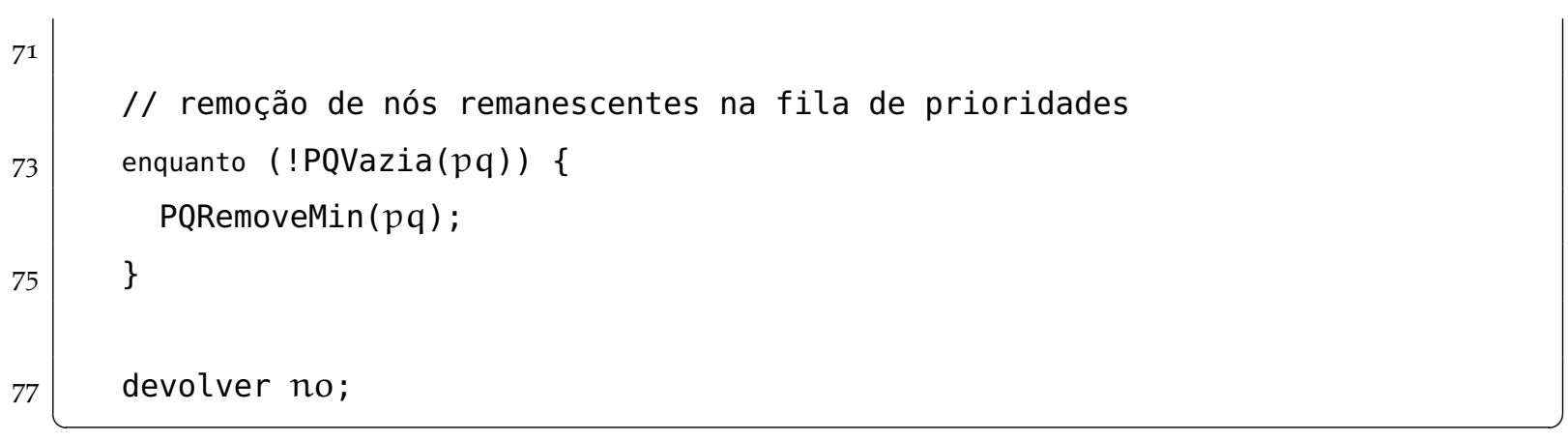

\subsubsection{Função Custo}

Como mencionado na subseção 3.6.2, a escolha do caminho a ser expandido no algoritmo de busca em árvore é determinada pela minimização de uma função custo pré-definida, a qual deve considerar não apenas a estrutura dos grafos sob comparação, mas também os vetores de atributos de objetos e relacionais.

A escolha de tal função é de fundamental importância para o problema de reconhecimento de objetos, pois, sendo responsável pela atribuição de custo aos mapeamentos entre grafos, afeta diretamente a solução encontrada pelo algoritmo de busca em árvore, a qual constitui a classificação dos objetos da entrada segundo o modelo.

Considere, novamente, os grafos $G_{\text {inter }}$ e $G_{\text {model }}$, bem como vértices $a_{1}, b_{1} \in V$, $a_{2}, b_{2} \in V_{\text {model }}$ e arestas $e_{1}$, referente a $E$, e $e_{2}$, referente a $E_{\text {model }}$. Considere também um subgrafo $\tilde{G}_{S}$ do grafo de associação $\tilde{G}_{A}$, como descrito na subseção 3.6.1. Nesta metodologia, a escolha de um mapeamento é baseada na minimização da seguinte função custo:

$$
f\left(\tilde{G}_{S}\right)=\frac{\alpha}{\left|V_{S}\right|} \sum_{\left(a_{1}, a_{2}\right) \in V_{S}} c_{V}\left(a_{1}, a_{2}\right)+\frac{(1-\alpha)}{\left|E_{S}\right|} \sum_{e \in E_{S}} c_{E}(e) .
$$

A função $f$ exprime, portanto, uma média ponderada de medidas que avaliam a associação entre vértices (primeiro somatório) e a compatibilidade entre arestas (segundo somatório) induzidas por tais associações. Assim, tanto os atributos que caracterizam os objetos, quanto as relações estruturais que estes compartilham são consideradas no cálculo da função custo.

A importância dispensada às associações entre vértices e arestas é regularizada 
através do parâmetro $\alpha$, cuja escolha é feita empiricamente de acordo com a avaliação do problema a ser tratado. Por exemplo, se as características estruturais apresentadas por $G_{\text {inter }}$ e $G_{\text {model }}$ forem pouco discriminantes, é preferível valorizar as medidas relativas aos vértices, o que é equivalente a aplicar um valor $\alpha$ maior do que seu complemento ao primeiro fator de $f$.

Os elementos $c_{V}$ e $c_{E}$ consistem em medidas de dissimilaridade, respectivamente, entre vértices e arestas. Quanto mais semelhante for um par de vértices ou um par de arestas, menor será seu grau de dissimilaridade e, conseqüentemente, menor sua contribuição no respectivo somatório que compõe f. Dessa forma, elementos semelhantes contribuem para minimizar $f$ e representam potenciais casamentos desejados. As definições de tais medidas são apresentadas a seguir.

$$
c_{V}\left(a_{1}, a_{2}\right)=\gamma_{V}\left|g\left(a_{1}\right)-g\left(a_{2}\right)\right|+\left(1-\gamma_{V}\right) d_{e}\left(c\left(a_{1}\right), c\left(a_{2}\right)\right)
$$

Na equação 3.5, o fator $d_{e}\left(c\left(a_{1}\right), c\left(a_{2}\right)\right)$ é simplesmente a distância euclidiana entre os centróides das regiões representadas pelos vértices $a_{1}$ e $a_{2}$. Logo, o custo calculado para associações entre vértices leva em consideração as diferenças absolutas entre os níveis de cinza de uma região da entrada e outra do modelo, bem como as distâncias entre seus respectivos centróides.

$$
c_{\mathrm{E}}(e)= \begin{cases}w(\vec{v}), & \text { se } \exists e_{2} \in E_{\text {model }} \\ 0, & \text { se } \nexists e_{1} \in \text { E e } \nexists e_{2} \in E_{\text {model }} \\ & \text { ou } \exists e_{2}=\left(a_{2}, a_{2}\right) \in E_{\text {model }} \\ \infty, & \text { c.c. }\end{cases}
$$

em que,

$$
w(\vec{v})= \begin{cases}\gamma_{E}\left|\left\|\vec{v}_{1}\right\|-\left\|\vec{v}_{2}\right\|\right|+\left(1-\gamma_{E}\right) \frac{|\cos \theta-1|}{2}, & \text { se } e_{1} \notin \mathrm{E}_{\text {inter }} \\ \frac{1}{\operatorname{dt}\left(e_{1}\right)+1}\left(\gamma_{E}\left|\left\|\vec{v}_{1}\right\|-\left\|\vec{v}_{2}\right\|\right|+\left(1-\gamma_{E}\right) \frac{|\cos \theta-1|}{2}\right), & \text { c.c. }\end{cases}
$$

A equação 3.6 introduz o custo de uma aresta $e=(v, w) \in E_{S}, v=\left(a_{1}, a_{2}\right) \in V_{S}$ 
e $w=\left(b_{1}, b_{2}\right) \in V_{S}$, cujo valor $c_{E}(e)$ expressa uma medida de comparação entre as arestas $e_{1}=\left(a_{1}, b_{1}\right) \in$ E e $e_{2}=\left(a_{2}, b_{2}\right) \in E_{\text {model }}$.

Já na equação $3 \cdot 7, \cos \theta=\frac{\vec{v}_{1} \vec{v}_{2}}{\left\|\vec{v}_{1}\right\|\left\|\vec{v}_{2}\right\|^{\prime}}$, sendo o custo calculado para associações entre arestas uma comparação entre os vetores atribuídos a elas. Entretanto, se a aresta sob análise pertence ao conjunto de arestas temporais, seu atributo dt é utilizado para marcar a influência que a mesma deverá exercer no custo relativo à estrutura.

De maneira intuitiva, os casos que constituem a equação 3.6 exprimem, respectivamente, as seguintes situações:

- Se a aresta sob análise existir em $\mathrm{G}_{\text {model }}$, então a dissimilaridade entre arestas é avaliada conforme uma função que considera diferenças de módulo e ângulo entre seus vetores geométricos correspondentes. Caso a aresta correspondente em $G_{i n t e r}$ não exista explicitamente na estrutura do grafo, ela é calculada instantaneamente pelo algoritmo.

- A dissimilaridade entre dois pares de vértices casados é mínima quando as respectivas arestas derivadas são inexistentes tanto em $G_{\text {inter, }}$ quanto em $\mathrm{G}_{\text {model }}$. Esse mínimo também é alcançado quando a aresta induzida em $\mathrm{G}_{\text {model }}$ é, na verdade, um laço, o que equivale a se incentivar mapeamentos que mantenham a homogeneidade de rótulos compartilhados por determinados grupos de vértices.

- A medida de dissimilaridade das arestas é projetada para penalizar casamentos que consideram válidas regiões não-adjacentes no ARG modelo. Portanto, se houver adjacência entre dois vértices de $G_{\text {inter }}$ e tal relação for inválida em $G_{\text {model }}$ o mapeamento em questão assume um valor de dissimilaridade máxima.

Finalmente, nas equações 3.5 e 3.7, os valores $\gamma_{V}$ e $\gamma_{E}$ são pesos atribuídos às parcelas envolvidas, os quais são determinados empiricamente conforme as características apresentadas pelo vídeo digital a ser processado, de forma semelhante às observações feitas para o peso $\alpha$.

\subsection{PROCESSO DE RASTREAMENTO}

Devido às suposições quanto ao movimento que rege os objetos contidos num vídeo submetido à metodologia (subseção 3.2.1), a organização estrutural da cena e as 


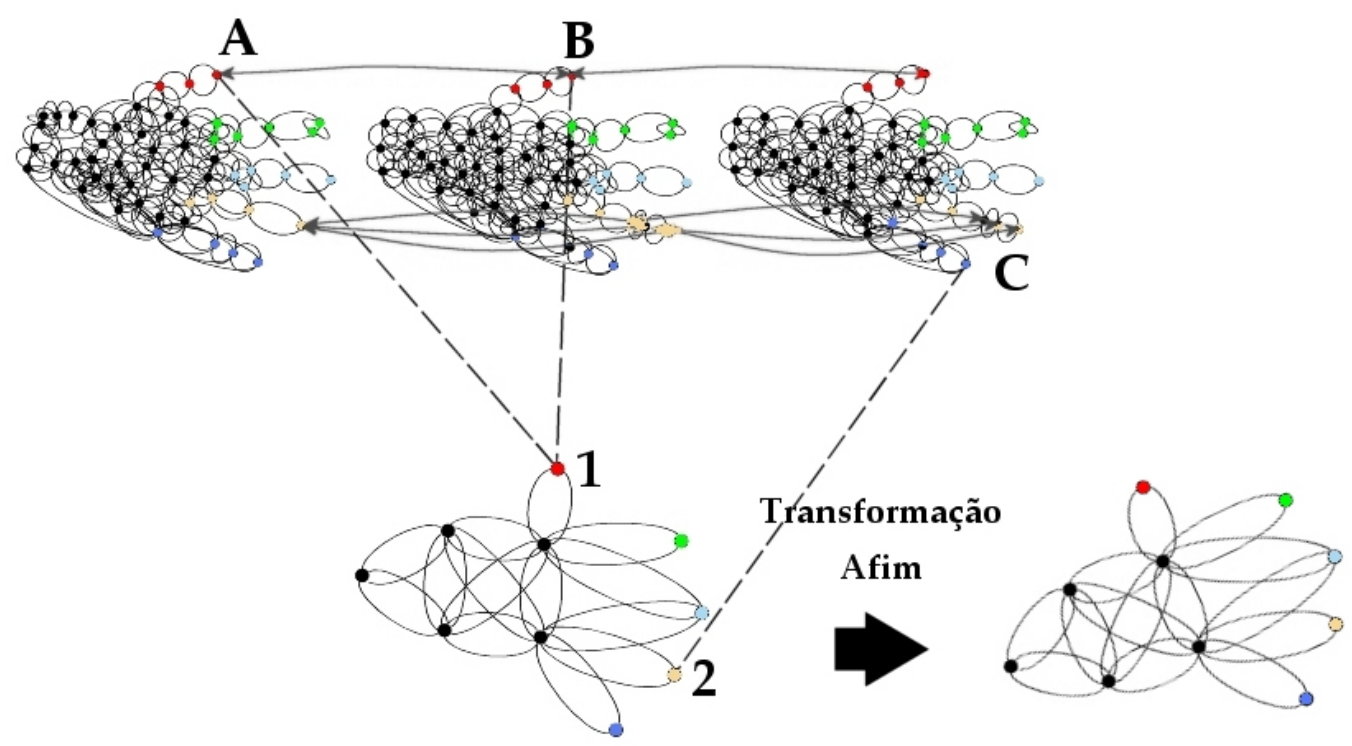

Figura 15. Ilustração do processo de rastreamento: a partir das novas coordenadas dos centróides de cada parte ou objeto, calculadas com base na classificação dos vértices do ARG-inter, uma transformação afim é determinada e aplicada aos centróides associados a cada vértice do ARG-intra modelo, resultando no rastreamento das partes ou objetos de interesse.

coordenadas dos centróides dos objetos (e suas partes componentes) não mudam consideravelmente de um quadro para outro.

Assim, a classificação encontrada para um dado conjunto de quadros pode ser utilizada para atualizar a informação armazenada no ARG-modelo, referente às coordenadas dos centróides relativos a cada vértice desse grafo. Esse procedimento equivale ao rastreamento dos objetos no transcorrer da seqüência de imagens, pois permite estimar a localização de cada parte do modelo e que deverá ser considerada no processamento dos quadros seguintes.

A atualização supracitada pode ser aproximada através de uma transformação afim $A$, que consiste em qualquer transformação que possa ser escrita da seguinte maneira [6]:

$$
\vec{q}=\alpha(A \vec{s}+\vec{b})
$$


em que $A$ é uma matriz real não singular qualquer $2 \times 2, \vec{s}$ é um vetor de valores reais representantes de pontos de uma forma, $\vec{b}$ é um vetor $2 \times 1$ de valores reais, e $\alpha$ é qualquer valor escalar real. Este último valor não está relacionado ao parâmetro $\alpha$ definido na subseção 3.6.3.

A aplicação de uma transformação afim a um conjunto de pontos representantes de uma forma (ou objeto), portanto, produz uma nova forma composta por pontos $\vec{q}$, preservando o mapeamento de linhas em linhas. Desse modo, as transformações de objetos expressas por uma transformação afim são rotação, translação, escalas e cisalhamentos (shearing). Embora esse conceito não comporte transformações elásticas (ou não-afins, como transformações perspectivas), as transformações fornecidas são suficientes em diversas situações.

Para o propósito da metodologia, $\vec{s}$ corresponde ao conjunto de centróides relativos aos vértices de $G_{\text {model, }}$, enquanto $\vec{q}$ representa os centróides resultantes dos vértices de $G_{i n t e r}$ atribuídos a um mesmo vértice do ARG-modelo. Mais formalmente, um ponto em $\vec{s}$ corresponde às coordenadas do atributo de centróide de um vértice $v \in \mathrm{V}_{\text {model }}$, enquanto o respectivo ponto em $\overrightarrow{\mathrm{q}}$ representa as coordenadas de um centróide resultante $c_{\text {sum }}=\frac{1}{n} \sum^{n} c(w), w \in V$, tais que $l(w)=l(v)$ e $n$ é o número total de vértices de $G_{\text {inter }}$ que foram mapeados em $v$.

A partir de $\vec{s}$ e $\vec{q}$, é possível calcular a transformação afim que mapeia o primeiro no segundo e, em seguida, aplicá-la a todos os centróides dos vértices de $\mathrm{G}_{\text {model, }}$, resultando no rastreamento das regiões do modelo. 



\section{4}

\section{RESULTADOS EXPERIMENTAIS}

Preciso começar não com hipóteses, mas com casos específicos.

— Paul Klee, em Altes Fräulein, 1931

Para ilustrar a aplicabilidade da metodologia, serão discutidos alguns resultados obtidos a partir do processamento de seqüências de imagens reais e sintéticas, destacando-se como os diferentes tipos de atributos (de objeto, espacial e temporal) interagem e afetam as soluções encontradas na etapa de reconhecimento.

Assim, nas análises subseqüentes, uma descrição detalhada dos testes realizados será dada, incluindo informações sobre cada etapa do processo de reconhecimento e rastreamento de objetos: forma e condições de aquisição dos vídeos, técnicas de processamento de imagens adotadas para filtrar ou realçar as imagens, aspectos relacionados à construção dos ARGs-intra e ARGs-inter, adoção de pesos para os diferentes atributos nas parcelas da função-custo, resultados de classificação e de rastreamento.

Faz-se necessário chamar a atenção para a importância do parâmetro que define o número de quadros consecutivos da seqüência que serão considerados na formação do ARG-inter. Seja $n$ esse número. Como descrito na seção 3.1, se $n=1$, então o ARG-inter introduz simplesmente as mesmas informações carregadas por um ARGintra, já que seu conjunto de arestas temporais é vazio. Esse aspecto será abordado nos resultados seguintes a título de comparação com valores de $n>1$, definindo dois conjuntos de testes: aqueles que consideram apenas atributos de objeto e espaciais, e aqueles que consideram também atributos temporais. 


\section{I SEQÜÊNCIAS SINTÉTICAS}

Nesta seção, os resultados apresentados referem-se a algumas variações de uma seqüência de imagens sintética gerada através da ordenação de imagens $2 \mathrm{D}$ representantes de uma face simplificada contendo rosto, olhos e boca, criadas em ambiente de edição de imagens. O intuito dessas variantes é apresentar, de maneira simplificada, o comportamento da metodologia em relação a diferentes transformações rígidas, afins e elásticas (não-afins) como translação, rotação, mudança de escala e outras deformações. O tempo consumido para classificar e rastrear os objetos nos vídeos completos foi de poucos segundos em todos os casos discutidos nas próximas subseções.

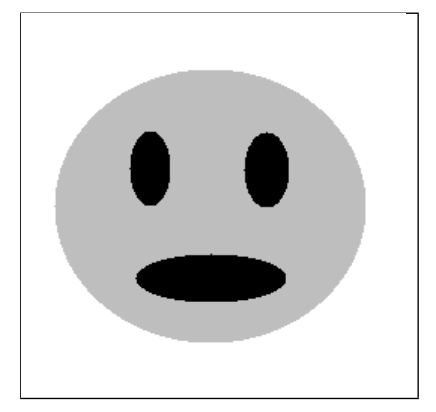

(a)

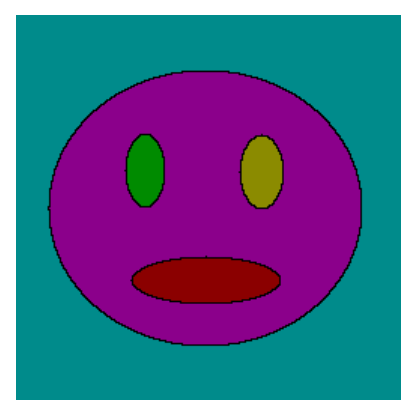

(c)

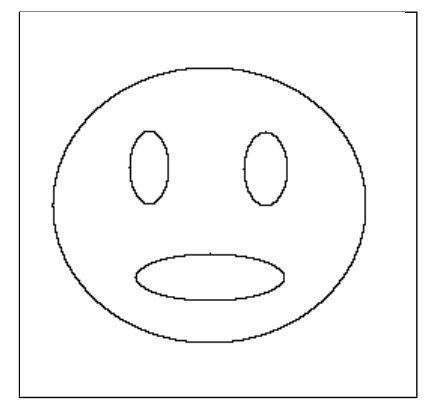

(b)

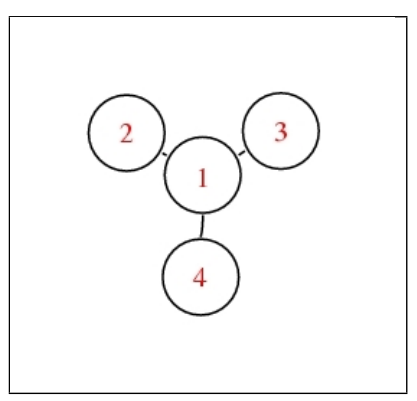

(d)

Figura 16. Imagem de referência (a); máscara modelo binária (b); máscara modelo rotulada (c) e ARG-modelo resultante (d).

CONFIGURAÇÃo. Em todas as variantes, o modelo utilizado é o mesmo e indica o objeto, neste caso, a face, e as partes que deverão ser reconhecidas ao longo das seqüências: rosto, boca e olhos esquerdo e direito. A imagem de referência adotada 


\begin{tabular}{lll}
\hline \multicolumn{1}{c}{ Tío } & \multicolumn{1}{c}{ Aтributo } & PEso \\
\hline \multirow{2}{*}{ Objeto } & Centróide & 0.8 \\
& Nível de cinza médio & 0.2 \\
\hline \multirow{2}{*}{ Estrutural } & Módulo do vetor & 0.2 \\
& Ângulo do vetor & 0.8 \\
\hline
\end{tabular}

Tabela 2. Seqüências sintéticas: pesos adotados para cada atributo.

é mostrada na figura 16 (a), assim como a máscara modelo criada manualmente (fig. 16 (b)) e sua respectiva rotulação (fig. 16 (c)). O ARG-modelo (fig. 16 (d)) obtido da máscara rotulada consiste num grafo com 4 vértices e 6 arestas, cujos respectivos atributos são aqueles descritos na seção 3.5.1.

Quanto ao pré-processamento efetuado sobre os quadros do vídeo, apenas o operador gradiente morfológico foi aplicado, ressaltando as bordas dos objetos para posterior aplicação do algoritmo de watershed. Outros filtros não foram utilizados, já que as imagens sintéticas não apresentavam ruídos ou degradações consideráveis, não sendo também necessário realçar outras características específicas das mesmas.

A etapa de segmentação foi constituída da aplicação do algoritmo de watershed sobre as imagens resultantes do operador gradiente morfológico, gerando uma partição das imagens, as quais serviram de base para a criação dos ARGs-intra de entrada.

Em seguida, de acordo com o $n$ escolhido, um ARG-inter foi derivado e o processo de classificação pôde ser aplicado entre esse grafo e o ARG-modelo. A distância máxima $\epsilon$ entre vértices conectados por arestas temporais utilizada foi 3.5. Os pesos adotados para compor as parcelas da função custo foram os seguintes: 0.8 para a parcela de custo dos nós e 0.2 para a parcela de custo das arestas. De maneira intuitiva, atribuiu-se um maior peso aos atributos de objeto, pois os centróides e níveis de cinza médio das regiões são, nesse caso, mais discriminantes do que o atributo estrutural, o qual é aproximadamente o mesmo entre todas as partes. Já os pesos individuais designados a cada atributo são apresentados na tabela 2.

Definida essa configuração, as próximas subseções introduzem efetivamente os resultados de classificação e reconhecimento atingidos. 


\subsubsection{Seqüência 1}

Esta seqüência sintética composta por 14 quadros apresenta a face criada sob o efeito de uma composição entre rotações e escalas, para simular um objeto rotacionado e filmado com zoom. Igualmente ao ARG-modelo, os ARGs-intra gerados foram compostos por 4 vértices e por 6 arestas.

Resultados obtidos do processo de reconhecimento e rastreamento dos objetos de interesse a partir de testes com essa seqüência podem ser vistos nas figuras 17 e 18 .

$\mathrm{O}$ primeiro conjunto de imagens ilustra os resultados para o processamento quadro-a-quadro, ou seja, com um ARG-inter criado a partir de um único quadro do vídeo. Logo, atributos temporais são desconsiderados. Já o segundo conjunto de imagens resulta do processamento do vídeo levando-se em consideração atributos temporais, a partir da construção de ARGs-inter referentes a $n=3$ quadros.

Embora o reconhecimento das partes de acordo com o modelo tenha sido muito semelhante e muito satisfatória em ambos os casos, uma discrepância entre as classificações dos quadros 17 (n) e 18 (n) sugere que o atributo temporal auxilia na manutenção da coerência espaço-temporal em quadros consecutivos. 


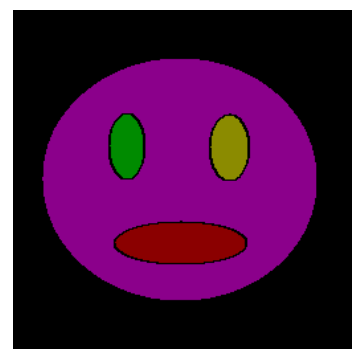

(a)

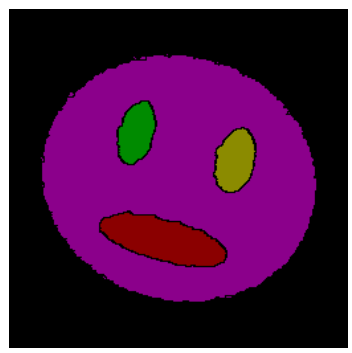

(e)

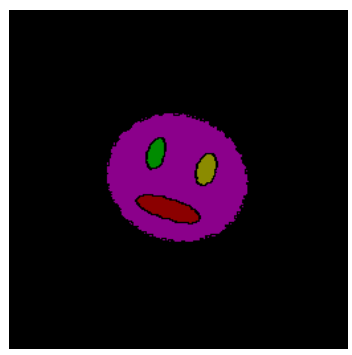

(i)

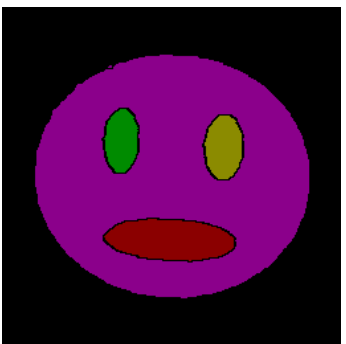

(b)

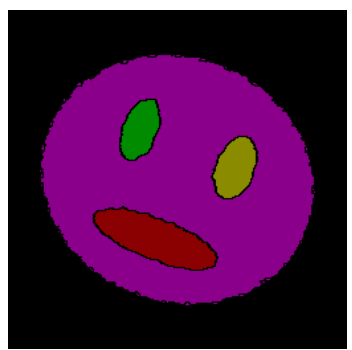

(f)

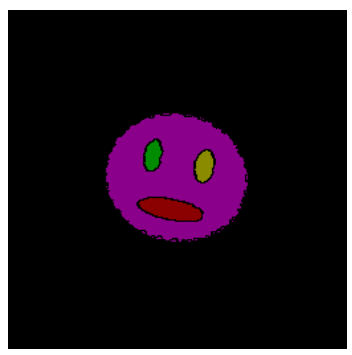

(j)

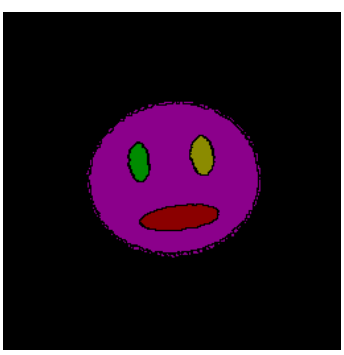

(m)

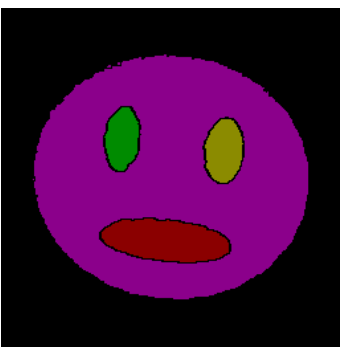

(c)

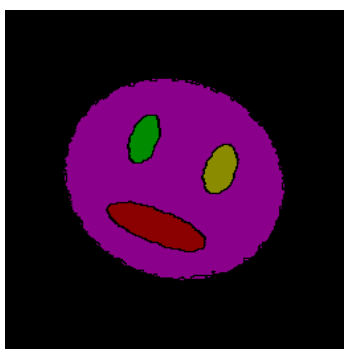

(g)

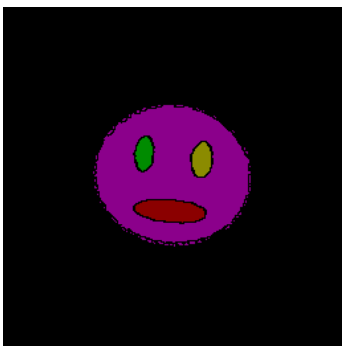

(k)

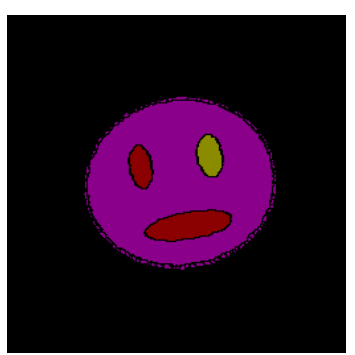

(n)

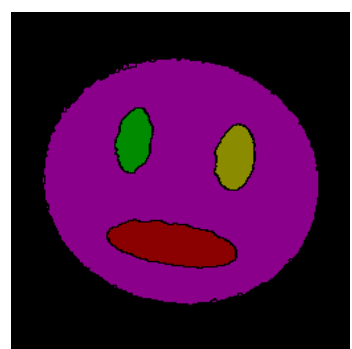

(d)

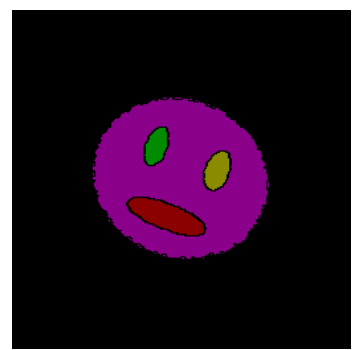

(h)

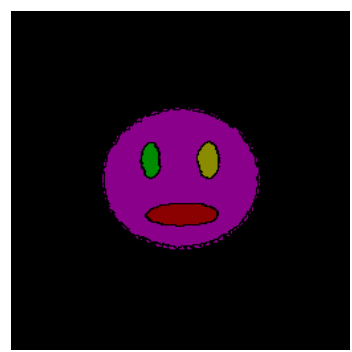

(l)

Figura 17. Seqüência sintética 1 - testes sem atributos temporais. 


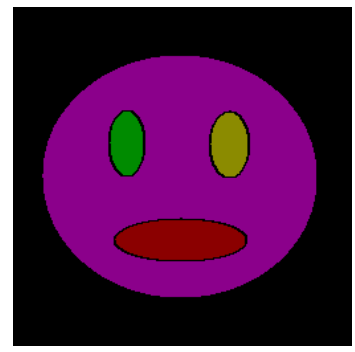

(a)

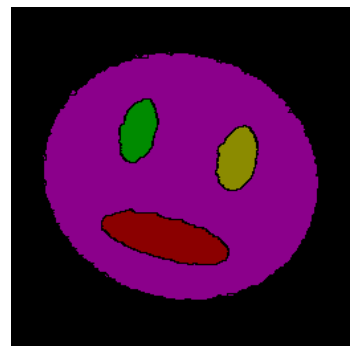

(e)

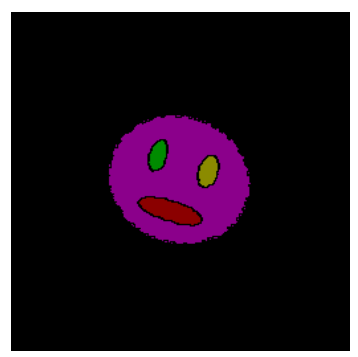

(i)

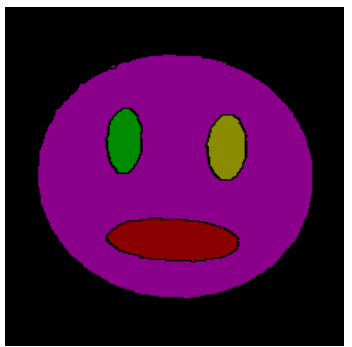

(b)

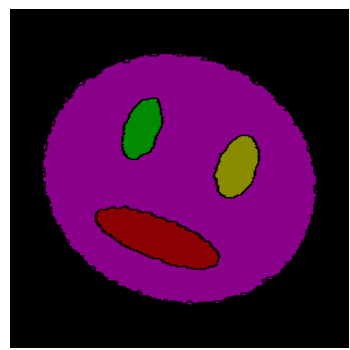

(f)

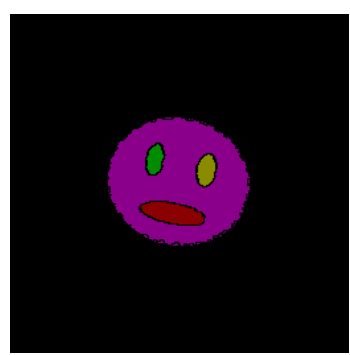

(j)

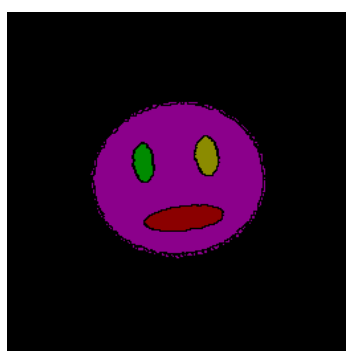

(m)

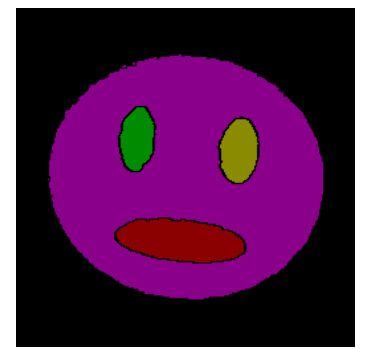

(c)

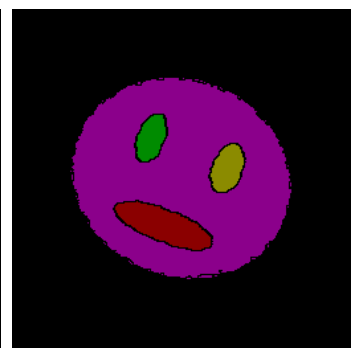

(g)

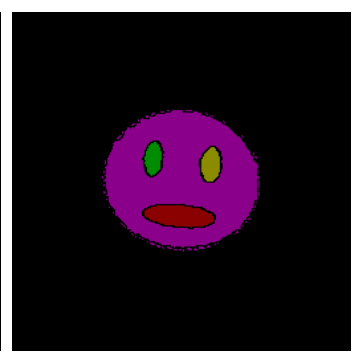

(k)

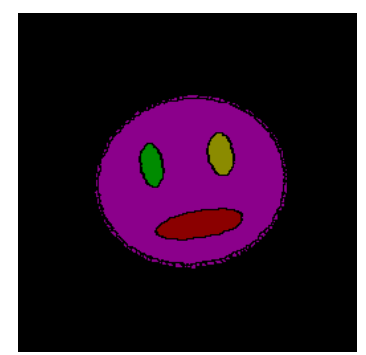

(n)

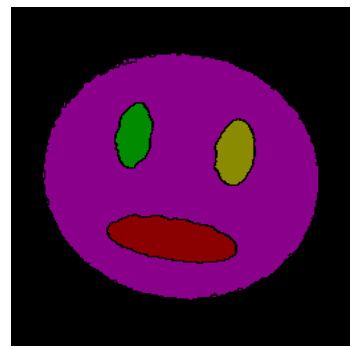

(d)

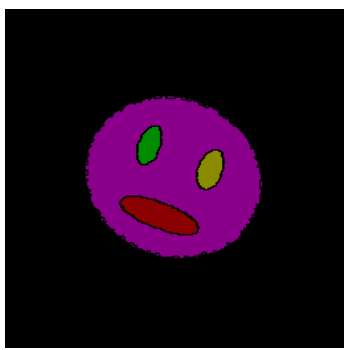

(h)

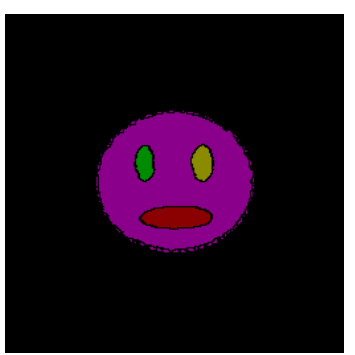

(1)

Figura 18. Seqüência sintética 1 - testes com ARG-inter composto por vértices e arestas extraídos de 3 quadros do vídeo. 


\subsubsection{Seqüência 2}

Nesta seqüência, a face sintética sofre modificações de naturezas diferentes: rígidas (translações e rotações), afins (escalas) e não-afins (warping). Um subconjunto de classificações obtidas da aplicação da metodologia sobre os 46 quadros do vídeo, com $n$ igual a 1,3 e 5, é exibido, respectivamente, nas figuras 19, 20 e 21. Em relação ao ARG-modelo, os ARGs-intra gerados foram compostos por 4 a 39 vértices e por 6 a 130 arestas, dependendo da segmentação obtida em cada quadro.

Nesses testes, o desempenho do processo de reconhecimento foi distinto daquele apresentado para a seqüência de imagens anteriormente discutida. Isso se deve, principalmente, ao fato das transformações envolvidas não serem apenas de natureza afim, o que se comprova pelos erros existentes nos três testes: em todos os casos, as imagens retratavam algum tipo de transformação não-afim mais acentuada.

Contudo, comparando-se os resultados obtidos em cada teste, nota-se uma melhoria progressiva nas classificações das partes de acordo com o modelo, conforme o número de quadros que compõem um ARG-inter é incrementado. Enquanto erros ocorreram em 9 quadros da figura 19 (i, j, k, l, m, n, o, s, t), tais ocorrências foram reduzidas para um total de 4 quadros na figura $20(\mathrm{i}, \mathrm{j}, \mathrm{o}, \mathrm{t})$ e de 2 quadros na figura $21(\mathrm{j}, \mathrm{s})$.

Mais uma vez, os resultados sugerem maior acuidade de classificações ao longo do tempo por meio da inclusão de atributos temporais na estrutura dos grafos. 


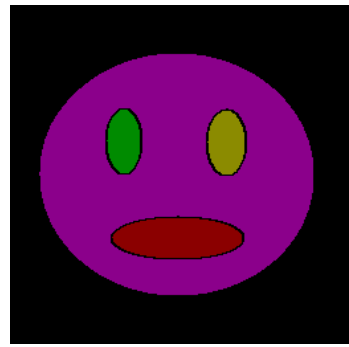

(a)

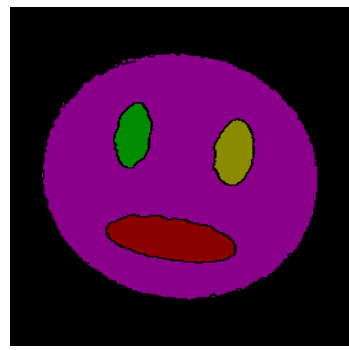

(e)

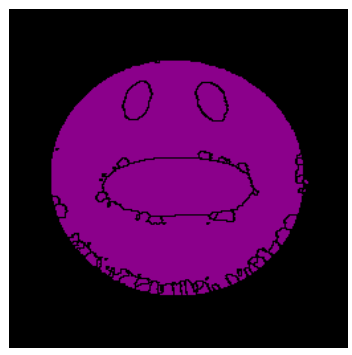

(i)

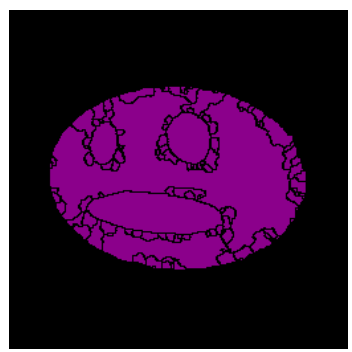

(m)

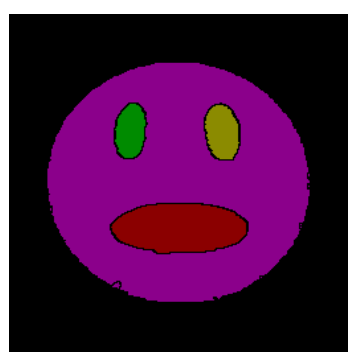

(q)

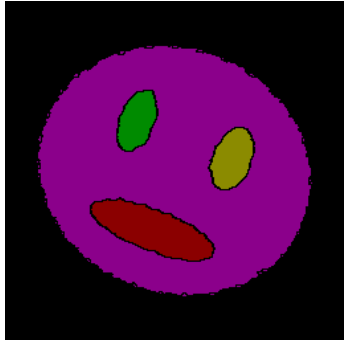

(b)

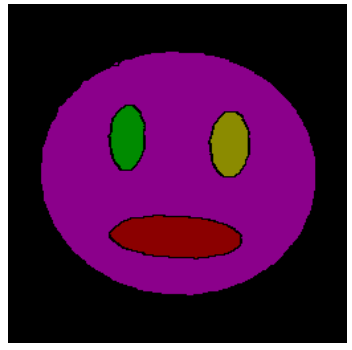

(f)

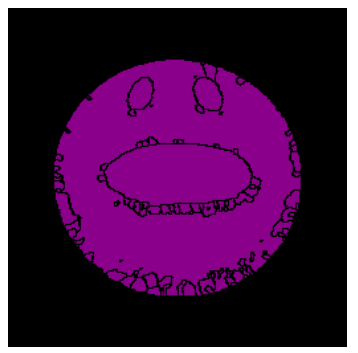

(j)

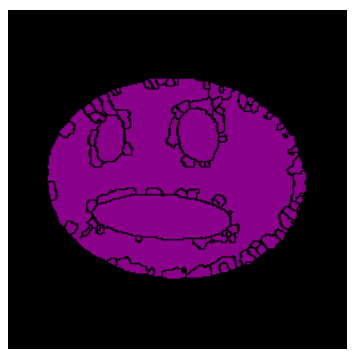

(n)

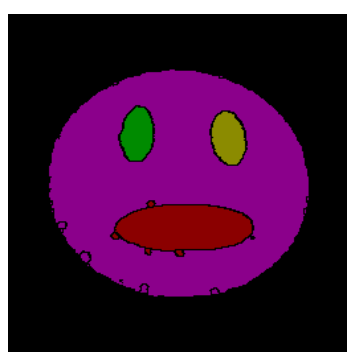

$(\mathrm{r})$

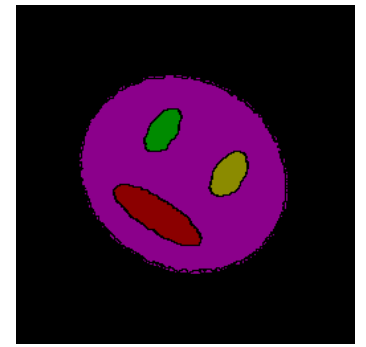

(c)

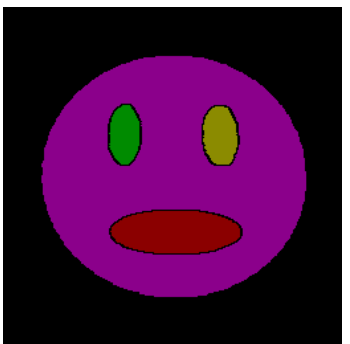

(g)

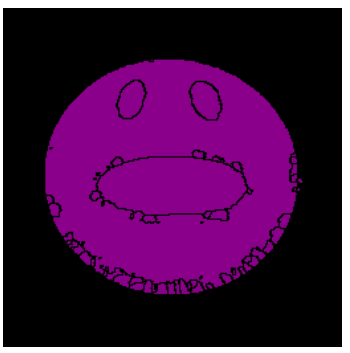

(k)

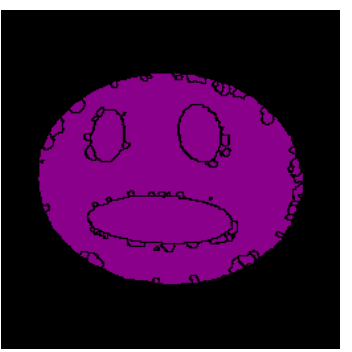

(o)

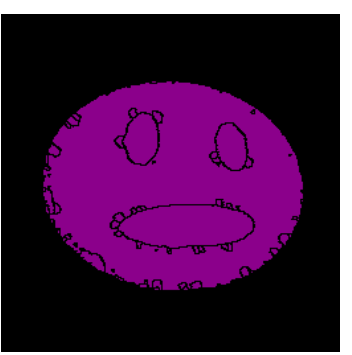

(s)

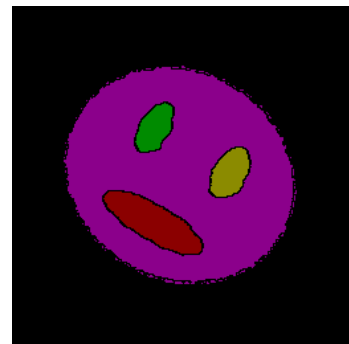

(d)

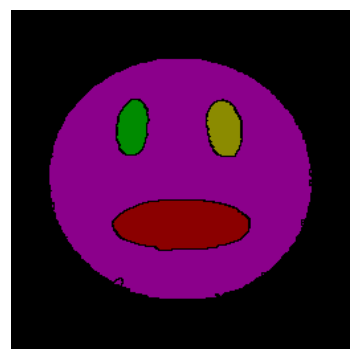

(h)

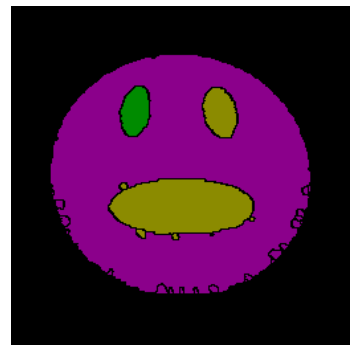

(1)

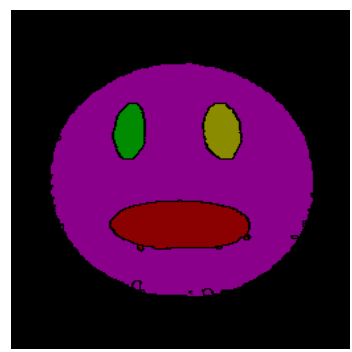

(p)

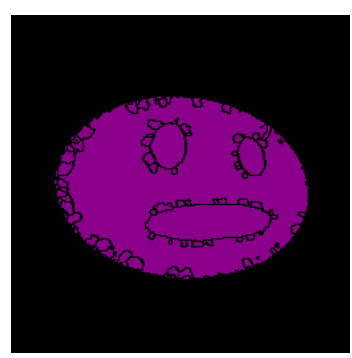

$(\mathrm{t})$

Figura 19. Seqüência sintética 2 - testes sem atributos temporais. 


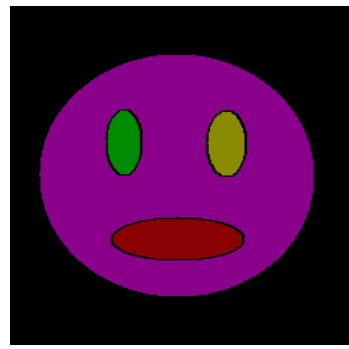

(a)

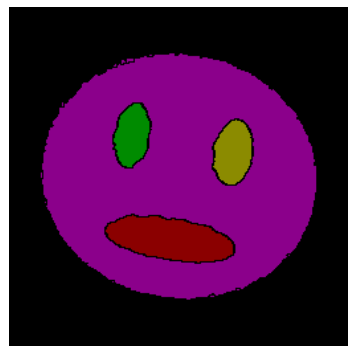

(e)

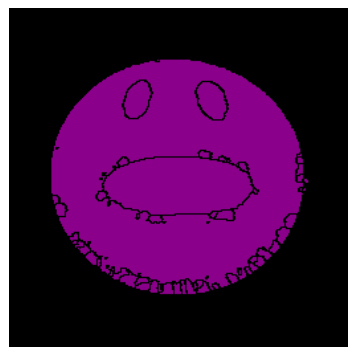

(i)

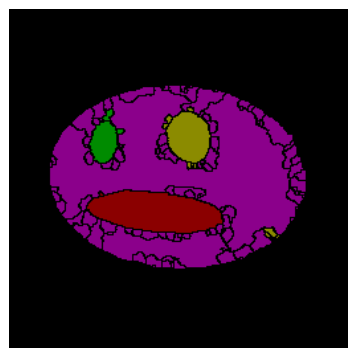

(m)

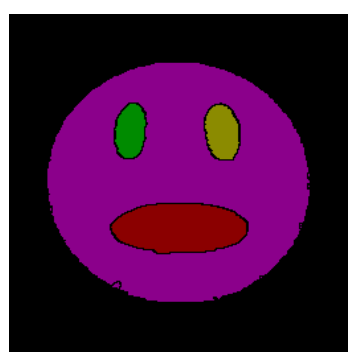

(q)

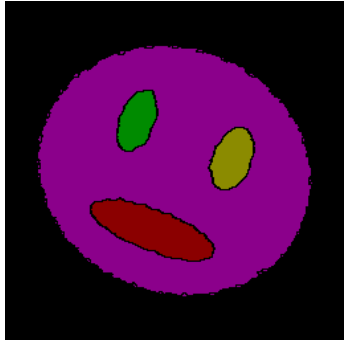

(b)

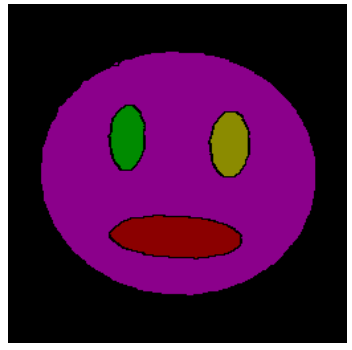

(f)

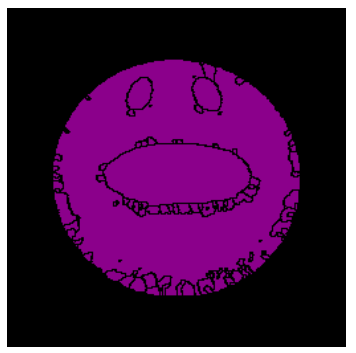

(j)

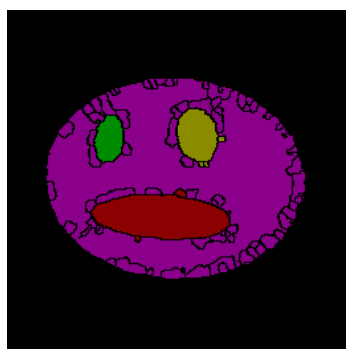

(n)

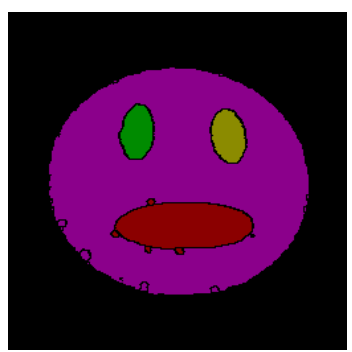

(r)

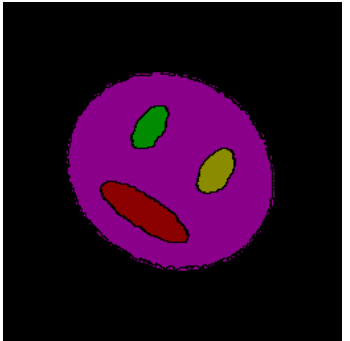

(c)

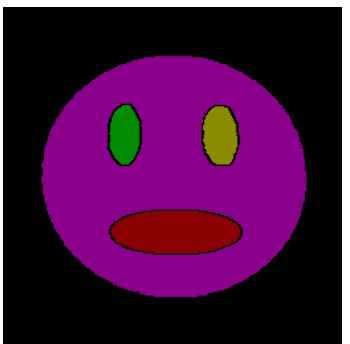

(g)

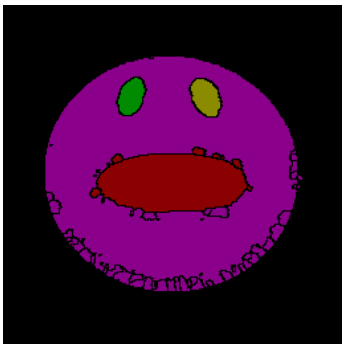

(k)

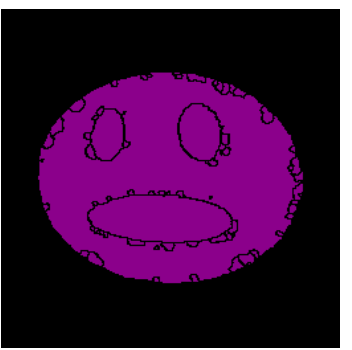

(o)

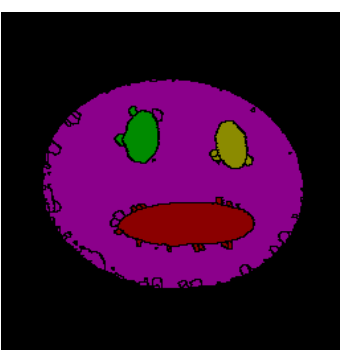

(s)

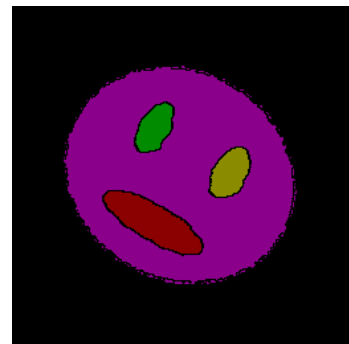

(d)

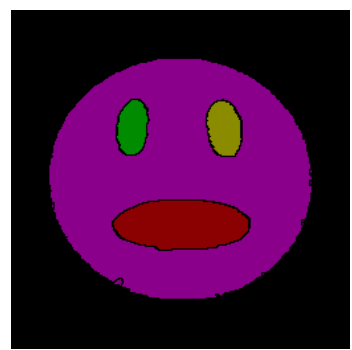

(h)

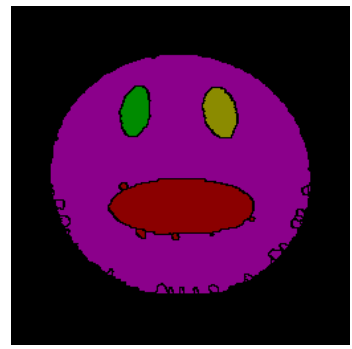

(l)

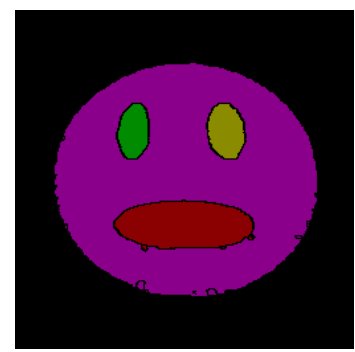

(p)

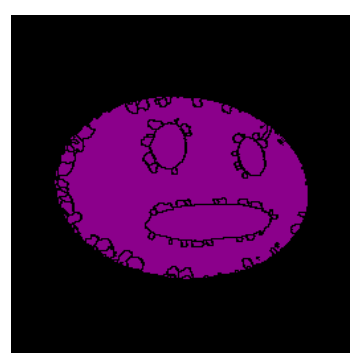

(t)

Figura 20. Seqüência sintética 2 - testes com ARG-inter composto por vértices e arestas extraídos de 3 quadros do vídeo. 


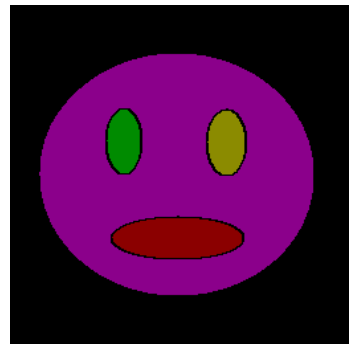

(a)

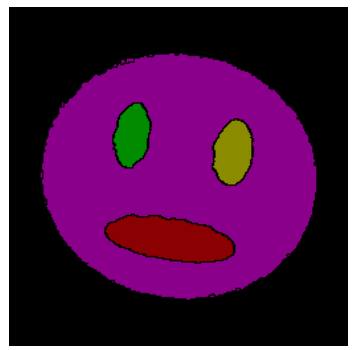

(e)

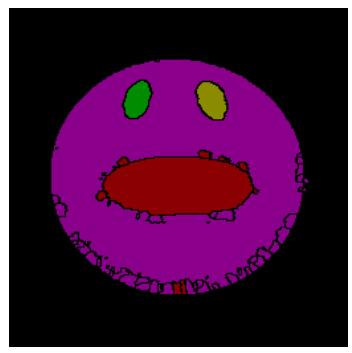

(i)

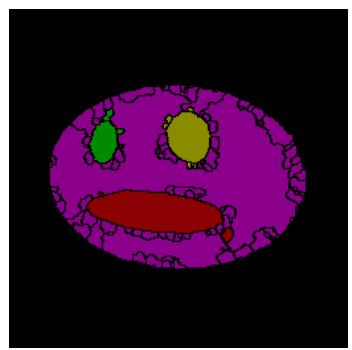

(m)

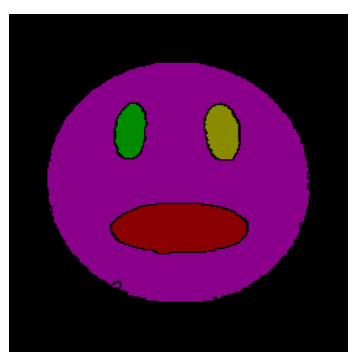

(q)

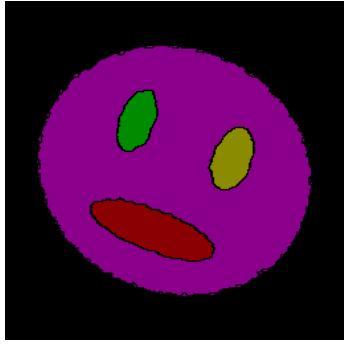

(b)

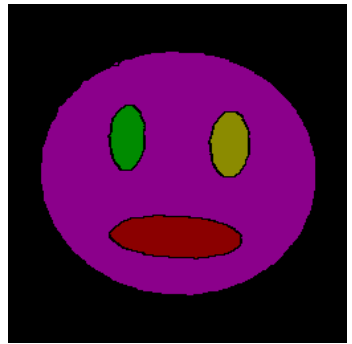

(f)

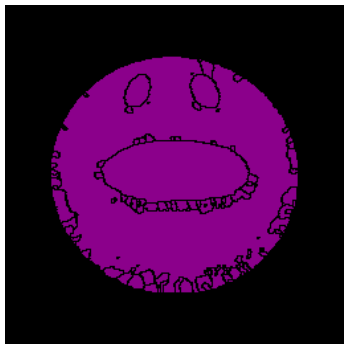

(j)

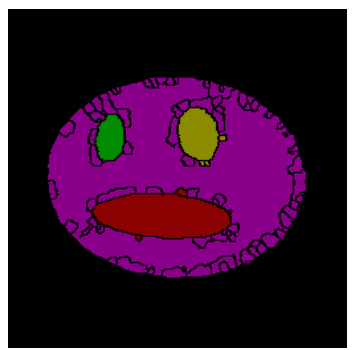

(n)

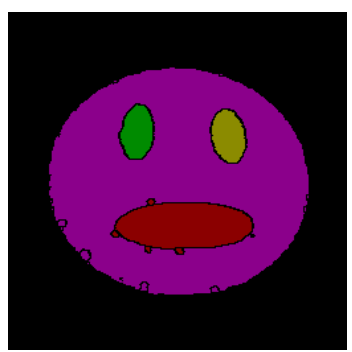

$(\mathrm{r})$

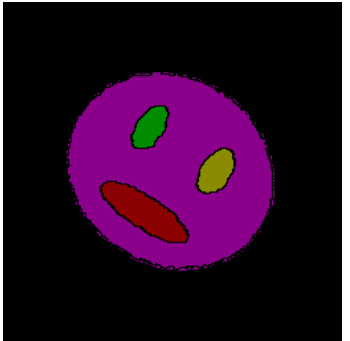

(c)

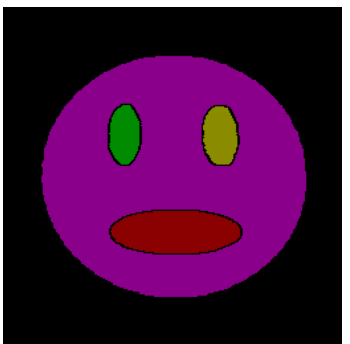

(g)

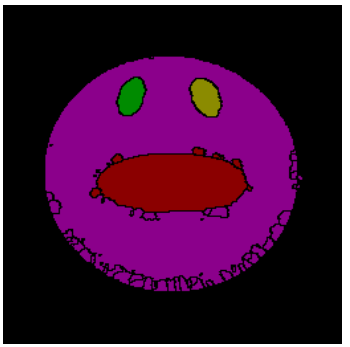

(k)

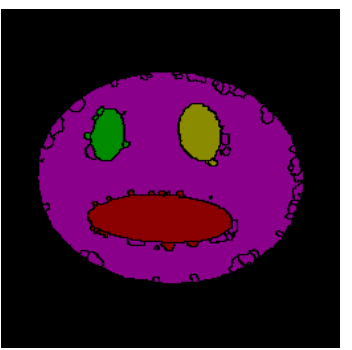

(o)

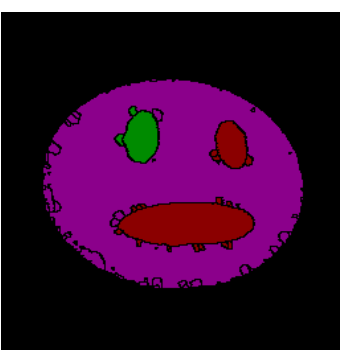

(s)

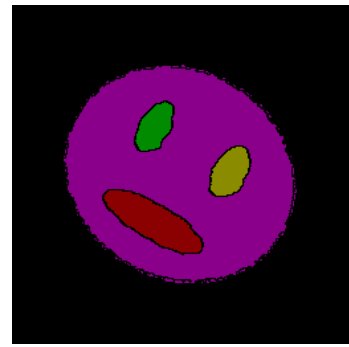

(d)

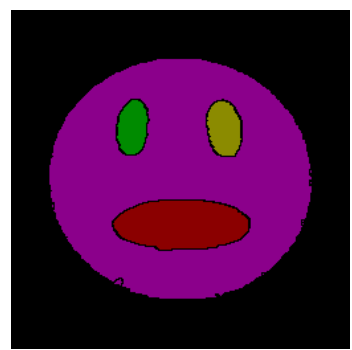

(h)

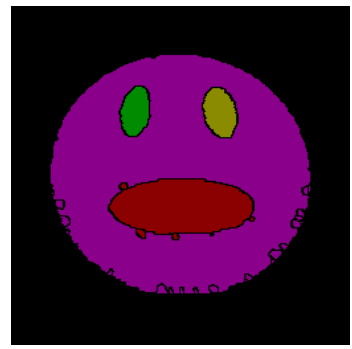

(l)

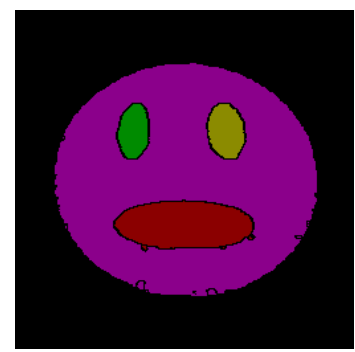

(p)

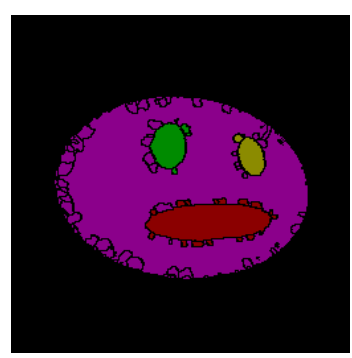

$(\mathrm{t})$

Figura 21. Seqüência sintética 2 - testes com ARG-inter composto por vértices e arestas extraídos de 5 quadros do vídeo. 


\subsection{SEQÜÊNCIAS REAIS}

Nesta seção, são exibidas duas seqüências de imagens obtidas através de câmera digital e de webcam.

\subsubsection{Mãos}

Neste vídeo digital composto de 166 quadros, imagens de uma mão em movimento sobre um fundo escuro foram capturadas através de uma webcam comum de baixa resolução, em ambiente sob condições de iluminação não controladas. O objeto de interesse consiste na mão como um todo e suas partes constituintes são os dedos e a superfície superior. O reconhecimento desses elementos pode ser útil, por exemplo, para posterior aplicação a um leitor de linguagem de sinais automatizado.

Embora a seqüência seja simples em termos da variabilidade de cores existentes, o reconhecimento das partes supracitadas pode não ser tão trivial. Um método de segmentação e de classificação baseado em cores, facilmente distingüiria o que pertence à mão do que pertence ao fundo. No entanto, seria extremamente difícil distinguir individualmente os dedos e a superfície superior, uma vez que seus níveis de cinza são praticamente homogêneos.

Seria, então, conveniente incorporar alguma informação de forma para diferenciar essas partes, mas esse adicional ainda seria limitado, pois alguns dedos (ex.: anelar e indicador) possuem formas e tamanhos extremamente semelhantes. Logo, a utilização de informação estrutural também seria desejável, pois esta permite conhecer a disposição dos dedos em relação à superfície da mão e aproveitar esse dado no reconhecimento para identificar as diferentes partes.

Assim, a metodologia aqui proposta agrega todos esses diferentes aspectos no reconhecimento das partes da mão, os quais são transmitidos pelos atributos dos ARGs, permitindo uma classificação bastante satisfatória desses diferentes elementos ao longo do vídeo. Além disso, o caráter não-rígido da mão, ou seja, suas transformações ao longo do tempo, é capturado através dos atributos temporais e do rastreamento das partes.

CONfigurAçÃo. Para testar a metodologia sobre esta seqüência, o ARG-modelo (fig. $22(\mathrm{~d})$ ) foi extraído a partir da imagem de referência e da máscara modelo 
exibidas, respectivamente, nas figuras 22 (a) e 22 (c). Cada dedo e região componente da superfície da mão originou um vértice distinto, e uma aresta foi adicionada ao grafo para conectar vértices representantes de regiões adjacentes, originando um total de 10 vértices e 28 arestas. Já os ARGs-intra gerados foram compostos, em média, por 50 vértices e por 240 arestas, com variações dependendo da segmentação obtida em cada quadro.

A subdivisão da superfície das costas da mão definida pela máscara modelo está relacionada às topologias que diferentes partições de uma imagem ou objeto definem sobre um ARG-intra. Se uma região razoavelmente extensa da imagem for utilizada em sua totalidade, seus atributos associados poderão não ser bons descritores dessa mesma região, o que afetará a classificação produzida na etapa de casamento entre grafos. Assim, a decomposição de uma mesma região em subpartes pode gerar representações por grafos mais adequadas num dado problema, como é o caso desta seqüência de imagens.

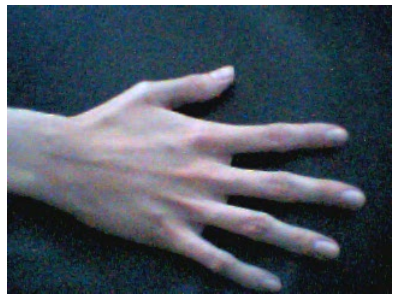

(a)

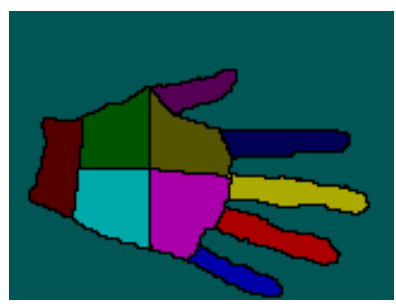

(c)

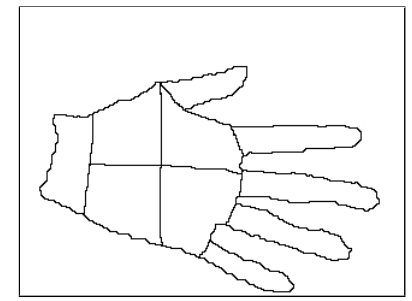

(b)

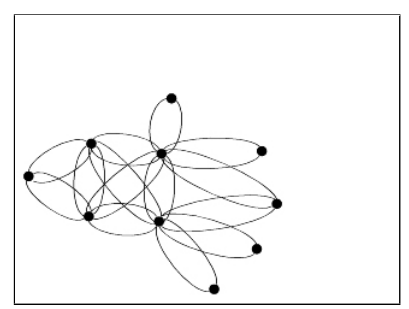

(d)

Figura 22. Imagem de referência (a); máscara modelo binária (b); máscara modelo rotulada (c) e ARG-modelo resultante (d).

Para o pré-processamento dos quadros da seqüência, as técnicas escolhidas consistiram numa suavização gaussiana de um quadro, seguida de limiarização para extrair os pixels referentes à mão. A imagem obtida desses passos foi utilizada para compor uma nova imagem em que pixels com valor 0 se referiam ao fundo, enquanto 


\begin{tabular}{|c|c|c|}
\hline TIPO & ATRIBUTO & PESO \\
\hline \multirow[t]{2}{*}{ Objeto } & Centróide & 0.95 \\
\hline & Nível de cinza médio & 0.05 \\
\hline \multirow[t]{2}{*}{ Estrutural } & Módulo do vetor & 0.3 \\
\hline & Ângulo do vetor & 0.7 \\
\hline
\end{tabular}

Tabela 3. Seqüência real 1: pesos adotados para cada atributo.

os demais se referiam à mão e assumiam valores originais do quadro. Sobre tal imagem, foi aplicado o operador gradiente morfológico, novamente para ressaltar as bordas dos objetos para posterior aplicação do algoritmo de watershed.

A seguir, a etapa de segmentação consistiu na aplicação do algoritmo de watershed sobre cada quadro pré-processado e as partições obtidas foram utilizadas para derivar os respectivos ARGs-intra de entrada. Uma restrição foi adotada na construção desses grafos, de modo que vértices relativos a regiões segmentadas compostas por um número de pixels menor do que 2 fossem fundidos com vértices vizinhos de maior similaridade em relação à cor.

No passo subseqüente, um ARG-inter foi construído conforme o $n$ pré-determinado e submetido ao processo de classificação. A distância máxima $\epsilon$ entre vértices conectados por arestas temporais utilizada foi 1.5. Os pesos adotados para compor as parcelas da função custo foram os seguintes: 0.95 para o custo dos nós e o respectivo complemento para o custo das arestas. Em particular, os pesos individuais escolhidos para a contribuição do centróide e do nível de cinza foram divididos em 0.95 e 0.05 , devido à homogeneidade dos tons da mão. Um resumo de todos os pesos de atributos é mostrado na tabela 3 .

Na figura 23, são exibidos alguns resultados extraídos de testes sem consideração de atributos temporais, enquanto as figuras 24 e 25 ilustram resultados obtidos, respectivamente, com o uso de ARGs-inter formados por $n=3$ e $n=5$ quadros.

Embora a mão seja um objeto deformável e, conseqüentemente, passível de movimentos não representáveis por transformações afins, uma avaliação visual das classificações e do rastreamento obtidos nos testes sugere resultados satisfatórios mesmo sob tais condições.

Em relação às seqüências sintéticas, este vídeo apresentou resultados mais fidedig- 
nos à composição do modelo para o processamento referente a $n=1$, ou seja, sem atributos temporais. Porém, a adoção de ARGs-inter derivados de $n>1$ quadros fornece melhores resultados quanto à manutenção da coerência espaço-temporal das classificações de quadros consecutivos. Esta última observação pode ser constatada pela análise comparativa das três colunas da figura 26.

Quanto ao tempo total gasto para classificar e rastrear os objetos em todos os quadros, o processamento com $n=1$ quadro levou 4 minutos, enquanto para $n=3$ quadros foram consumidos 7 minutos e para $n=5$ quadros, 10 minutos. 


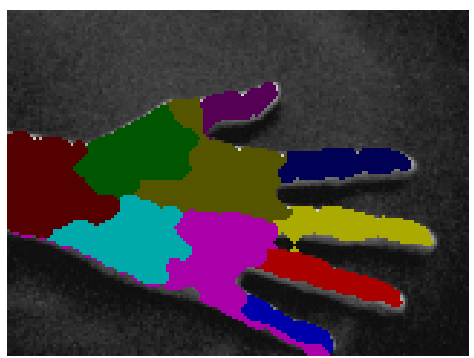

(a)

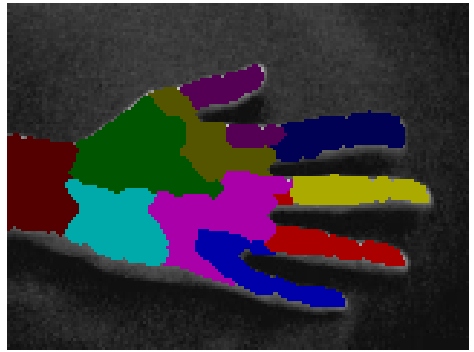

(d)

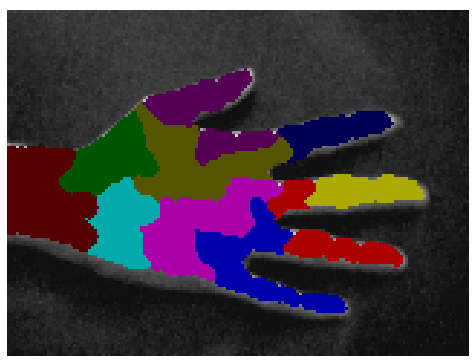

(g)

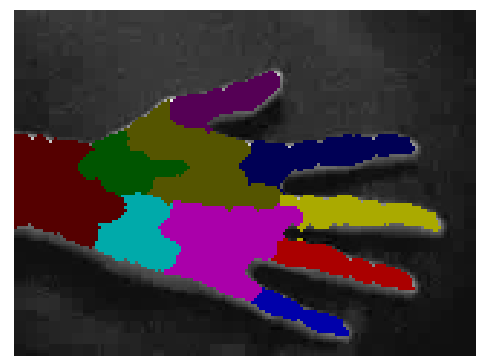

(b)

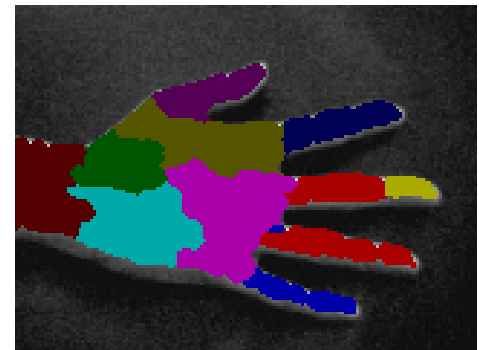

(e)

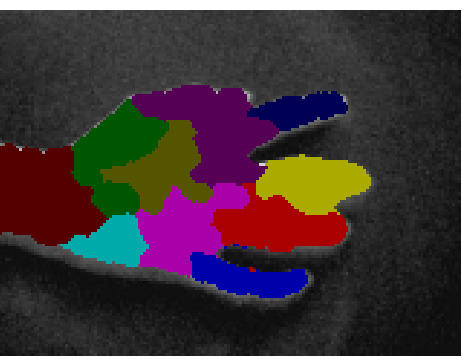

(h)

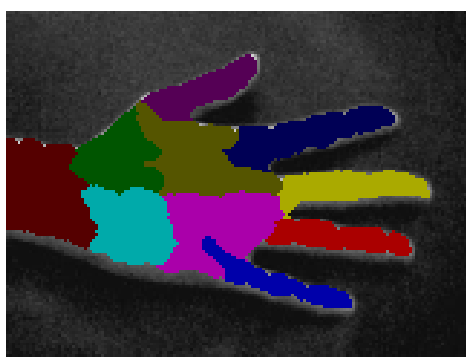

(c)

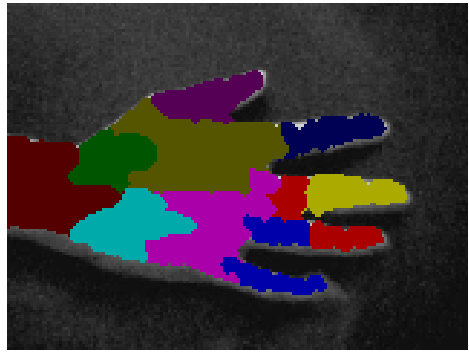

(f)

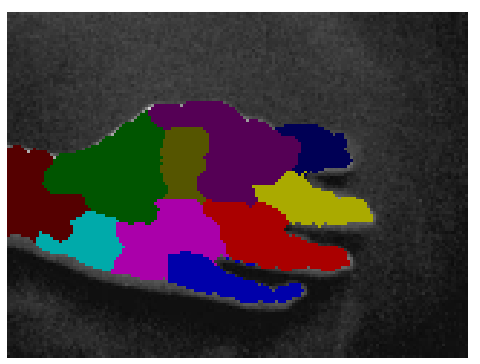

(i)

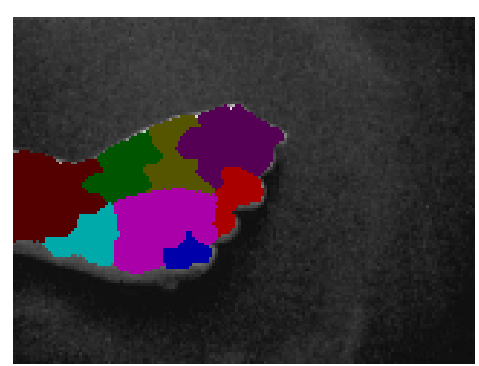

(j)

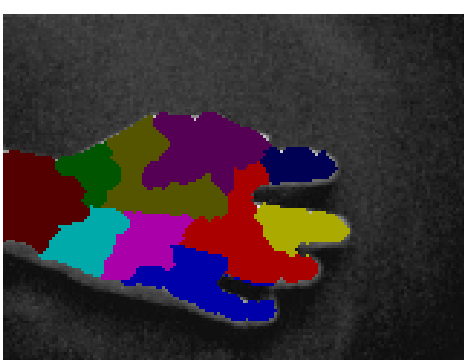

(k)

Figura 23. Seqüência real 1 - testes sem atributos temporais. 


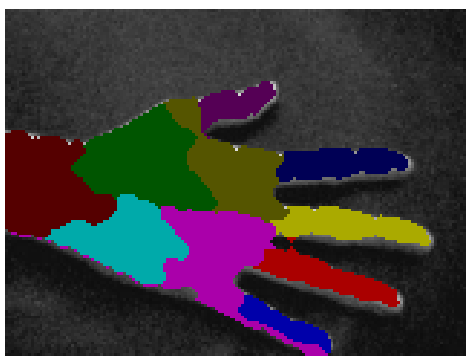

(a)

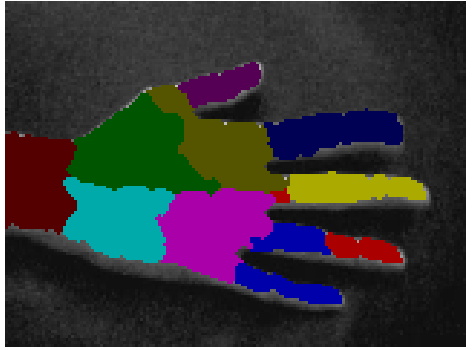

(d)

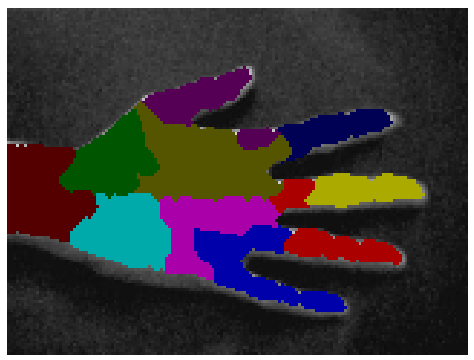

(g)

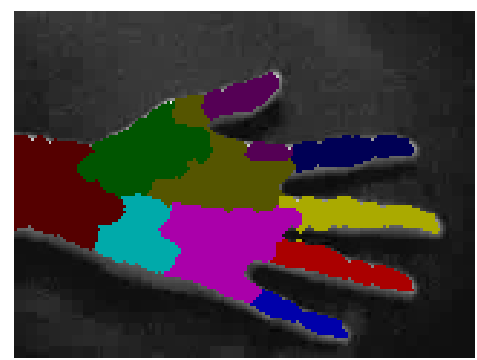

(b)

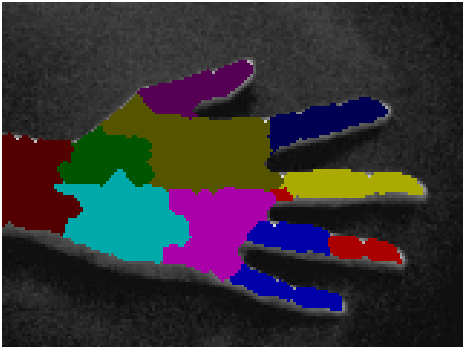

(e)

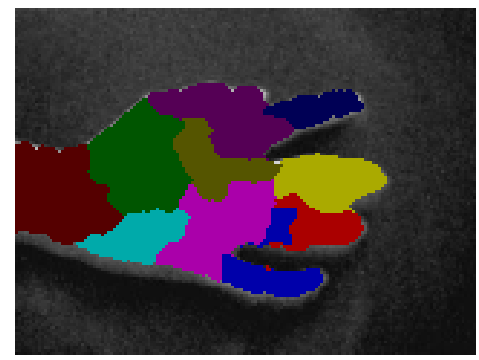

(h)

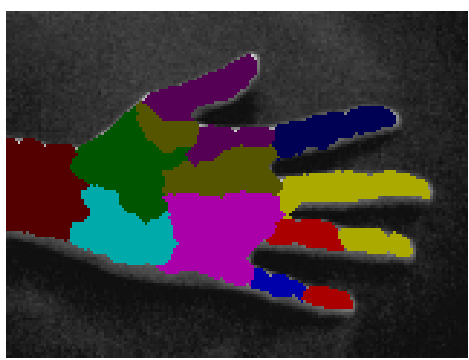

(c)

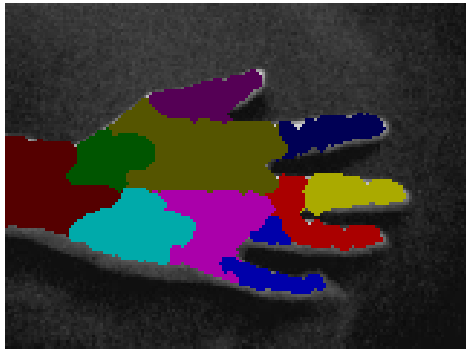

(f)

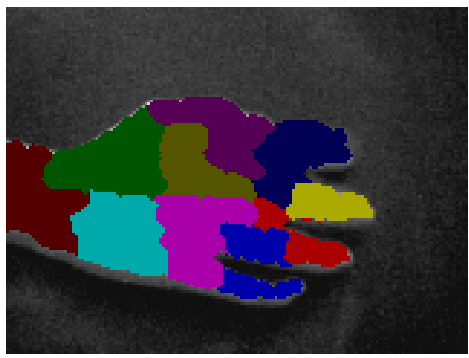

(i)

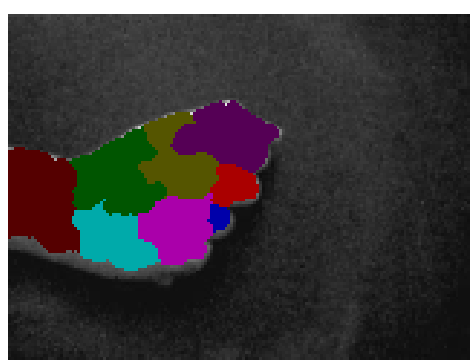

(j)

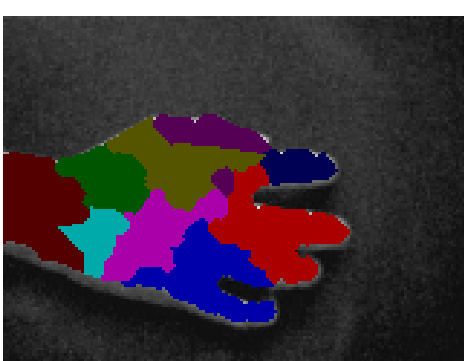

(k)

Figura 24. Seqüência real 1 - testes com ARG-inter composto por vértices e arestas extraídos de 3 quadros do vídeo. 


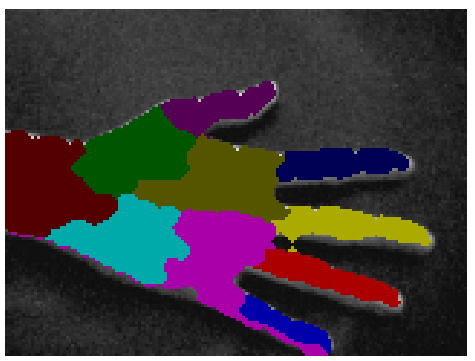

(a)

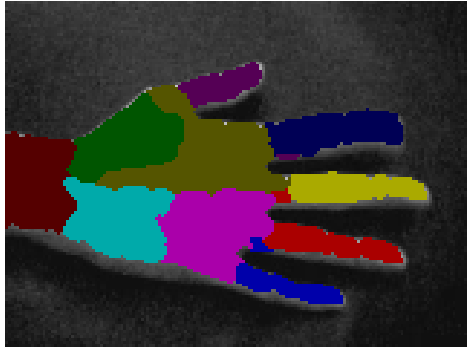

(d)

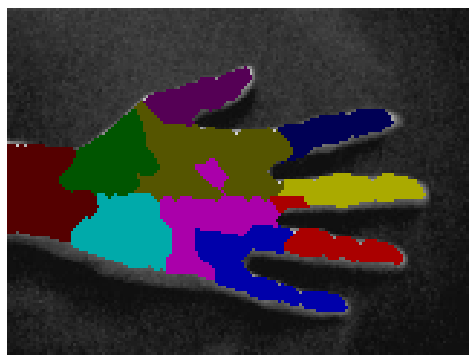

(g)

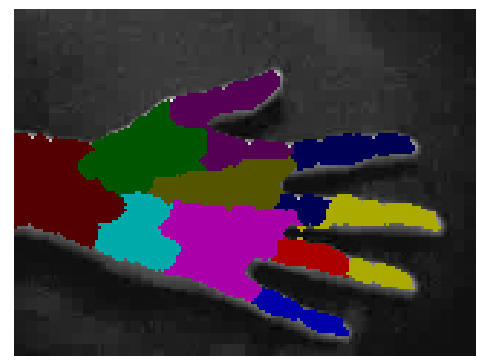

(b)

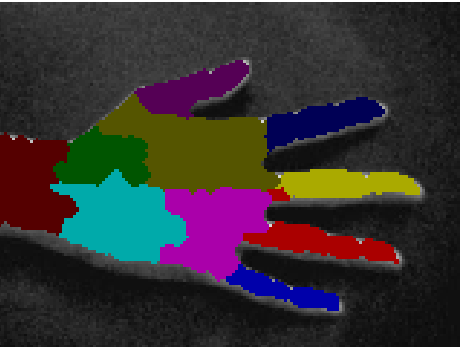

(e)

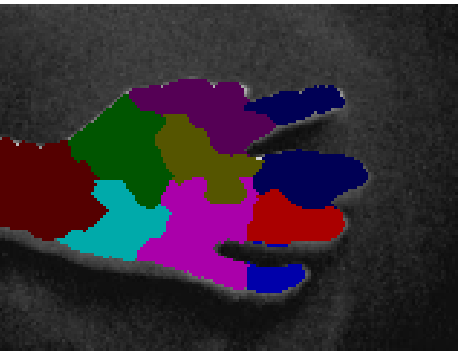

(h)

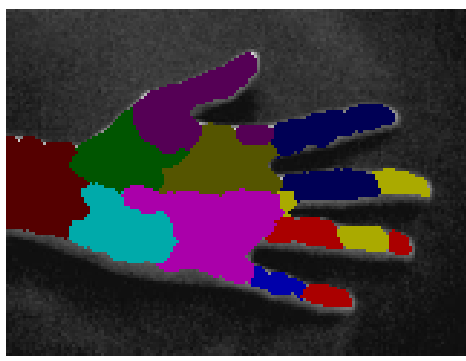

(c)

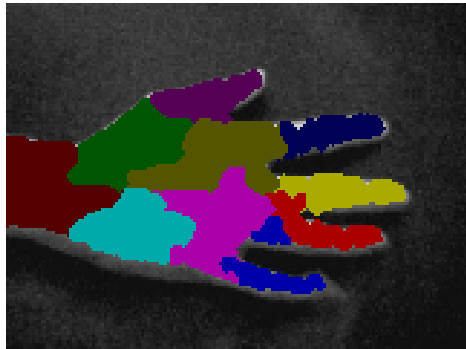

(f)

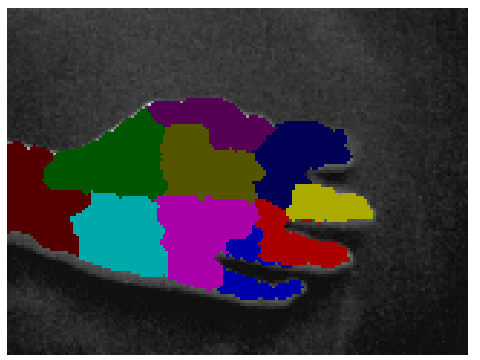

(i)

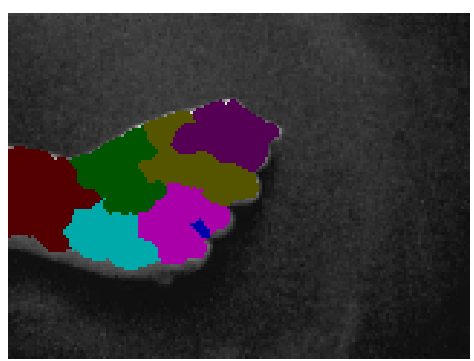

(j)

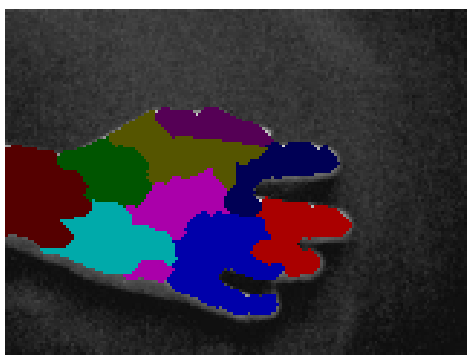

(k)

Figura 25. Seqüência real 1 - testes com ARG-inter composto por vértices e arestas extraídos de 5 quadros do vídeo. 


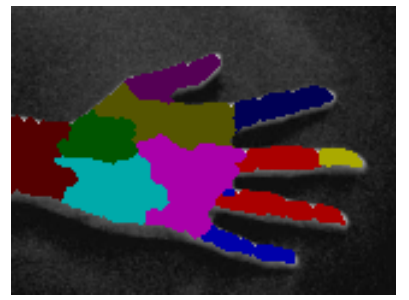

(a)

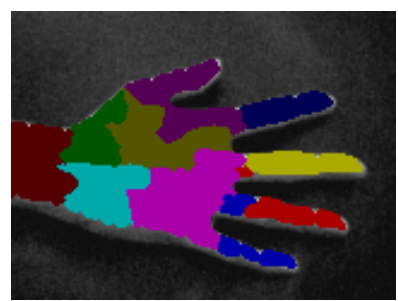

(d)

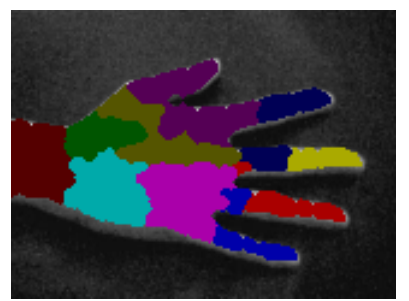

(g)

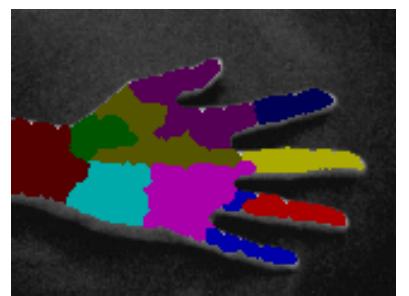

(j)

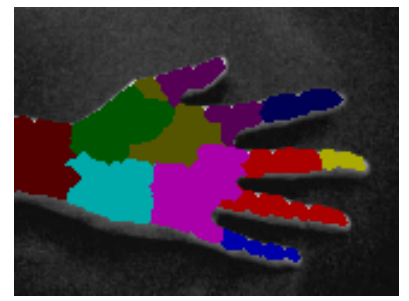

(m)

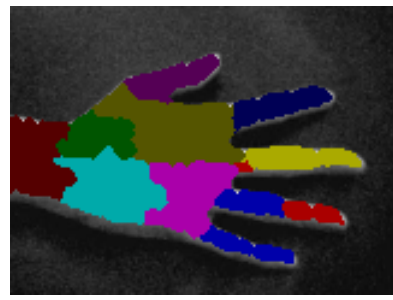

(b)

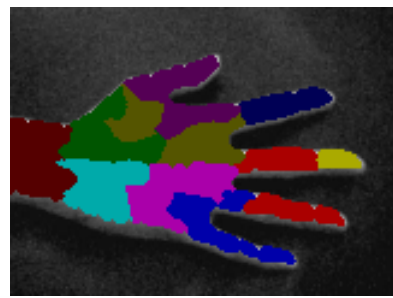

(e)

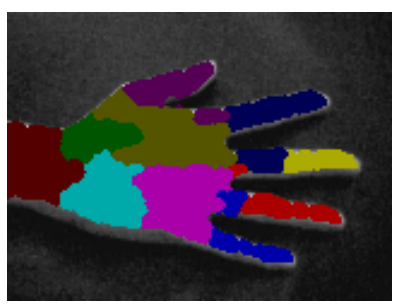

(h)

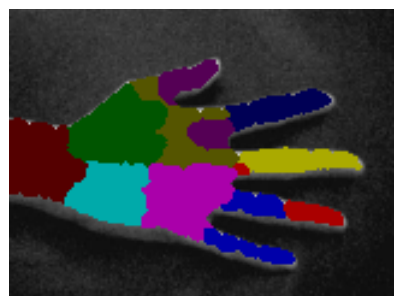

(k)

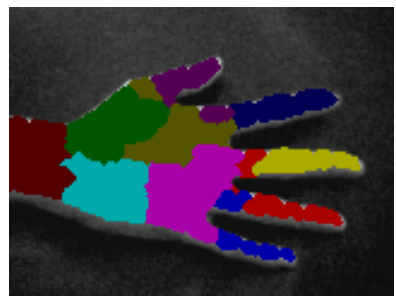

(n)

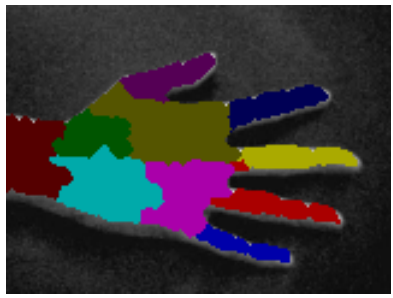

(c)

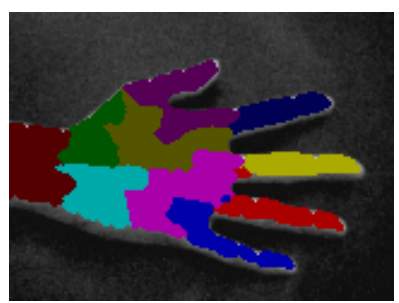

(f)

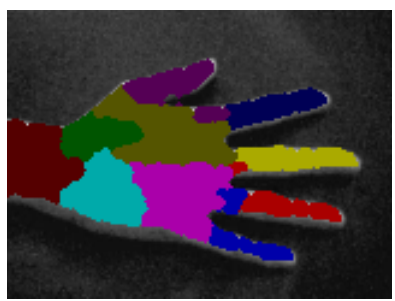

(i)

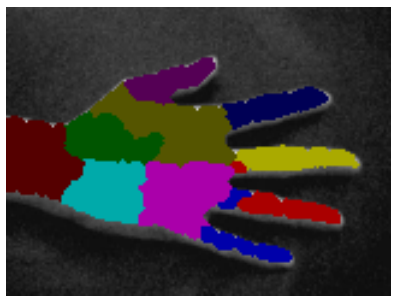

(1)

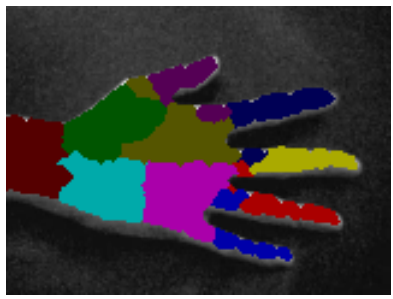

(o)

Figura 26. Exemplos de classificações obtidas para quadros consecutivos modelados por um ARG-inter representante de 1 quadro (coluna à esquerda), 3 quadros (coluna central) e 5 (coluna à direita) quadros correspondentes. 


\subsubsection{Brinquedo de corda}

Esta segunda seqüência de imagens real apresenta um brinquedo de corda em movimento sobre um fundo fixo, porém bastante diversificado, com texturas e outros objetos diversos. Em cada um dos 410 quadros do vídeo adquirido com uma câmera digital em resolução de $480 \times 320$, deseja-se rastrear o brinquedo caracterizado por uma gansa e classificar suas partes constituintes: bico, cabeça, corpo, asa e patas.

CONFIGURAção. A figura 27 (a) denota a imagem de referência utilizada como base para criação da máscara modelo (fig. 27 (b)) e que, juntamente com a versão rotulada dessa última (fig. 27 (c)), originou o ARG-modelo com 5 vértices e 8 arestas utilizado na classificação (fig. 16 (d)). Já os ARGs-intra gerados foram compostos, em média, por 65 vértices e por 275 arestas, com variações dependendo da segmentação obtida em cada quadro.

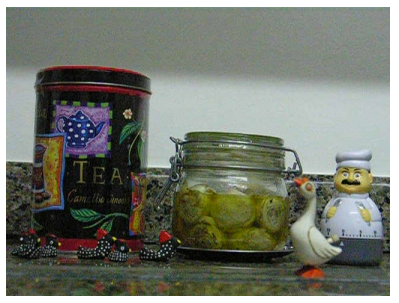

(a)

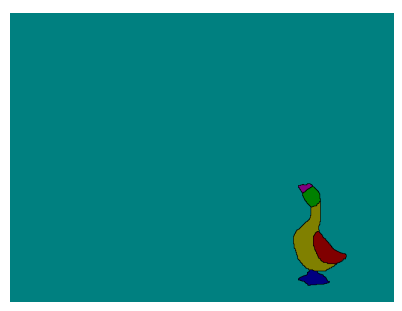

(c)

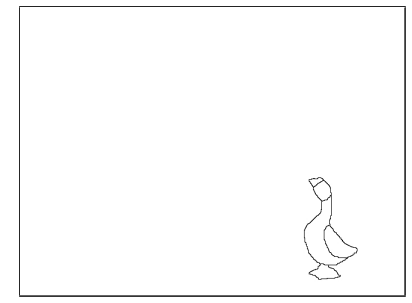

(b)

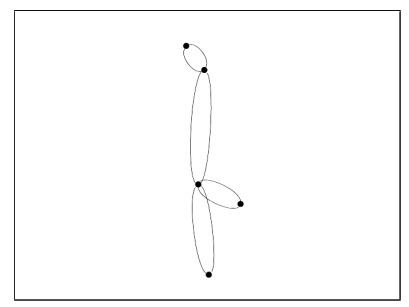

(d)

Figura 27. Imagem de referência (a); máscara modelo binária (b); máscara modelo rotulada (c) e ARG-modelo resultante (d)

Para segmentar os pixels relativos à gansa num certo quadro, adotou-se um algoritmo de detecção de movimento baseado em remoção de fundo (seção 3.4), já que esse é estático. Assim, subtraindo-se de cada quadro uma imagem representante do fundo, uma nova imagem foi criada em que pixels válidos assumiam o valor 


\begin{tabular}{|c|c|c|}
\hline TIPO & ATRIBUTO & PESO \\
\hline \multirow[t]{2}{*}{ Objeto } & Centróide & 0.985 \\
\hline & Nível de cinza médio & 0.015 \\
\hline \multirow[t]{2}{*}{ Estrutural } & Módulo do vetor & 0.5 \\
\hline & Ângulo do vetor & 0.5 \\
\hline
\end{tabular}

Tabela 4. Seqüência real 2: pesos adotados para cada atributo.

respectivo no quadro corrente, enquanto pixels de fundo correspondiam ao valor 0 .

A seguir, foram aplicadas, consecutivamente, as técnicas de suavização gaussiana, de abertura e fechamento, e do gradiente morfológico. O resultado desses passos foi, então, utilizado como entrada para o algoritmo de watershed, originando um ARGintra de entrada para cada quadro. Neste caso, também, vértices representantes de regiões com número de pixels menores do que 2 foram fundidos a vértices vizinhos que apresentavam maior similaridade em termos de níveis de cinza.

Finalmente, um ARG-inter foi constituído de $n$ ARGs de entrada, $n$ definido previamente, e submetido ao processo de classificação. A distância máxima $\epsilon$ entre vértices conectados por arestas temporais utilizada foi 1.5. Quanto aos parâmetros escolhidos para definição das parcelas da função custo, foi dedicado um maior peso ao custo dos nós (0.95) em detrimento do custo dos arcos (0.05). Os custos adotados para cada atributo são apresentados na tabela 4 .

Para ilustrar alguns testes típicos, a figura 28 apresenta um subconjunto de quadros resultantes e seus respectivos objetos classificados e rastreados sem o uso de atributos temporais, enquanto as figuras 29 e 30 são classificações obtidas para ARGs-inter compostos por $n=3$ e $n=5$ quadros, respectivamente. O processamento de todos os quadros do vídeo consumiu 78 minutos nos casos em que $n=1$ quadro e $n=3$ quadros, enquanto o tempo total gasto adotando-se $n=5$ quadros foi de 73 minutos.

Segundo esses resultados, é possível notar, novamente, que a inclusão de atributos temporais favorece classificações mais uniformes entre quadros consecutivos e mais precisas em relação ao modelo em cada quadro, preservando as relações de adjacência entre as partes e a estrutura global na maioria dos casos. 


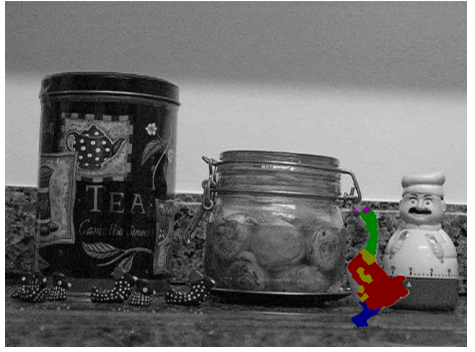

(a)

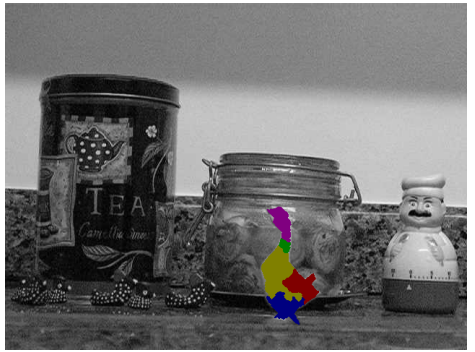

(d)

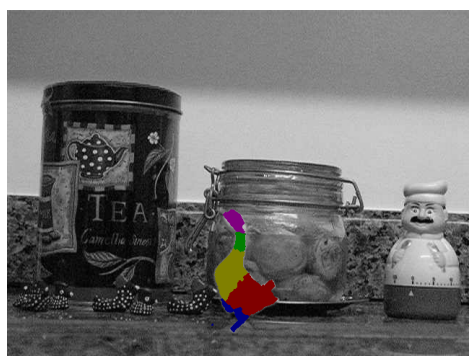

(g)

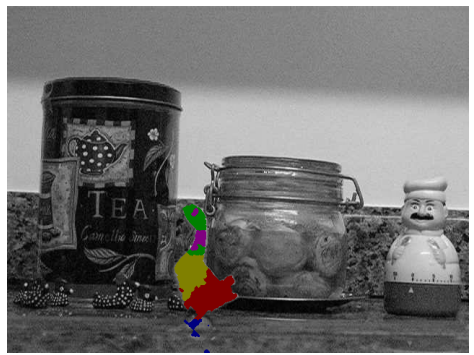

(j)

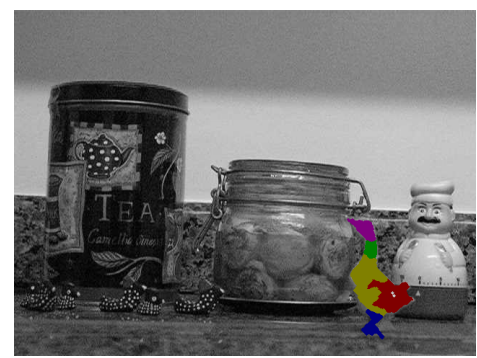

(b)

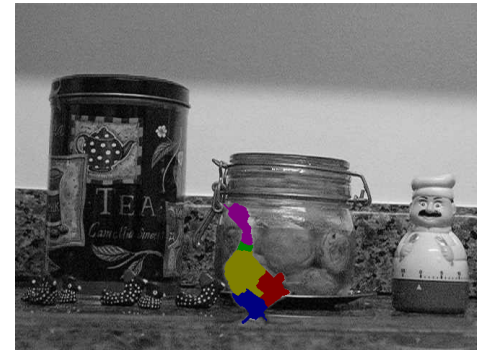

(e)

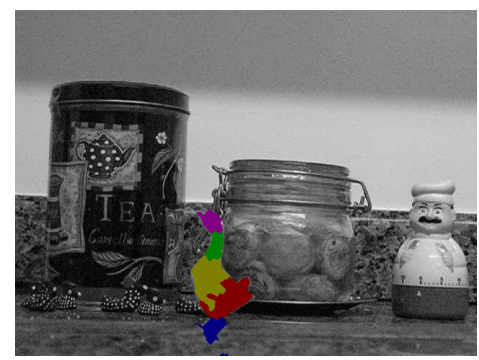

(h)

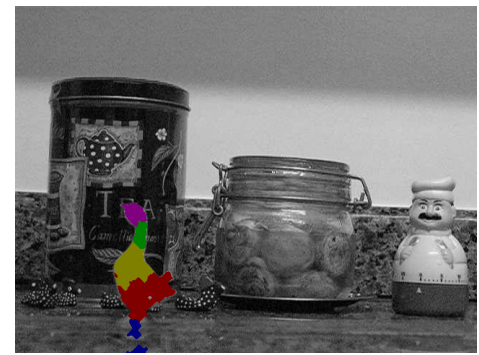

$(\mathrm{k})$

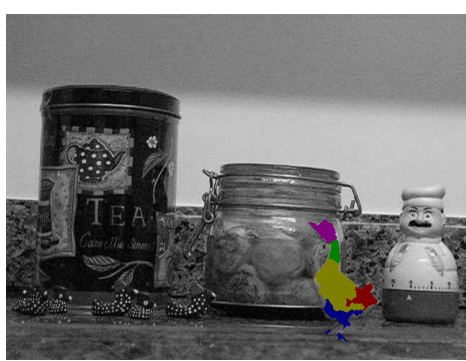

(c)

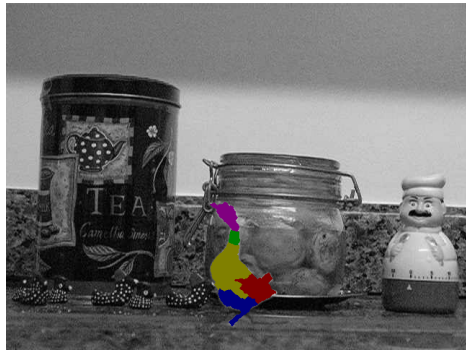

(f)

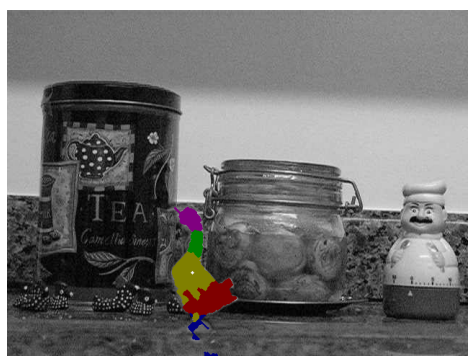

(i)

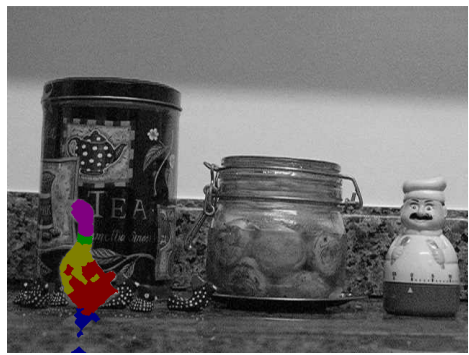

(l)

Figura 28. Seqüência real 2 - testes sem atributos temporais. 


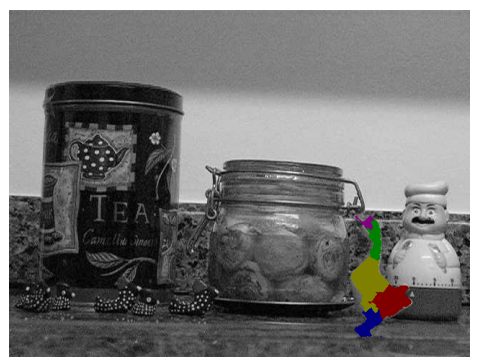

(a)

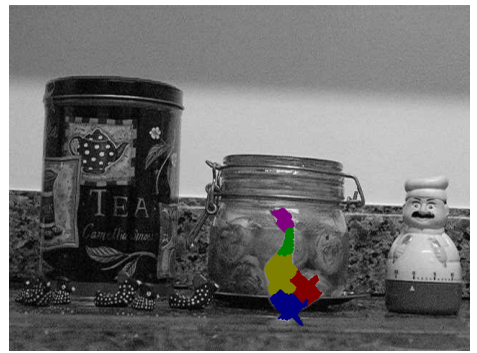

(d)

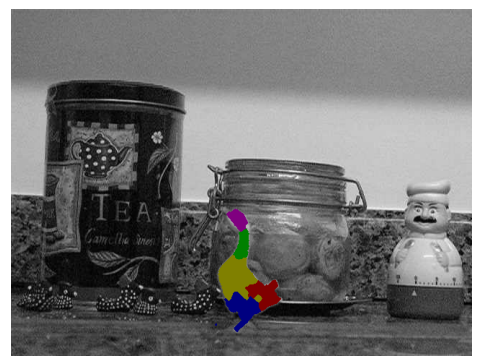

(g)

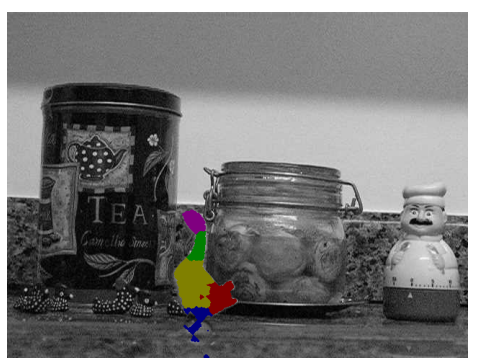

(j)

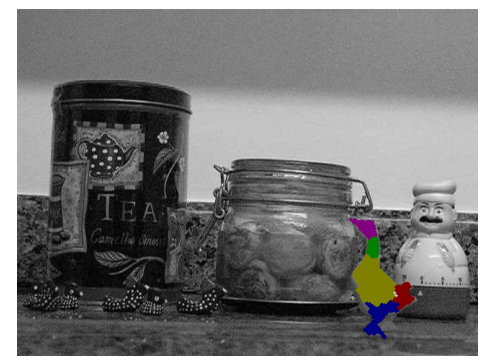

(b)

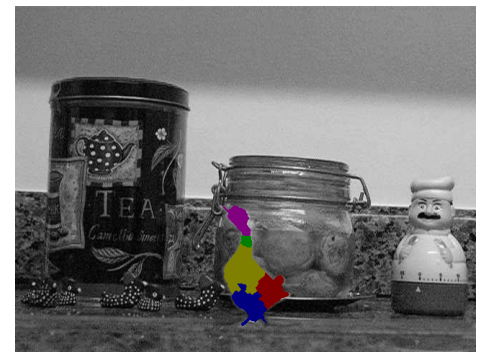

(e)

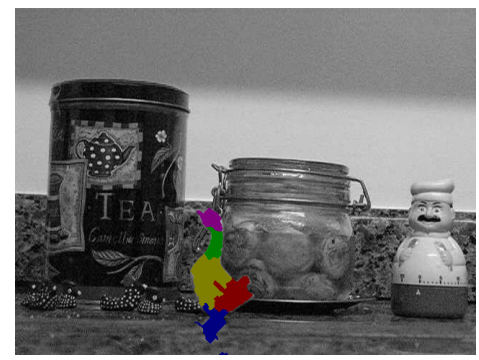

(h)

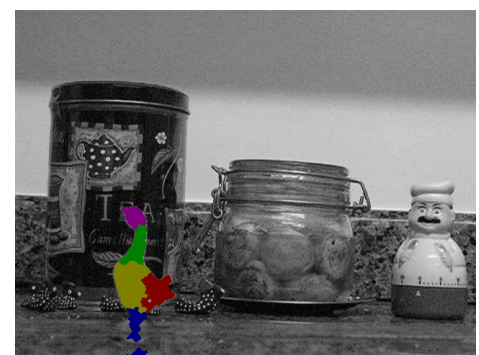

$(\mathrm{k})$

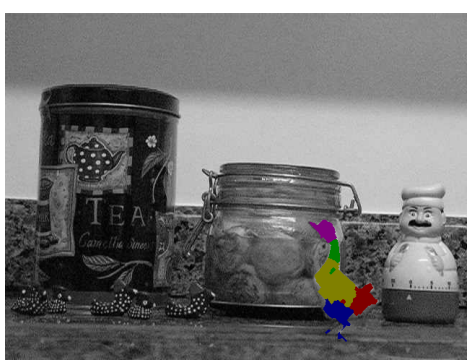

(c)

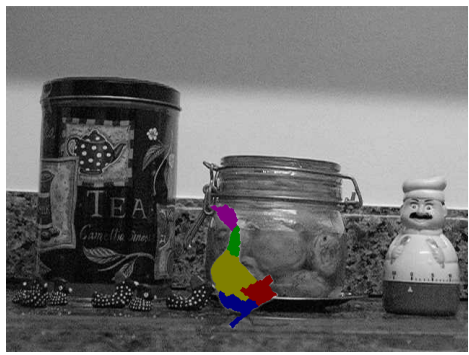

(f)

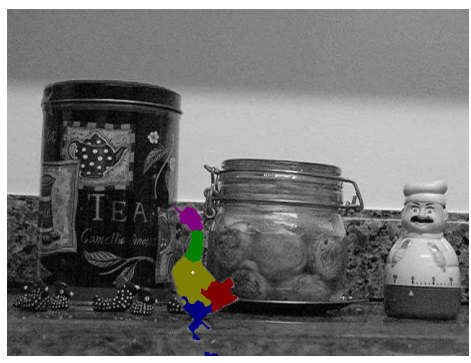

(i)

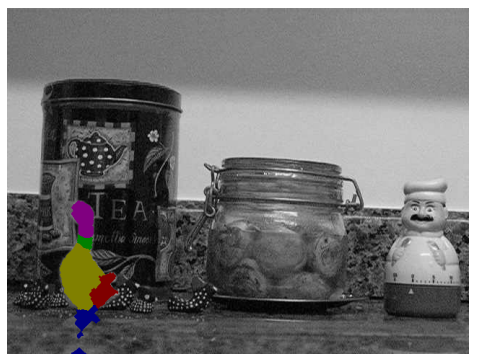

(1)

Figura 29. Seqüência real 2 - testes com ARG-inter composto por vértices e arestas extraídos de 3 quadros do vídeo. 


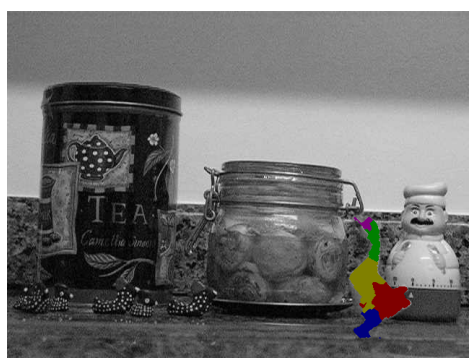

(a)

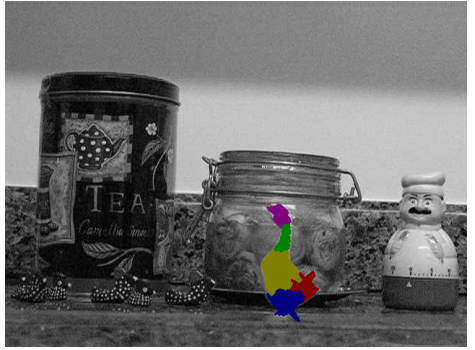

(d)

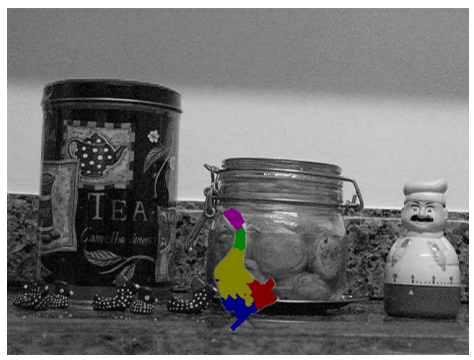

(g)

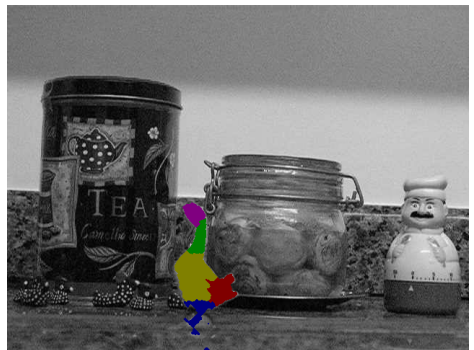

(j)

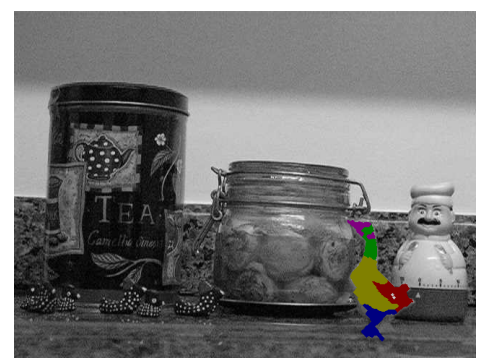

(b)

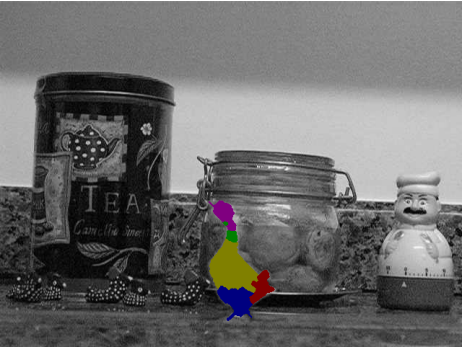

(e)

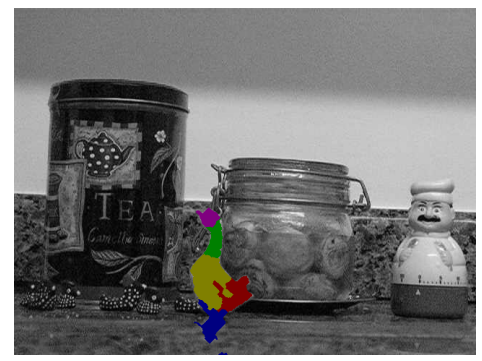

(h)

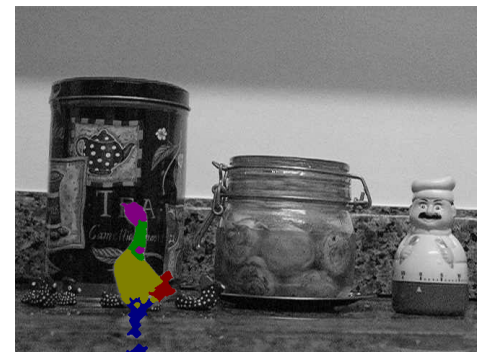

(k)

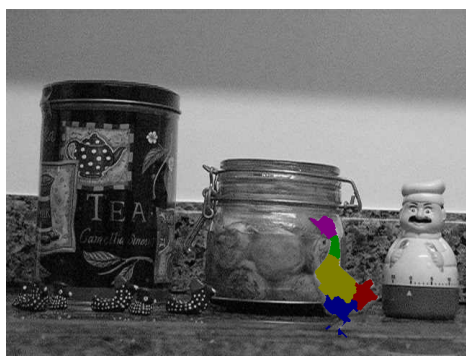

(c)

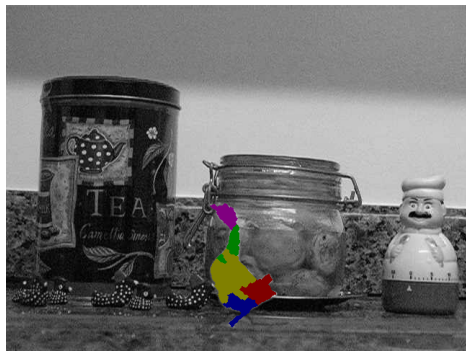

(f)

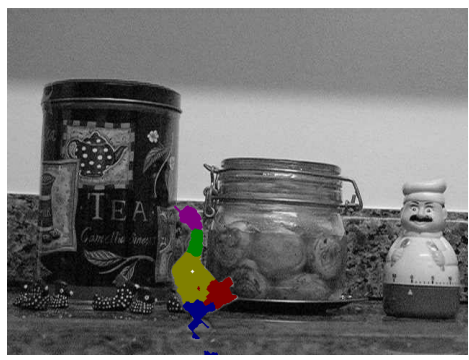

(i)

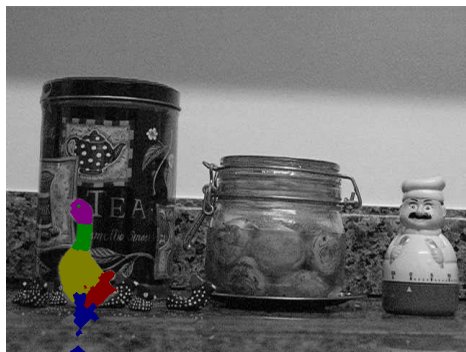

(1)

Figura 30. Seqüência real 2 - testes com ARG-inter composto por vértices e arestas extraídos de 5 quadros do vídeo. 


\subsection{COMENTÁRIOS ADICIONAIS}

Os testes apresentados na seção anterior indicam que a utilização de um ARG-inter construído com base em $n>1$ quadros produz resultados mais precisos quanto à manutenção da coerência espaço-temporal no reconhecimento e rastreamento de objetos em vídeo digital. Portanto, a relevância das arestas temporais incorporadas à estrutura de um ARG fica evidente.

Foi possível perceber também que a natureza das transformações aplicadas sobre um dado objeto afeta o reconhecimento e o rastreamento produzidos, mas, ao mesmo tempo, não restringe o uso da metodologia a deformações regidas por transformações afins.

Faz-se necessário, ainda, ressaltar outros dois fatores que podem ocasionar erros ou diferenças entre classificações: o papel desempenhado em conjunto pelos atributos relacional e estrutural, bem como a relação entre uma classificação e o particionamento gerado pelo algoritmo de watershed.

Atributos E CLASSificação. A escolha pelo uso de diferentes tipos de atributos permite incorporar uma vasta gama de características a respeito dos objetos de interesse. Por isso, o uso conjunto desses atributos em detrimento do uso de um ou outro individualmente resulta num processo de reconhecimento mais abrangente para tratar seqüências de imagens diversas, principalmente quando uma determinada característica ou categoria de atributo não apresenta caráter discriminante.

Para exemplificar, as figuras 31 (a) e 31 (b) apresentam resultados de reconhecimento e rastreamento baseados apenas em atributos de objeto e relacionais, respectivamente. No primeiro caso, como os níveis de cinza dos objetos são semelhantes, o método se confunde na classificação. Já no segundo caso, os erros se devem ao favorecimento da atribuição de rótulos semelhantes a regiões adjacentes.

PARTICIONAMENTO E CLASSIFICAÇÃo. As regiões reconhecidas estão intrinsecamente ligadas ao particionamento obtido pelo algoritmo de watershed. Embora regiões correspondentes possam ser igualmente classificadas em quadros consecutivos, a forma de tais regiões pode ser bastante variada devido à sensibilidade do algoritmo de watershed.

Outra decorrência importante dessa relação entre partições e classificação é re- 


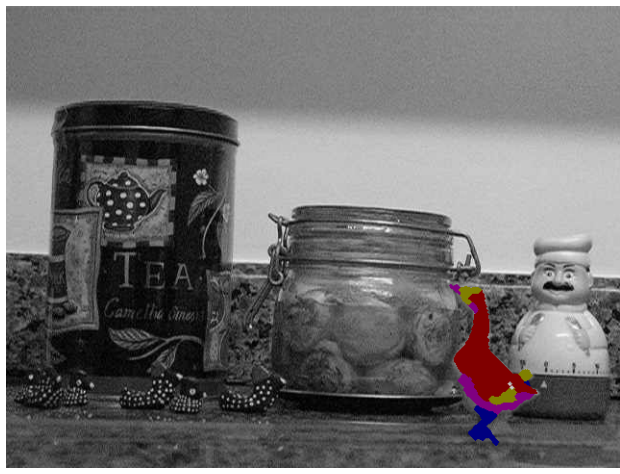

(a)

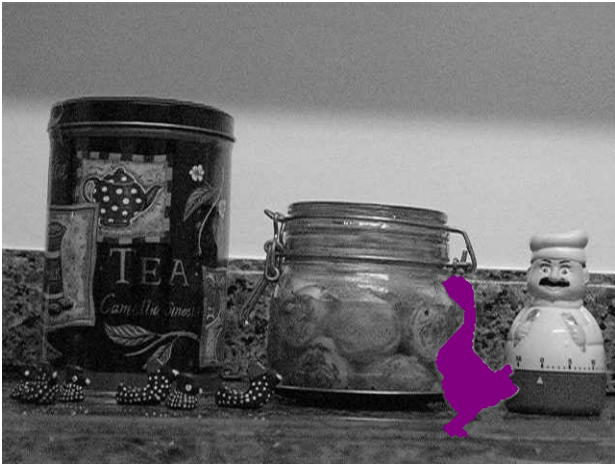

(b)

Figura 31. Reconhecimento derivado da consideração de atributos de objeto apenas (a) e de atributos relacionais apenas (b).

fletida no custo dos nós considerado pela função custo. Como o particionamento pelo algoritmo de watershed gera uma supersegmentação dos objetos (fig. 32 (a)), os atributos das arestas induzidas nos ARGs que representam esses objetos mostram-se bastante diferentes daqueles calculados para as arestas no ARG-modelo (fig. 32 (b)).

Portanto, a comparação entre arestas de um ARG-inter e do ARG-modelo está sujeita a essas diferenças, influenciando as classificações finais das regiões e justificando os baixos pesos escolhidos para os atributos relacionais comparativamente aos de objeto. Mesmo assim, como discutido anteriormente, a consideração desses atributos é relevante e os torna indispensáveis no cômputo de uma solução.

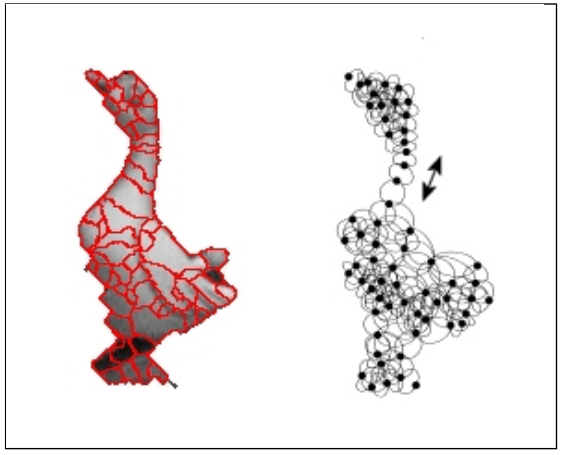

(a)

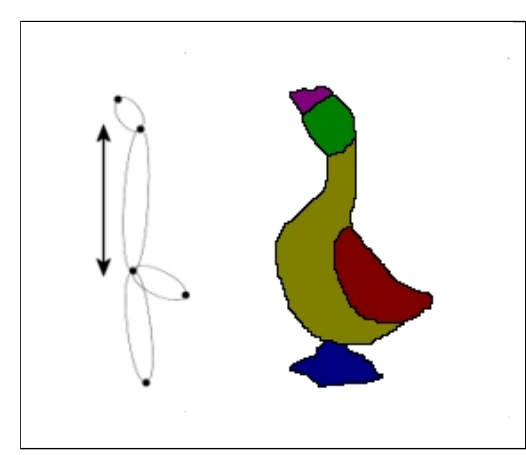

(b)

Figura 32. Imagem particionada pelo algoritmo de watershed e estrutura do respectivo ARG-intra (a); máscara modelo rotulada e respectivo ARG-modelo (b). 



\section{CONCLUSÃO}

Experiência não é o que acontece

a um homem, mas sim o que um homem aprende com o que acontece a ele.

- Aldous Huxley, em Textos e Pretextos, 1932

\subsection{CONSIDERAÇÕES FINAIS}

Esta dissertação teve por objetivo o estudo de técnicas para representação, classificação e rastreamento de objetos em seqüências de imagens através de grafos relacionais com atributos. A reunião dessas diversas técnicas culminou no desenvolvimento de uma metodologia para reconhecer objetos em vídeo digital, seguindo o paradigma baseado em modelos de objetos descritos por partes.

O propósito almejado constituiu um desafio considerável, posto que um sistema computacional para reconhecimento de objetos envolve uma série de etapas freqüentemente interdependentes e solucionadas através da junção de conhecimentos oriundos de processamento de imagens, visão computacional, reconhecimento de padrões, dentre outras áreas.

Além disso, agregavam-se a esses fatores as dificuldades inerentes ao processamento de seqüências de imagens, causadas pela introdução do aspecto de temporalidade, tais como deformações dos objetos, oclusões, não-uniformidade de iluminação e manutenção de coerência espaço-temporal ao longo dos quadros.

Contudo, a adoção da estrutura de grafos relacionais com atributos para descrever objetos mostrou-se bastante adequada e permitiu que diferentes tipos de informações fossem utilizados ao longo das etapas do sistema de reconhecimento, incluindo restrições de caráter temporal. 
Ainda, a interpretação da etapa de classificação como um problema de casamento inexato entre grafos possibilitou uma maior flexibilidade na metodologia para tratar discrepâncias entre o modelo e o conteúdo da seqüência de imagens, particularmente ao longo do tempo e com a evolução do modelo.

Esses dois aspectos importantes puderam ser constatados através dos testes realizados para validar a metodologia, aplicados a vídeos digitais sintéticos e reais, cujo conteúdo representava objetos rígidos (brinquedo de corda e rosto) ou deformáveis (mãos e rosto) sobre fundos estáticos mas com propriedades distintas.

\subsection{CONTRIBUIÇÕES}

De maneira sucinta, é possível agrupar as principais contribuições deste trabalho dentro das seguintes etapas de um sistema de reconhecimento de objetos: representação e descrição de imagens ou objetos, classificação (ou reconhecimento) e rastreamento de objetos.

Em primeiro lugar, a utilização do conceito de grafo relacional com atributos permitiu efetivamente a incorporação de inúmeros descritores de objetos e de suas relações na representação dos mesmos, além de sua adequação à modelagem de objetos em função de suas partes. Particularmente, a introdução da formulação de um ARG-inter quadros possibilitou a extensão e aplicação de ARGs no tratamento de vídeo digital, comportando características relacionadas à dimensão do tempo.

Essa nova formulação, aliada às alterações propostas para a expansão da árvore criada no algoritmo de busca heurística durante o processo de classificação, permitiu alcançar uma das metas da metodologia: a manutenção da coerência espaço-temporal dos rótulos atribuídos a uma mesma região semântica ao longo do tempo, como discutido no capítulo 4 .

Por fim, a tarefa de rastreamento foi atingida através da atualização do atributo de centróide dos vértices do ARG-modelo, renovados de acordo com a aplicação de uma transformação afim calculada com base nas classificações encontradas para os vértices do ARG-inter. Portanto, o próprio processo de classificação serviu para alimentar o ARG-modelo e evoluí-lo ao longo da seqüência de imagens.

IMPLEMENTAÇÃo. Além da contribuição teórica deste trabalho de mestrado, é importante destacar também sua implementação em C++ com auxílio das ferramen- 
tas disponibilizadas pela biblioteca OpenCV sob licença de código aberto. Todo o arcabouço de estruturas de dados, algoritmos e manipulação de vídeo digital, poderá ainda ser reaproveitado e expandido na continuidade dos estudos envolvendo esta metodologia.

ARtigos. Por fim, duas publicações resultantes da etapa inicial de desenvolvimento deste projeto encontram-se anexadas ao presente documento e podem também ser consultadas pela rede de acordo com as seguintes referências:

A. Homomorfismo entre grafos para segmentação e reconhecimento de características faciais em sequências de vídeo: Resultados preliminares [19], SIBGRAPI, 2003.

в. Inexact Graph Matching for Facial Feature Segmentation and Recognition in Video Sequences: Results on Face Tracking [20], CIARP, 2003.

\section{$5 \cdot 3$ TRABALHOS FUTUROS}

Como mencionado anteriormente, o desempenho global e o resultado final de um sistema de reconhecimento de objetos podem ser alterados ora devido à possível interdependência dos resultados de suas fases intermediárias, ora pela escolha do conjunto de características ou atributos que define o modelo e que será comparado aos dados de entrada, dentre tantos outros fatores.

Em vista dessa observação, a análise dos testes efetuados sobre a metodologia aqui introduzida e limitações encontradas ao longo do seu desenvolvimento apontaram alguns pontos passíveis de serem explorados. Logo, certas propostas de aprofundamento, modificações ou inserções na metodologia sugerem torná-la mais robusta e mais eficiente em determinadas situações.

REPRESENTAÇÃo dos objetos. Embora os atributos de objeto, relacionais e temporais escolhidos (centróide, nível de cinza médio, vetor entre centróides, etc.) na composição dos grafos relacionais com atributos sejam simples, genéricos e tenham se mostrado eficazes para validação da metodologia, outras características podem ser incorporadas, tais como medidas de formas e de similaridade [6], de textura e, principalmente, informações a respeito de cor (RGB, HSI, etc.).

Simultaneamente, há o interesse em se aplicar os conceitos de ARGs-intra e ARGs- 
inter na representação de seqüências de imagens 3D, já que a estrutura de grafos relacionais com atributos é naturalmente extensível e adequada para modelar objetos tridimensionais. Com uma tal representação, seria também investigada a validade da metodologia no tratamento dessa classe de vídeo digital.

MODELO. De acordo com a seção 3.2.2, o ARG modelo adotado para uma determinada seqüência de imagens é construído com base no primeiro quadro em que o objeto de interesse esteja presente e numa máscara modelo derivada manualmente desse quadro.

Portanto, os objetos de interesse, suas partes constituintes, os atributos calculados e a estrutura depreendida estão diretamente ligados à visão da cena capturada nesse quadro 2D. Porém, essa visão pode não ser suficiente para descrever completamente as características tridimensionais dos objetos em questão que possam aflorar nos demais quadros do vídeo. Essa limitação seria reduzida com a introdução de dados 3D na composição dos ARGs, assim como proposto no parágrafo a respeito de representação de objetos.

Um outro fator envolvendo o modelo refere-se à criação da máscara modelo. Embora sua obtenção manual seja simples, a automação desse processo seria de grande valia para o sistema de reconhecimento de objetos, pois reduziria a necessidade de intervenção humana na metodologia.

PROCESSO DE CLASSIFICAÇÃ̃o. Esta etapa fundamental da metodologia aponta uma série de tópicos cujo estudo pode trazer ganhos significativos em termos de qualidade de resultados e performance computacional.

Primeiramente, a função-custo projetada para guiar a expansão dos nós da árvore de busca heurística apóia-se na média ponderada de duas parcelas representantes do custo acumulado dos mapeamentos de vértices e arestas considerados num certo caminho da árvore. Cada uma dessas parcelas é também subdividida de acordo com os atributos que a compõem, os quais também possuem pesos associados. Esses pesos atribuídos a parcelas e a atributos são definidos intuitivamente na fase de configuração do sistema de reconhecimento de objetos e permanecem os mesmos ao longo de todo o vídeo.

No entanto, seria interessante que esses pesos fossem escolhidos automaticamente e de maneira adaptativa. Essa modificação permitiria que vértices pertencentes a 
vizinhanças mais homogêneas em relação aos atributos de objeto contribuíssem mais com seus atributos relacionais, ou vértices representantes de regiões de fronteira contribuíssem mais com seus atributos de objetos, dentre outras situações.

Um outro ponto relevante está relacionado ao cálculo da parcela referente às arestas consideradas num caminho da árvore. Como o algoritmo de watershed produz uma segmentação dos objetos em partes muito menores do que aquelas que constituem o modelo, os vetores entre os centróides de vértices adjacentes no ARG-inter tendem a ser bem menores, em módulo, do que os vetores entre centróides de vértices adjacentes no ARG-modelo.

Portanto, seria mais coerente comparar o vetor entre dois vértices do ARG-modelo com um vetor entre o centróide resultante de um conjunto de vértices já rotulados e um dado vértice em expansão do ARG-inter, pois, assim, compararíamos arestas com grau crescente de semelhança. Essa alteração ocasionaria mudanças também na estrutura de dados de armazenamento da árvore de busca, para facilitar o acesso às regiões classificadas com um mesmo rótulo.

Ainda, a busca por uma solução para cada conjunto de $n$ quadros consecutivos é realizada sem qualquer informação adicional proveniente de soluções encontradas previamente. No entanto, tal informação poderia ser aplicada ao algoritmo de busca, guiando a nova solução procurada e possivelmente reduzindo o espaço de busca e tempo de convergência do algoritmo.

Porém, incorporar informações prévias na busca de novas classificações não é uma tarefa trivial, pois dificilmente os vértices criados para um dado ARG-inter coincidirão com os que derivaram de um segundo ARG-inter, dificultando o aproveitamento de soluções.

Um último aspecto a ser explorado consiste na realização de uma espécie de pósprocessamento sobre a solução determinada pelo algoritmo de busca heurística. A utilidade dessa operação torna-se evidente ao considerarmos que a segmentação dos objetos na etapa de watershed pode gerar regiões não necessariamente pertencentes aos objetos, ou seja, pixels do fundo podem ser selecionados, gerando vértices no ARG-inter.

Desse modo, o pós-processamento removeria vértices desse grafo, calcularia uma nova solução e, se o custo final da mesma diminuísse, os vértices eliminados seriam desconsiderados permanentemente. Tal procedimento permitiria, então, uma classificação mais acurada apenas dos elementos do ARG-inter representantes de regiões 
de objetos verdadeiras.

processo de rastreamento. Como os parâmetros para a atualização da posição dos vértices do ARG modelo são obtidos da etapa de classificação, o processo de rastreamento está ligado à solução encontrada a cada rodada da metodologia.

Quando o número de quadros representados pelos componentes do ARG-inter é igual a 1, o calculo dos parâmetros é trivial, como descrito na seção 3.7. Porém, se $n>1$, então surgem novas possibilidades além do cálculo da média aritmética.

Para exemplificar, considere um ARG-inter $G_{\text {inter }}$ construído a partir de n ARGsintra $G_{1}, \ldots, G_{n}$. Para que os parâmetros de atualização estejam mais próximos das posições dos objetos no quadro referente a $G_{n}$, é interessante considerar as posições dos vértices de $G_{\text {inter }}$ oriundos desse $A R G$-intra como sendo a melhor aproximação para os objetos que serão encontrados no quadro seguinte.

Assim, é razoável adotar apenas os centróides desses vértices no cálculo dos parâmetros de atualização de posição. Numa versão mais tolerante, porém, a adoção de uma média ponderada em que o maior peso é atribuído aos vértices de $G_{n}$ também seria possível.

ReCURsos computacionais. Finalmente, seria desejável reduzir o tempo de processamento da metodologia sobre uma seqüência de vídeo para que ela seja apropriada ao uso em aplicações que exigem resultados em tempo real. Alcançar esta meta, contudo, está intrinsecamente ligado a melhorias no desempenho computacional do algoritmo de busca heurística ou na adoção de simplificações sobre este. 
ÍNDICE REMISSIVO

Casamento entre grafos, 8, 23

exato, 24

algoritmos, 25

inexato, 26

algoritmos, 26-28, 57

função custo, 63

Diagrama de Voronoi, 16

Distância, 15

chessboard, 15

cityblock, 15

euclidiana, 15

Gradiente morfológico, 42

Grafo, 9

aplicações, 9

definições, 11

derivado de imagens, 15

árvore geradora mínima, 17

de adjacência de regiões, 19

distância máxima, 15

Gabriel, 16

k-vizinhos mais próximos, 15

vizinhança relativa, 16

vizinhos do baricentro, 15

homomorfismo, 25, 56

isomorfismo, 24

monomorfismo, 25

Grafo relacional com atributos, 7, 23, 34 inter-quadros, 7, 52

atributos, 52

implementação, 53

intra-quadros, 7, 45

atributos, 45

implementação, 49

Imagem digital, 13

amostragem, 13

quantização, 13

representação de objetos em, 13, 35

Objeto, 34

parte, 34

Operações morfológicas, 41

Reconhecimento de objetos, 2

baseado em modelo, 4, 55

baseado em partes, 4

em vídeo digital, veja Vídeo digital

sistemas de, 2

Reconhecimento de Padrões, 20

estatístico, 20

estrutural ou sintático, 21, 22

grafos, veja Casamento entre grafos

redes neurais, 21

Segmentação de imagens

algoritmo de watershed, veja Watershed 
102 Índice Remissivo

limiarização, 43

remoção de fundo, 42

Seqüências de imagens, veja Vídeo digital

Sistemas de visão computacional, I grafos em, 28

Suavização Gaussiana, 41

Transformação afim, 66

Triangulação de Delaunay, 16

Vídeo digital

conceito, 33

definição, 34

detecção de movimento em, 5

rastreamento de objetos em, 5, 33,

65

Vizinhança de um pixel

4-vizinhança, 19

8-vizinhança, 19

Watershed

algoritmo, 18 


\section{REFERÊNCIAS BIBLIOGRÁFICAS}

[1] S. Beucher e F. Meyer. The morphological approach to segmentation: The watershed transform. Em E. R. Dougherty, editor, Mathematical Morphology in Image Processing, capítulo 12, páginas 433-481. Marcel Dekker Inc., 1993. (Citado na página 18.)

[2] J. D. Boissonnat e M. Yvinec. Géométrie Algorithmique. Ediscience International, 1995. (Citado nas páginas 16 e 17.)

[3] H. Bunke. Recent developments in graph matching. Em ICPR, páginas 21172124, 2000. (Citado na página 26.)

[4] H. Bunke. Graph matching: Theoretical foundations, algorithms, and applications. Em Proceedings of Vision Interface 2000, Montreal, páginas 82-88, 2000. (Citado nas páginas 10 e 26.)

[5] M. A. Carvalho e R. Lotufo. Hierarchical regions matching in image sequences through association graph. Em 140. Simpósio Brasileiro de Computação Gráfica e Processamento de Imagens - Sibgrapi'01, página 396, 2001. (Citado na página 29.)

[6] R. M. Cesar-Jr. e L. da F. Costa. Shape Analysis and Classification - Theory and Practice. CRC Press, 1a. edição, 2001. (Citado nas páginas 14, 40, 41, 42, 66 e 97.)

[7] R. M. Cesar-Jr, E. Bengoetxea, e I. Bloch. Inexact graph matching using stochastic optimization techniques for facial feature recognition. Em ICPR (2), páginas 465-468, 2002. (Citado na página 28.)

[8] R. M. Cesar-Jr, E. Bengoetxea, P. Larranaga, e I. Bloch. Inexact graph matching for model-based recognition: Evaluation and comparison of optimization algorithms. Pattern Recognition, 38(11):2099-2113, Novembro 2005. (Citado nas páginas $19,27,28,29,57,58$ e 59.)

[9] D. Conte, P. Foggia, C. Sansone, e M. Vento. Graph matching applications in pattern recognition and image processing. Em ICIP (2), páginas 21-24, 2003. (Citado nas páginas 10, 24 e 27.) 
[10] D. Conte, P. Foggia, C. Sansone, e M. Vento. Thirty years of graph matching in pattern recognition. IJPRAI, 18(3):265-298, 2004. (Citado nas páginas 24 e 27.)

[11] T. H. Cormen, C. E. Leiserson, R. L. Rivest, e C. Stein. Introduction to Algorithms. The MIT Press, 2a. edição, 2001. (Citado na página 58.)

[12] R. Cucchiara, C. Grana, M. Piccardi, e A. Prati. Detecting moving objects, ghosts and shadows in video streams. IEEE Transactions on Pattern Analysis and Machine Intelligence, 25(10):1337-1342, 2003. (Citado na página 43.)

[13] S. J. Dickinson, A. Shokoufandeh, Y. Keselman, M. Fatih Demirci, e D. Macrini. Object categorization and the need for many-to-many matching. Em DAGMSymposium, páginas 501-510, 2005. (Citado na página 10.)

[14] E. Dougherty e R. A. Lotufo. Hands-on Morphological Image Processing. SPIEInternational Society for Optical Engineering, 2003. (Citado na página 4.)

[15] R. O. Duda, P. E. Hart, e D. G. Stork. Pattern Classification. John Wiley \& Sons, 2001. (Citado nas páginas 20 e 21.)

[16] P. F. Felzenszwalb. Representation and detection of deformable shapes. IEEE Transactions on Pattern Analysis and Machine Intelligence, 27(2):208-220, 2005. ISSN 0162-8828. (Citado na página 10.)

[17] R. C. Gonzalez e R. E. Woods. Digital Image Processing. Addison-Wesley Publishing Company, 1a. edição, 1993. (Citado nas páginas 3, 40, 41 e 42.)

[18] R. C. Gonzalez e R. E. Woods. Digital Image Processing. Prentice Hall, 2a. edição, 2002. (Citado nas páginas $21 \mathrm{e} 42$.

[19] A. B. V. Graciano, R. M. Cesar-Jr., e I. Bloch. Homomorfismo entre grafos para segmentação e reconhecimento de características faciais em sequências de vídeo: Resultados preliminares. Em II Workshop de Teses e Dissertações em Computação Gráfica e Processamento de Imagens, CD-ROM - 16o. Simpósio Brasileiro de Computação Gráfica e Processamento de Imagens - Sibgrapi’03, 2003. (Citado na página 97.)

[20] A.B.V. Graciano, R.M. Cesar-Jr., e I. Bloch. Inexact graph matching for facial feature segmentation and recognition in video sequences: results on face tracking. 
Em CIARP, volume 2905 de Lecture Notes in Computer Science, páginas 71-78. Springer-Verlag, 2003. (Citado na página 97.)

[21] S. Haykin. Neural Networks: A Comprehensive Foundation. Prentice Hall, 2a. edição, 1998. (Citado na página 21.)

[22] A. K. Jain, R. Duin, e J. Mao. Statistical pattern recognition: a review. IEEE Transactions on Pattern Analysis and Machine Intelligence, 22(1):4-37, 2000. (Citado na página 20.)

[23] R. Jain, R. Kasturi, e B. G. Schunck. Machine vision. McGraw-Hill, Inc., 1995. (Citado nas páginas 2 e 42.)

[24] S.N. Efstratiadis K. Haris e N. Maglaveras. Hierarchical image segmentation based on contour dynamics. Em Proceedings of the 2001 International Conference on Image Processing, páginas 54-57, Thessaloniki, Grécia, Outubro 2001. (Citado na página 19.)

[25] D. Kim, I. Yun, e S. Lee. A comparative study on attributed relational graph matching algorithms for perceptual 3D shape descriptor in mpeg-7. Em XII ACM International Conference on Multimedia, 2004. (Citado na página 29.)

[26] T. Y. Kong e A. Rosenfeld. Digital topology: Introduction and survey. Computer Vision, Graphics and Image Processing, 48:357-393, 1989. (Citado na página 10.)

[27] S. M. Kosslyn. Visual mental images as re-presentations of the world: A cognitive neuroscience approach. Em J. S. Gero e B. Tversky, editores, Visual and Spatial Reasoning in Design 99. KCDC, Key Centre of Design Computing and Cognition, University of Sydney, 1999. (Citado na página 1.)

[28] N. J. Nilsson. Artificial Intelligence: A New Synthesis. Morgan Kaufmann Publishers, 1998. (Citado na página 25.)

[29] R. M. Cesar-Jr. O. Colliot, A. V. Tuzikov e I. Bloch. Approximate reflectional symmetries of fuzzy objects with an application in model-based object recognition. Fuzzy Sets and Systems, 147(1):141-163, Outubro 2004. (Citado na página 47.)

[30] T. Pavlidis. Structural Pattern Recognition. Springer, 1980. (Citado nas páginas 21 e 22.) 
[31] J. B. T. M. Roerdink e A. Meijster. The watershed transform: Definitions, algorithms and parallelization strategies. FUNDINF: Fundamenta Informaticae, 41:187-228, 2000. (Citado na página 18.)

[32] S. Russell e P. Norvig. Artificial Intelligence: A Modern Approach. Artificial Intelligence. Prentice Hall, Englewood Cliffs, New Jersey, 1995. (Citado na página 25.)

[33] G. Economou S. Makrogiannis e S. Fotopoulos. A graph theory approach for automatic segmentation of color images. Em International Workshop on Very Low Bit-rate Video, páginas 162-166, 2001. (Citado na página 19.)

[34] T. Saxena, P. Tu, e R. Hartley. Recognizing objects in cluttered images using subgraph isomorphism. Em DARPA Image Understanding Workshop, IUW 98, páginas 875-882, 1999. (Citado na página 28.)

[35] R. J. Schalkoff. Pattern Recognition: statistical, structural and neural approaches. John Wiley \& Sons, 1992. (Citado nas páginas 20, 21 e 22.)

[36] J. Serra. Image Analysis and Mathematical Morphology, volume 2 of Computational Imaging and Vision. Academic Press, 1997. (Citado nas páginas 10, 14, 41 e 42.)

[37] A. Trémeau e P. Colantoni. Regions adjacency graph applied to color image segmentation. IEEE Transactions on Image Processing, 9(4):735-744, 2000. (Citado na página 19.)

[38] L. Velho e J. Gomes. Fundamentos da Computação Gráfica. IMPA, 2003. (Citado na página 34.)

[39] L. Velho e J. Gomes. Sistemas Gráficos 3D. IMPA, 2001. (Citado na página 34.)

[40] L. Vincent. Graphs and mathematical morphology. Signal Processing, 16:365-388, 1989. (Citado nas páginas 10, 15, 16 e 17.)

[41] L. Vincent. Algorithmes Morphologiques à Base de Files d'Attente et de Lacets. Extension aux Graphes. Tese de doutorado, École Nationale Supérieure des Mines de Paris, 1990. (Citado nas páginas 10 e 15.) 
[42] L. Vincent e P. Soille. Watersheds in digital spaces: An efficient algorithm based on immersion simulations. IEEE Transactions on Pattern Analysis and Machine Intelligence., 13(6):583-598, 1991. (Citado nas páginas 18 e 44.)

[43] L. Vincent, P. Nacken, A. Toet, e H. J. A. M. Heijmans. Graph morphology. Journal of Visual Communications e Image Representation, 3(1):24-38, 1992. (Citado na página 14.)

[44] Z. Wu e R. Leahy. An optimal graph theoretic approach to data clustering: theory and application to image segmentation. IEEE Transactions on Pattern Analysis and Machine Intelligence., (15):1101-1113, 1993. (Citado na página 10.)

[45] Y. Xu e E.C. Uberbacher. 2D image segmentation using minimum spanning trees. Image and Vision Computing, 15:47-57, 1997. (Citado na página 10.)

[46] A. L. Yuille e S. Ullman. Computational theories of low-level vision. Em D. N. Osherson, S. M. Kosslyn, e J. M. Hollerbach, editores, Visual Cognition and Action: An Invitation to Cognitive Science, volume 2, páginas 5-39. MIT Press, Cambridge, MA, 1990. (Citado na página 1.)

[47] F. A. Zampirolli. Operadores Morfológicos Baseados em Grafos de Vizinhança: uma extensão da MMach toolbox. Tese de doutorado, Instituto de Matemática e Estatística, Universidade de São Paulo, 1997. (Citado nas páginas 14 e 15.) 



\section{ANEXOS}





\title{
Homomorfismo entre Grafos para Segmentação e Reconhecimento de Características Faciais em Sequências de Vídeo: Resultados Preliminares
}

\author{
Ana Beatriz V. Graciano ${ }^{1}$, Roberto Marcondes Cesar JR. ${ }^{1}$, IsAbelle Bloch $^{3}$ \\ ${ }^{1}$ Departamento de Ciência da Computação, IME, Universidade de São Paulo. São Paulo, Brasil. \\ $\{$ cesar, abvg\}@ime.usp.br \\ ${ }^{2}$ Departamento TSI, CNRS URA 80, École Nationale Supérieure des Télécommunications. Paris, França. \\ Isabelle.Bloch@enst. fr
}

\begin{abstract}
Este artigo apresenta uma metodologia baseada em homomorfismo entre grafos para segmentação e reconhecimento de características faciais em sequências de vídeo. Tal metodologia estende uma técnica previamente proposta para imagens estáticas de modo a aplicá-la a sequências de vídeo. Essa generalização se dá através da incorporação do aspecto temporal inerente a tais sequências. Características faciais são representadas por grafos relacionais atribuídos e um modelo de referência é utilizado para assinalar as características de interesse. O processo de reconhecimento, por sua vez, consiste na busca por um homomorfismo ótimo entre os grafos correspondentes à imagem modelo e ao quadro corrente da sequência de vídeo.
\end{abstract}

\section{Introdução}

Este artigo aborda a segmentação e o reconhecimento de características faciais em sequências de vídeo digitais através de homomorfismos entre grafos. A técnica proposta consiste nos primeiros passos para a extensão da metodologia apresentada para imagens estáticas em $[1,2]$ e foi motivada pelo potencial de aplicação apresentado, tais como em biometria, bancos de dados multimeios e interação humanocomputador inteligente. Outras abordagens para o problema incluem o uso de fluxo óptico [9], redes de Gabor Wavelets [6] e outras redes neurais [8].

De modo geral, características faciais são modeladas através de um grafo relacional atribuído, ou ARG (do inglês, attributed relational graph). Esses grafos são obtidos a partir da imagem do gradiente supersegmentado derivado de cada quadro da sequência. Já o processo de reconhecimento das características faciais consiste em buscar um homomorfismo apropriado entre o grafo de um quadro da sequência e aquele de uma imagem modelo em que as características faciais de interesse foram previamente escolhidas.

A Seção 2 aborda os aspectos de representação da face. A Seção 3 explica o passo de busca por homomorfismos entre ARGs, enquanto a Seção 4 explora o processo de rastreamento de características faciais ao longo da sequência de vídeo. Por fim, a Seção 5 apresenta alguns resultados e a Seção 6, conclusões.

\section{Representação da Face}

Grafos Relacionais Atribuídos. Neste trabalho, um grafo dirigido será representado por $\tilde{G}=(N, E)$, onde $N$ representa o conjunto de vértices de $\tilde{G}$ e $E \subseteq N \times N$, seu conjun- to de arestas. Dois vértices $a, b$ de $N$ são ditos adjacentes se $(a, b) \in E$. Se todos os vértices de $\tilde{G}$ são adjacentes entre si, então $\tilde{G}$ é denominado completo. Ainda, $|N|$ e $|E|$ denotam, respectivamente, o número de vértices e de arestas de $G$.

Um grafo relacional atribudo é um grafo a cujos vértices e arestas são associados vetores de atributos. Formalmente, um ARG é definido como $G=(N, E, \mu, \nu)$, onde $N$ e $E \subseteq N \times N$ representam, respectivamente, o conjunto de vértices e de arestas de $G$. Ainda, $\mu: N \rightarrow L_{N}$, também chamado de atributo de objeto, é associado a cada vértice de $G$, enquanto $\nu: E \rightarrow L_{E}$, ou atributo relacional, é associado a cada aresta.

Para os fins deste trabalho, vértices representam regiões conexas de características faciais e arestas denotam relações entre as mesmas, ou seja, carregam informações sobre o arranjo espacial de tais características.

Atributos. Para a discussão a seguir, consideremos um ARG $G=(N, E, \mu, \nu)$ e dois vértices quaisquer $a, b$ de $N$.

$\mathrm{O}$ atributo de objeto $\mu(a)$ é definido como:

$$
\mu(a)=(g(a), w(a), l(a))
$$

O termo $g(a)$ indica o nível de cinza médio da região da imagem associada ao vértice $a$, enquanto $w(a)$ é um coeficiente obtido através da aplicação de uma wavelet de Morlet. Além disso, $g(a)$ e $w(a)$ são normalizados entre 0 e 1 em relação ao maior nível de cinza possível. Finalmente, $l(a)$ é um rótulo de região.

$\mathrm{O}$ atributo relacional $\nu(a, b)$, para $a, b$ em $E$, é defi- 
nido como:

$$
\nu(a, b)=(\vec{v}, \operatorname{sym}(a, b)) .
$$

$\mathrm{O}$ atributo $\vec{v}$ denota o vetor $\left(p_{b}-p_{a}\right) / 2 d_{\max }$, em que $d_{m a x}$ é a distância máxima entre quaisquer dois vértices do grafo da imagem de entrada enquanto $p_{a}$ e $p_{b}$ são os centróides das regiões às quais os vértices $a \mathrm{e} b$ correspondem. $\mathrm{O}$ termo $\operatorname{sym}(a, b)$ representa uma simetria reflexiva calculada como descrito em [3].

O Modelo de Referência da Face. Uma imagem-modelo da face é usada como referência para reconhecer características faciais de interesse. Tipicamente, é utilizado o primeiro quadro da sequência a ser processada, que é segmentado manualmente em regiões relevantes. Ainda, seu respectivo ARG é obtido e deve conter vértices associados a cada característica facial que se deseja rastrear (ex: íris, lábios, sobrancelhas).

\section{O Processo de Reconhecimento de Características Faciais}

Homomorfismo entre Grafos. Considere dois ARGs $G_{1}=\left(N_{1}, E_{1}, \mu_{1}, \nu_{1}\right)$, proveniente de um quadro da sequência, e $G_{2}=\left(N_{2}, E_{2}, \mu_{2}, \nu_{2}\right)$, derivado do modelo. Eles serão chamados, respectivamente, de grafo de entrada e grafo do modelo, e terão seus vértices, arcos e atributos indexados pelos mesmos valores que os identificam.

Um grafo de associação $\tilde{G}_{A}$ entre $G_{1}$ e $G_{2}$ é definido como o grafo completo $\tilde{G}_{A}=\left(N_{A}, E_{A}\right)$, onde $N_{A}=N_{1} \times$ $N_{2}$ e $E_{A}=E_{1} \times E_{2}$.

Um homomorfismo $h$ entre $G_{1}$ e $G_{2}$ é um mapeamento $h: N_{1} \rightarrow N_{2}$ tal que, $\forall a_{1} \in N_{1}, \forall b_{1} \in N_{1}$, se $\left(a_{1}, b_{1}\right) \in$ $E_{1} \Rightarrow\left(h\left(a_{1}\right), h\left(b_{1}\right)\right) \in E_{2}$. Essa definição pressupõe que todos os vértices em $G_{1}$ serão mapeados em $G_{2}$. No caso deste trabalho, tal mapeamento corresponde à fusão de subregiões coerentes na imagem de entrada supersegmentada e, portanto, a obtenção de um homomorfismo apropriado entre $G_{1}$ e $G_{2}$ é essencial.

Como proposto em [1], uma solução para encontrar um homomorfismo entre $G_{1}$ e $G_{2}$ pode ser definida como um sub-grafo completo $\tilde{G}_{S}=\left(N_{S}, E_{S}\right)$ do grafo de associação $\tilde{G}_{A}$, em que $N_{S}=\left\{\left(a_{1}, a_{2}\right), a_{1} \in N_{1}, a_{2} \in N_{2}\right\}$ é tal que $\forall a_{1} \in N_{1}, \exists a_{2} \in N_{2},\left(a_{1}, a_{2}\right) \in E_{S}$, e $\forall\left(a_{1}, a_{2}\right) \in$ $E_{S}, \forall\left(a_{1}{ }^{\prime}, a_{2}{ }^{\prime}\right) \in E_{S}, a_{1}=a_{1}{ }^{\prime} \Rightarrow a_{2}=a_{2}{ }^{\prime}$, garantindo que cada vértice do grafo de entrada corresponda a exatamente um vértice do grafo do modelo e $\left|N_{S}\right|=\left|N_{1}\right|$. Note que tal solução considera apenas as estruturas de $G_{1}$ e $G_{2} \mathrm{e}$ que há outros homomorfismos possíveis.

Função Critério. Para avaliar a qualidade e a adequação de um dado homomorfismo entre os grafos de entrada e do modelo, é necessário definir uma função critério que considere não somente as estruturas dos grafos, mas também as relações entre os atributos das características faciais. Neste trabalho, a adequação de um homomorfismo é analisada minimizando-se a seguinte função critério:

$f\left(\tilde{G}_{S}\right)=\frac{\alpha}{\left|N_{S}\right|} \sum_{\left(a_{1}, a_{2}\right) \in N_{S}} c_{N}\left(a_{1}, a_{2}\right)+\frac{(1-\alpha)}{\left|E_{S}\right|} \sum_{e \in E_{S}} c_{E}(e)$

onde $c_{N}$ e $c_{E}$ são as seguintes medidas de dissimilaridade:

$$
\begin{array}{r}
c_{N}\left(a_{1}, a_{2}\right)=\left\{\begin{array}{l}
\gamma_{N}\left|g_{1}\left(a_{1}\right)-g_{2}\left(a_{2}\right)\right|+ \\
\left(1-\gamma_{N}\right)\left|w_{1}\left(a_{1}\right)-w_{2}\left(a_{2}\right)\right|, \\
\operatorname{se} l\left(a_{1}\right)=l\left(a_{2}\right) \\
\infty, \text { c.c }
\end{array}\right\} \\
c_{E}(e)=\gamma_{E} \phi_{v}+\left(1-\gamma_{E}\right) \phi_{s y m}
\end{array}
$$

e $\phi_{v}, \phi_{s y m}$ são definidos como:

$$
\begin{gathered}
\phi_{v}=\gamma_{v}\left|\left\|\vec{v}_{1}\right\|-\left\|\vec{v}_{2}\right\|\right|+\left(1-\gamma_{v}\right) \frac{|\cos \theta-1|}{2} \\
\phi_{\text {sym }}=\left|\operatorname{sym}\left(a_{1}, b_{1}\right)-\operatorname{sym}\left(a_{2}, b_{2}\right)\right| .
\end{gathered}
$$

Nesse caso, $\cos \theta=\frac{\vec{v}_{1} \vec{v}_{2}}{\left\|\vec{v}_{1}\right\|\left\|\vec{v}_{2}\right\|}$ e os valores $\gamma_{N}, \gamma_{E} \mathrm{e}$ $\gamma_{v}$ são pesos.

Encontrando um Homorfismo. Neste trabalho, a procura por um homomorfismo adequado entre os grafos de entrada e do modelo é realizada a partir de um algoritmo de otimização baseado em busca em árvores. Outras alternativas possíveis são abordadas em [1], [4] e [5].

Em linhas gerais, tal algoritmo gera uma árvore de busca em que cada vértice representa um par de vértices $(k, l), k \in N_{1}$ e $l \in N_{2}$. O vértice raiz é rotulado com $(0,0)$ e expandido em $\left|N_{2}\right|$ filhos rotulados com $(1, l), l=$ $1 \ldots\left|N_{2}\right|$. A cada passo $k$ do algoritmo, o filho que minimiza a função critério, digamos $\left(k, l_{\min }\right)$, é escolhido e também expandido em $\left|N_{2}\right|$ filhos $(k+1, i), i=1 \ldots\left|N_{2}\right|$. Esse processo é repetido até que um vértice $\left(\left|N_{1}\right|, l\right)$ seja alcançado, o que garante que todos os vértices de $G_{1}$ tenham sido mapeados em um vértice de $G_{2}$, estabelecendo um homomorfismo entre os grafos de entrada e do modelo.

\section{O Processo de Rastreamento}

Nesta seção, serão apresentados o processo geral para rastreamento de características faciais ao longo de uma sequência de vídeo, bem como as contribuições deste trabalho para a generalização do que foi proposto em [1]. 
Processo Geral. A Figura 1 apresenta a sequência geral de etapas para a realização da segmentação e do reconhecimento de características faciais num quadro qualquer da sequência de vídeo.

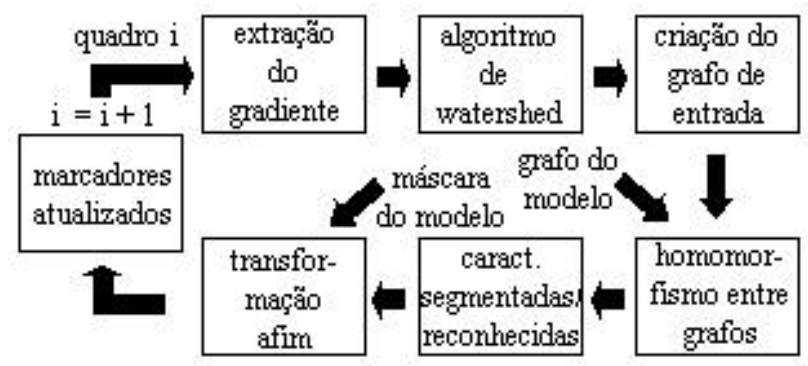

Figura 1: Esquema geral do processo de rastreamento.

Inicialmente, são localizados marcadores aproximados (landmarks) para as características faciais de interesse no quadro, os quais serão utilizados posteriormente para restringir a região em que a imagem deverá ser supersegmentada. Tais marcadores são obtidos através do uso de uma rede de Gabor wavelets (GWN - Gabor Wavelet Networks) [6], caracterizada como um processo de rastreamento global de faces. O passo seguinte consiste na aplicação do algoritmo proposto para imagens estáticas.

Uma das contribuições mais relevantes à metodologia está relacionada à atualização dos marcadores que serão usados no quadro subsequente da sequência de vídeo, permitindo a independência do processo em relação ao uso da GWN.

Como uma sequência de vídeo possui um caráter dinâmico e suas imagens, em geral, variam em função do tempo, a atualização dos marcadores mostra-se importante para a manutenção da qualidade da segmentação e para o rastreamento adequado das características faciais.

Atualização dos Marcadores. Embora a técnica GWN possa ser aplicada a cada quadro da sequência para atualizar os marcadores, seria interessante aproveitar as informações obtidas diretamente dos grafos e da imagem-modelo. Para tanto, uma transformação afim é aplicada para mapear a imagem-modelo ao quadro atual baseando-se nas características faciais reconhecidas e, então, atualizando-se os marcadores.

No primeiro quadro da sequência, os marcadores previamente obtidos relativos ao modelo são também usados para essa imagem. Nos quadros subsequentes, após o término do processo de reconhecimento, são calculados os centróides das regiões das características faciais de interesse. Além disso, são calculados os centróides das regiões prédefinidas do modelo. Então, a transformação afim que me- lhor mapeia o conjunto de centróides do modelo para o conjunto relativo ao quadro considerado é estimada e aplicada usando-se a seguinte fórmula [7]:

$$
\vec{q}=\alpha(A \vec{s}+\vec{b})
$$

onde $A$ corresponde a uma matriz $2 \times 2$ não-singular representando a transformação procurada, $\alpha$ é um valor escalar qualquer, e $\vec{q}, \vec{s}$ são os vetores das coordenadas dos centróides do quadro e do modelo respectivamente.

Essa transformação afim permite, além da atualização dos marcadores, a projeção da imagem-modelo sobre o quadro segmentado e reconhecido, permitindo uma avaliação visual do processo de reconhecimento.

Possíveis Extensões. Embora a mudança supracitada torne a metodologia mais robusta para ser aplicada a sequências de vídeo, nossa pesquisa em andamento objetiva um maior aproveitamento das informações possivelmente redundantes presentes em quadros distintos.

Possíveis abordagens incluem a inserção de arestas temporais à estrutura dos ARGS, as quais representariam transições e relações entre quadros consecutivos da sequência e permitiriam recalcular atributos de objeto e relacionais, ou ainda adicionar novas características faciais ao rastreamento durante o processo, tornando o modelo desnecessário.

Além disso, o resultado obtido na busca de um homomorfismo entre o grafo modelo e aquele correspondente ao do $i$-ésimo quadro poderia ser reutilizado como solução inicial da busca a ser realizada no quadro $i+1$, reduzindose a expansão dos nós e considerando-se transições suaves entre quadros consecutivos.

\section{Resultados}

Nesta seção, mostramos alguns dos primeiros resultados obtidos a partir da aplicação dos novos passos apresentados na seção anterior.

Os testes foram realizados a partir de sequências de vídeo com mudanças consideráveis na face ao longo do tempo, tais como sorrisos, piscar de olhos, movimentação da cabeça, entre outras.

A Figura 2 exibe os resultados obtidos da projeção da máscara do modelo sobre alguns quadros de uma sequência composta por 96 imagens coloridas de tamanho $512 \times 512$, que foram convertidas para níveis de cinza para o propósito do algoritmo. O tempo de processamento da sequência completa foi de, aproximadamente, duas horas e meia num computador com processador de $1.8 \mathrm{Ghz}$ e $1 \mathrm{~Gb}$ de RAM. Como esta primeira etapa pretendia avaliar a metodologia em relação à qualidade dos resultados, o desempenho computacional não recebeu atenção especial. Porém, esse aspecto será considerado na continuação do trabalho. 


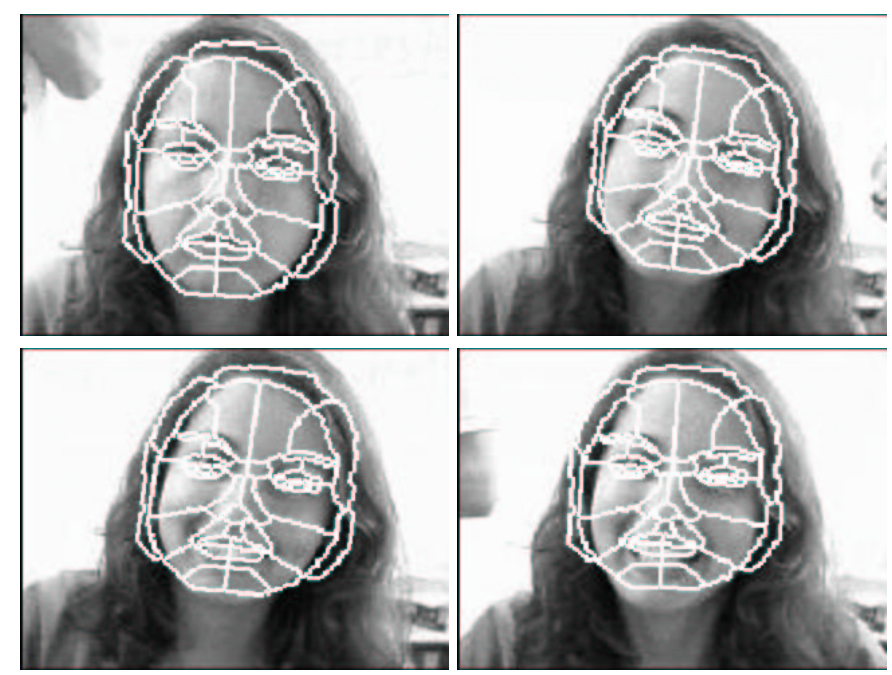

Figura 2: Máscaras do modelo projetadas sobre seus respectivos quadros segmentados e reconhecidos, de acordo com as transformações afins encontradas.

É possível verificar que a máscara do modelo é satisfatoriamente projetada sobre a face, permitindo o rastreamento da mesma ao longo da sequência. Ainda, grande parte das características faciais que podem ser de interesse (ex: sobrancelhas, narinas, nariz, lábios) são corretamente rastreadas, comprovando a validade do processo de reconhecimento e da atualização dos marcadores.

No entanto, certos refinamentos ainda são necessários à metodologia, especialmente em relação a mudanças bruscas entre quadros e às ações que devem ser tomadas quando novas características faciais são introduzidas na sequência.

\section{Conclusões}

Neste artigo, foi proposto um primeiro passo para a generalização da metodologia proposta em [1]. Os resultados preliminares mostraram que é possível refletir as mudanças nas características faciais entre quadros através de transformações afins. Apesar dos resultados encorajadores provenientes dessa modificação, as outras possibilidades listadas na Seção 4 são o tópico de nossa pesquisa em andamento.

\section{Agradecimentos}

Este trabalho foi parcialmente realizado com o auxílio de uma verba CAFES-COFECUB. A. Graciano recebeu apoio do CNPQ (132562/2003-0). R. Cesar recebeu apoio da FAPESP (99/12765-2) e do CNPQ (300722/98-2).

\section{Referências}

[1] R. Cesar, E. Bengoetxea and I.Bloch. Inexact graph matching using stochastic optimization techniques for facial fea- ture recognition. In 16th International Conference on Pattern Recognition, volume 2, pages 465-468, August 2002.

[2] R.M. Cesar Jr. and I. Bloch. First results on facial feature segmentation and recognition using graph homomorphisms. In Proc. VI Simpósio Ibero-Americano de Reconhecimento de Padrões, pages 95-99, Florianópolis, Brazil, 2001.

[3] O. Colliot, A.V. Tuzikov, R.M. Cesar Jr. and I. Bloch. Approximate reflectional symmetries of fuzzy objects with an application in model-based object recognition. In Press. Fuzzy Sets and Systems, 2003.

[4] A. Perchant and I. Bloch. Fuzzy morphisms between graphs. In Fuzzy Sets and Systems, 128(2):149-168, 2002.

[5] R.C. Wilson and E.R. Hancock. A Bayesian compatibility model for graph matching. In Pattern Recognition Letters, 17(3):263-276, 1996.

[6] V. Kruger and G. Sommer. Affine real-time face tracking using a wavelet network. In Proc. of ICVV'99 Workshop Recognition, Analysis, and Tracking of Faces and Gestures in Real-Time Systems, pages 141-148, Corfu, Greece, 1999.

[7] R.M. Cesar Jr. and L. da F. Costa. Shape Analysis and Classification - Theory and Practice. CRC Press, 1 edition, 2001.

[8] S.H. Lin, S.Y. Kung, and L.J. Lin. Face Recognition/Detection by Probabilistic Decision-Based Neural Network. In IEEE Transactions on Neural Networks, 8(1):114132.

[9] Y. Yacoob and L.S. Davis. Computing Spatio-Temporal Representations of Human Faces. In CVPR94, pages 70-75, 1994. 


\title{
Inexact Graph Matching for Facial Feature Segmentation and Recognition in Video Sequences: Results on Face Tracking
}

\author{
Ana Beatriz V. Graciano ${ }^{1}$, Roberto M. Cesar-Jr ${ }^{1}$, and Isabelle Bloch ${ }^{2}$ \\ 1 Department of Computer Science, IME, University of São Paulo. São Paulo, Brazil. \\ \{cesar, abvg\}@ime.usp.br \\ 2 Signal and Image Processing Department, CNRS UMR 5141 LTCI, École Nationale \\ Supérieure des Télécommunications. Paris, France. \\ Isabelle.Bloch@enst.fr
}

\begin{abstract}
This paper presents a method for the segmentation and recognition of facial features and face tracking in digital video sequences based on inexact graph matching. It extends a previous approach proposed for static images to video sequences by incorporating the temporal aspect that is inherent to such sequences. Facial features are represented by attributed relational graphs, in which vertices correspond to different feature regions and edges to relations between them. A reference model is used and the search for an optimal homomorphism between its corresponding graph and that of the current frame leads to the recognition.
\end{abstract}

\section{Introduction}

This paper deals with segmentation and recognition of facial features in digital video sequences through the use of an inexact graph matching technique. The proposed technique constitutes a first approach to the generalization of the methodology developed in $[3,4]$ for facial feature segmentation and recognition in static images.

This extension is motivated by the fact that the subject of face analysis and recognition arises in various computer vision applications involving human activity recognition, such as affective computing, surveillance, teleconferencing and multimedia databases. Since many of these involve video sequence processing, it is also interesting to incorporate the notion of motion-based recognition [8] in the methodology.

The main idea is to model the target facial features in a given face through an attributed relational graph (ARG), a structure in which vertices represent the facial features and their attributes, while edges represent spatial relations among them. The model image is manually segmented into the facial features of interest and relations are computed to derive a model ARG. In each input image where recognition has to be performed, i.e. each frame, its gradient is extracted and a watershed algorithm is applied to it. Then, an input ARG is obtained from the resulting oversegmented image as for the model. The recognition step relies on an 
inexact graph matching procedure that finds a suitable homomorphism between the graph obtained from the model and the one obtained from the image.

The technique of inexact graph matching has been extensively studied in several different domains $[2,9,10]$, such as pattern recognition, computer vision, cybernetics, among others. This approach is justified here due to the difficulty in finding an isomorphism between the model image graph and the input image one: since the latter represents an oversegmented image, it is not possible to expect a bijective correspondence between both structures.

It is worth noting that the term facial feature recognition used hereby means that each facial feature of interest will be located and classified as such. Therefore, it is not related to the recognition performed as a means of matching a face against a known database of faces for instance (no face recognition is performed). Based on [3] where the static methodology is introduced and on [4] where the optimization of the graph matching process is addressed using several methods, the main contribution of the present work is to develop a methodology that can be applied to video sequences, i.e. incorporating the temporal dimension.

This paper is organized as follows. Section 2 explains how a face is modeled as an attributed relational graph. Section 3 explains the inexact graph matching step of the methodology. Section 4 shows how the tracking process is performed throughout the video frames. Section 5 presents some obtained results and conclusions.

\section{Face Representation}

Attributed Relational Graphs. In this work, a directed graph will be denoted by $\tilde{G}=(N, E)$, where $N$ represents the set of vertices of $\tilde{G}$ and $E \subseteq N \times N$ the set of edges. Two vertices $a, b$ of $N$ are said to be adjacent if $(a, b) \in E$. When each vertex of $\tilde{G}$ is adjacent to all others, then $\tilde{G}$ is said to be complete. Furthermore, $|N|$ denotes the number of vertices in $G$, while $|E|$ denotes its number of edges.

An attributed relational graph (also referred to as ARG) is a graph in which attribute vectors are assigned to vertices and to edges. Formally, we define an ARG as $G=(N, E, \mu, \nu)$, where $N$ represents the set of vertices of $G$ and $E \subseteq N \times N$ the set of edges. Furthermore, $\mu: N \rightarrow L_{N}$ assigns an attribute vector to each vertex of $G$, while $\nu: E \rightarrow L_{E}$ assigns an attribute vector to each edge in $G$.

The structure of a face can be thought of as being a collection of features (e.g: lips, eyebrows, nostrils, chin) which are somehow related in terms of their relative positions on the face. In the proposed model, facial feature regions are represented by vertices in a graph, while relations between them are represented by edges. The attribute vectors $\mu$ and $\nu$ may also be called object and relational attributes, respectively. The former refers to connected regions in the image and the latter to the spatial arrangement of the regions.

Attributes. The object and relational attributes convey the knowledge about faces to the ARG structure. The attributes which have been considered in this 
work are the same as in [3]. Let us consider an ARG $G=(N, E, \mu, \nu)$ and any two vertices $a, b$ in $N$.

The object attribute $\mu(a)$ is defined as:

$$
\mu(a)=(g(a), w(a), l(a)) .
$$

The term $g(a)$ corresponds to the average gray-level of the image region associated to vertex $a$, whereas $w(a)$ is a coefficient obtained from the application of a Morlet wavelet. Both $g(a)$ and $w(a)$ are normalized between 0 and 1 with respect to the maximum possible grey-level. Finally, $l(a)$ is a region label.

The relational attribute $\nu(a, b)$, for $a, b$ in $E$, is defined as:

$$
\nu(a, b)=(\vec{v}, \operatorname{sym}(a, b)) .
$$

The first attribute is the vector $\vec{v}=\left(p_{b}-p_{a}\right) / 2 d_{\max }$, where $d_{\max }$ is the maximum distance between any two points of the input graph, while $p_{a}$ and $p_{b}$ denote the centroids of the image regions to which vertices $a$ and $b$ correspond. The term $\operatorname{sym}(a, b)$ denotes a reflectional symmetry calculated as described in [1].

The Face Model. A face model image is used as a reference to recognize facial features of interest. This image can be for instance the first frame of a given video sequence. It is manually segmented into facial feature regions of interest and the landmark of each region is calculated. Then, the corresponding ARG is derived.

The model graph should contain vertices associated to each target facial feature region (e.g. lips, iris, eyebrows, skin). However, if a single feature presents considerable variability within its domain, it might need to be subdivided into smaller sub-regions, so that the averages considered when calculating both vertex and edge attributes can be more representative.

\section{The Facial Feature Recognition Process}

Graph Homomorphism. Consider two ARGs $G_{1}=\left(N_{1}, E_{1}, \mu_{1}, \nu_{1}\right)$ derived from the image and $G_{2}=\left(N_{2}, E_{2}, \mu_{2}, \nu_{2}\right)$ derived from the model. They will be called input and model graphs respectively. Also, subscripts will be used to refer to vertices and edges in each graph, e.g. $a_{1} \in N_{1}$ is a vertex in $G_{1},\left(a_{2}, b_{2}\right) \in E_{2}$ is an edge in $G_{2}$. It is also important to notice that, since $G_{1}$ results from an oversegmented image, $\left|N_{1}\right|$ is much greater than $\left|N_{2}\right|$ in general.

An association graph $\tilde{G}_{A}$ between $G_{1}$ and $G_{2}$ is defined as the complete graph $\tilde{G}_{A}=\left(N_{A}, E_{A}\right)$, where $N_{A}=N_{1} \times N_{2}$ and $E_{A}=E_{1} \times E_{2}$.

A graph homomorphism $h$ between $G_{1}$ and $G_{2}$ is a mapping $h: N_{1} \rightarrow N_{2}$ such that $\forall a_{1} \in N_{1}, \forall b_{1} \in N_{1},\left(a_{1}, b_{1}\right) \in E_{1} \Rightarrow\left(h\left(a_{1}\right), h\left(b_{1}\right)\right) \in E_{2}$. This definition assumes that all vertices in $G_{1}$ should be mapped to $G_{2}$.

Finding a homomorphism between $G_{1}$ and $G_{2}$ is essential to the face feature recognition process. Since $\left|N_{1}\right|$ is greater than $\left|N_{2}\right|$, a suitable homomorphism between the input and model graphs should map distinct vertices of $G_{1}$ into a 
single vertex of $G_{2}$, which corresponds to merging coherent sub-regions in the input oversegmented image.

As proposed in [3], a solution for finding a homomorphism between $G_{1}$ and $G_{2}$ may be defined as a complete sub-graph $\tilde{G}_{S}=\left(N_{S}, E_{S}\right)$ from the association graph $\tilde{G}_{A}$, in which $N_{S}=\left\{\left(a_{1}, a_{2}\right), a_{1} \in N_{1}, a_{2} \in N_{2}\right\}$ such that $\forall a_{1} \in N_{1}, \exists a_{2} \in$ $N_{2},\left(a_{1}, a_{2}\right) \in E_{S}$, and $\forall\left(a_{1}, a_{2}\right) \in E_{S}, \forall\left(a_{1}{ }^{\prime}, a_{2}{ }^{\prime}\right) \in E_{S}, a_{1}=a_{1}{ }^{\prime} \Rightarrow a_{2}=a_{2}{ }^{\prime}$, assuring that each vertex from the input graph corresponds to exactly one vertex of the model graph and $\left|N_{S}\right|=\left|N_{1}\right|$. It should be clear that such a solution only considers the structures of $G_{1}$ and $G_{2}$, and that it gives rise to many possible homomorphisms between both graphs.

Objective Function. In order to evaluate the quality and suitability of a given homomorphism between the input and model graphs, an objective function must be defined. It should consider not only the structure of the graphs, but also the attributes of the facial features and their relations. In this paper, the assessment of a certain homomorphism is accomplished through the minimization of the following function:

$$
f\left(\tilde{G}_{S}\right)=\frac{\alpha}{\left|N_{S}\right|} \sum_{\left(a_{1}, a_{2}\right) \in N_{S}} c_{N}\left(a_{1}, a_{2}\right)+\frac{(1-\alpha)}{\left|E_{S}\right|} \sum_{e \in E_{S}} c_{E}(e)
$$

where $c_{N}$ and $c_{E}$ are dissimilarity measures given as follows:

$$
\left.\begin{array}{c}
c_{N}\left(a_{1}, a_{2}\right)=\left\{\begin{array}{l}
\gamma_{N}\left|g_{1}\left(a_{1}\right)-g_{2}\left(a_{2}\right)\right|+\left(1-\gamma_{N}\right)\left|w_{1}\left(a_{1}\right)-w_{2}\left(a_{2}\right)\right|, \\
\text { if } l\left(a_{1}\right)=l\left(a_{2}\right) \\
\infty, \text { otherwise }
\end{array}\right\} \\
c_{E}(e)=\gamma_{E} \phi_{v}+\left(1-\gamma_{E}\right) \phi_{\text {sym }}
\end{array}\right\}
$$

and $\phi_{v}$ and $\phi_{s y m}$ are defined as

$$
\begin{gathered}
\phi_{v}=\gamma_{v}\left|\left\|\vec{v}_{1}\right\|-\left\|\vec{v}_{2}\right\|\right|+\left(1-\gamma_{v}\right) \frac{|\cos \theta-1|}{2} \\
\phi_{\text {sym }}=\left|\operatorname{sym}\left(a_{1}, b_{1}\right)-\operatorname{sym}\left(a_{2}, b_{2}\right)\right| .
\end{gathered}
$$

In this case, $\cos \theta=\frac{\vec{v}_{1} \vec{v}_{2}}{\left\|\vec{v}_{1}\right\|\left\|\vec{v}_{2}\right\|}$ and the values $\gamma_{N}, \gamma_{E}$ and $\gamma_{v}$ are weighting parameters.

Performing Inexact Graph Matching. Many approaches have been explored for optimizing inexact graph matching for pattern recognition purposes, such as those mentioned in [3], [7] and [10].

In this work, the matching is achieved through the use of a tree search algorithm. Other possible alternatives include genetic and estimation of distribution algorithms [3]. 
In general terms, the tree-search optimization algorithm builds a search-tree where each vertex represents a pair of vertices $(k, l), k \in N_{1}$ and $l \in N_{2}$. The root vertex is labelled $(0,0)$ and it is expanded in $\left|N_{2}\right|$ sons labelled $(1, l), l=1 \ldots\left|N_{2}\right|$. At each step $k$ of the algorithm, the son which minimizes the objective function, say $\left(k, l_{\text {min }}\right)$ is chosen and therefore expanded in $\left|N_{2}\right|$ sons $(k+1, i), i=1 \ldots\left|N_{2}\right|$. The process is repeated until a vertex $\left(\left|N_{1}\right|, l\right)$ is reached, which guarantees that all vertices of $G_{1}$ have been assigned to a vertex of $G_{2}$, thus establishing a homomorphism between the input and model graphs.

\section{The Tracking Process}

In this section, we aim at generalizing the previous approach to video sequences. Since digital video is composed of a sequence of images which change over time, it is needed to incorporate in the methodology this temporal aspect and transitions between images, reflecting facial feature changes throughout the video (e.g. a progressive smile or a blink). In this section, we present our first approach towards reflecting such changes in the facial features.

General Scheme. The overall sequence of steps performed in order to segment and recognize the facial features of interest in a generic frame of the input video sequence is illustrated in Figure 1.

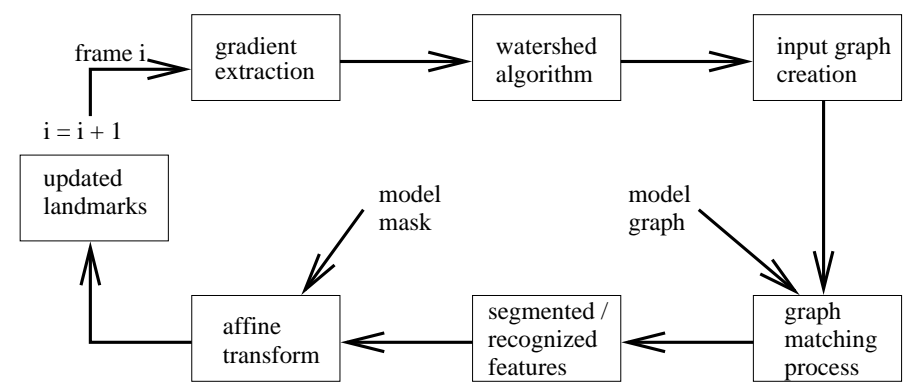

Fig. 1. Overview of the tracking process.

Initially, approximative landmarks of the target facial features are located in the first frame for future constraint on the region in which the oversegmentation will be performed. They are obtained through the use of the Gabor Wavelet Network (GWN) [6]. Then the previous algorithm for static images is applied in the regions of the face around the landmarks.

One of the main contributions in the methodology is related to updating the landmarks which will be used in the subsequent frame in the video sequence, thus avoiding the need for a global face tracking procedure (i.e. GWN in our specific case) in addition to the graph matching. If the same landmarks were applied to all frames, the matching and recognition results would possibly not be satisfactory, 
since the features in each frame usually have considerable differences in terms of their positions.

Landmark Updating. The GWN technique could be applied to each frame of the sequence in order to update the landmarks. However, it would be interesting to make use of the information obtained directly from the graph methodology and the model image. To accomplish this, an affine transformation is applied in order to map the model image to the frame under consideration based on the recognized facial features, allowing the landmark updating.

For the first frame, the model landmarks, which have been obtained as explained in Sect. 2, are also used as landmarks for that frame. For the subsequent frames, once the recognition procedure is finished, the centroids of the facial features of interest are calculated. Also, the centroids of the pre-defined regions in the model are calculated. Then, the affine transformation that best maps the model set of centroids to that of the considered frame is estimated and applied through the following formula [5]:

$$
\vec{q}=\alpha(A \vec{s}+\vec{b})
$$

where $A$ corresponds to a $2 \times 2$ non-singular matrix representing the sought transformation, $\alpha$ is any scalar value, and $\vec{q}, \vec{s}$ are the centroid-coordinate vectors for the frame and model respectively.

This affine transformation allows us not only to update the input face landmarks to be applied to the following frame in the process, but also to project the model image onto the segmented and recognized target frame, conveying a visual assessment of the matching process.

Possible Extensions. Although this change in the methodology already makes it more robust for the application in video sequences, our ongoing research aims at making better use of the possibly redundant information present in distinct frames.

One possible approach is to insert temporal edges to the set $E$ of an ARG $G$. These edges would represent the transitions and relations among vertices of consecutive frames in the sequence. Through this, it would be possible to recalculate both vertex and edge attributes and a model image could be no longer needed for the recognition. Also, features which were not present in the first frame could be added to the recognition process on-the-fly.

Furthermore, the results obtained in the graph matching procedure for, say, frame $i$ could be reused as the initial solution for the matching step in frame $i+1$, thus reducing the tree expansion and taking into account the smooth changes presented in frame transitions. This generalization belongs to our ongoing research.

\section{Results and Conclusion}

In this section we show some of the first results obtained from the application of the new steps introduced in the previous section. For the tests, different video 
sequences were considered, such as sequences of male and female faces with static or changing background. All sequences presented considerable changes in the face (e.g. smiles, head movement, blinking) throughout time.

Figure 2 depicts the results obtained for the frame-to-frame projection of the model-mask onto the corresponding target frames. The video sequence was composed of 96 color frames of size $512 \times 512$ which have been converted to grey-level images for the purpose of the algorithm. As it can be seen, the model mask is successfully matched up to the face, thus allowing it to be tracked along the video sequence. The facial features defined by the mask are approximately matched up to their correspondents in the image, though some mismatched regions (mouth in the last image) may be noted due to the global nature of the affine transform and to differences in the facial expressions among the frames.
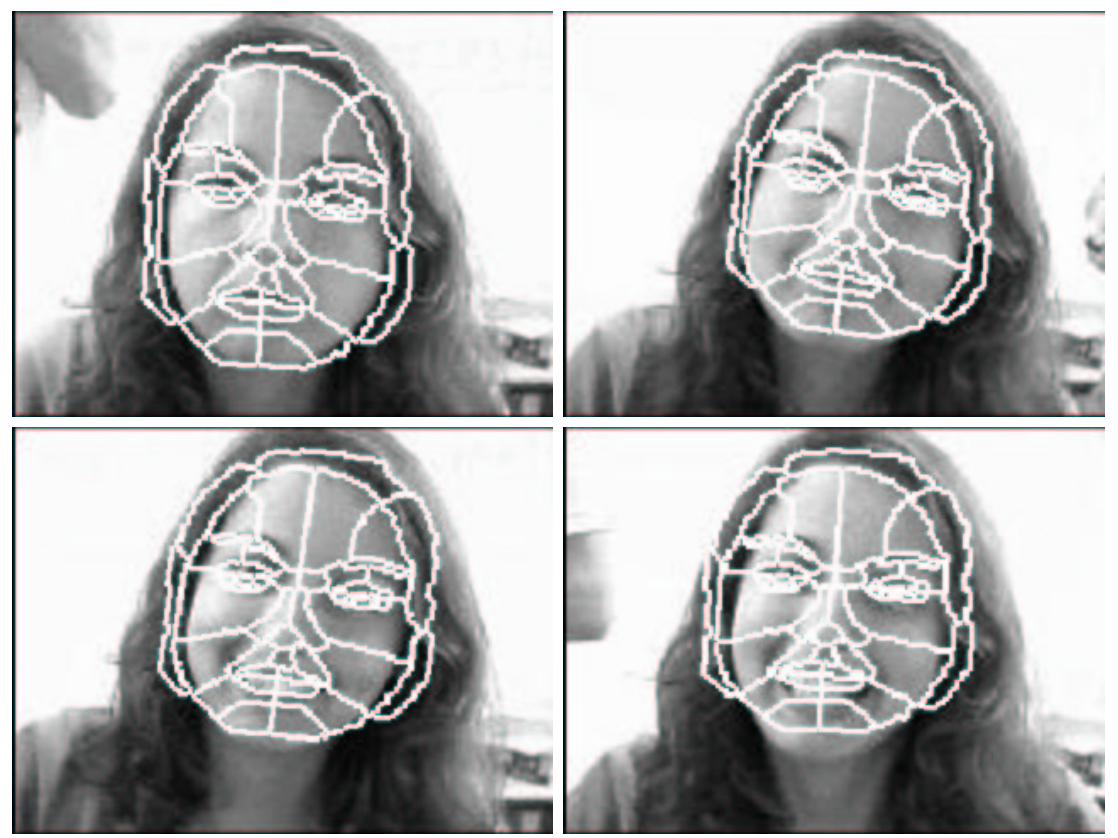

Fig. 2. Model masks superimposed on successive target frames using the recognized facial features.

In terms of the results obtained by the advances proposed in this paper, i.e, the landmark updating and its assessment through the projection of the model mask onto the input face, it can be seen that the mask projection follows the head movements in a plausible manner. Also, most facial features which may be of interest are correctly tracked (e.g.: eyebrows, nostrils, nose, lips), showing that the recognition process and the landmark updating can be effective and provide encouraging results. 
Nevertheless, certain refinements in the technique are still called for, especially when a considerable sudden change is present between frames, or when unknown facial features, i.e. those which were not present in the model, appear throughout the sequence. In such cases, the unknown facial features will be necessarily mapped to one of the classified facial features, which might lead to results such as the one seen in the frames of Figure 2 where a smile occurs.

Thus, in this paper we have proposed a first approach towards the generalization of the methodology presented in [3]. The first results have shown that it is possible to reflect the changes in facial features in each frame that occurs throughout time using appropriate affine transformations. Although the introduced steps have provided encouraging results, the other possibilities mentioned in Sect. 4 are being considered in our ongoing work.

Acknowledgments. This work was partially funded by a CAPES/COFECUB grant. A. Graciano is grateful to $\mathrm{CNPq}(132562 / 2003-0)$. R. Cesar is grateful to FAPESP (99/12765-2) and to CNPq (300722/98-2).

\section{References}

[1] O. Colliot, A.V. Tuzikov, R.M. Cesar Jr., and I. Bloch. Approximate reflectional symmetries of fuzzy objects with an application in model-based object recognition. Fuzzy Sets and Systems, 2003. In Press.

[2] D. Fontaine and N. Ramaux. An approach by graphs for the recognition of temporal scenarios. IEEE Transactions on Systems, Man, and Cybernetics - Part B: Cybernetics, 28(3):387-403, June 1998.

[3] R.M. Cesar Jr., E. Bengoetxea, and I.Bloch. Inexact graph matching using stochastic optimization techniques for facial feature recognition. In 16th International Conference on Pattern Recognition, volume 2, pages 465-468, August 2002.

[4] R.M. Cesar Jr. and I. Bloch. First results on facial feature segmentation and recognition using graph homomorphisms. In Proc. VI Simpósio Ibero-Americano de Reconhecimento de Padrões, pages 95-99, Florianópolis, Brazil, 2001.

[5] R.M. Cesar Jr. and L. da F. Costa. Shape Analysis and Classification - Theory and Practice. CRC Press, 1 edition, 2001.

[6] V. Kruger and G. Sommer. Affine real-time face tracking using a wavelet network. In Proc. of ICVV'99 Workshop Recognition, Analysis, and Tracking of Faces and Gestures in Real-Time Systems, pages 141-148, Corfu, Greece, 1999.

[7] A. Perchant and I. Bloch. Fuzzy morphisms between graphs. Fuzzy Sets and Systems, 128(2):149-168, 2002.

[8] M. Shah and R. Jain, editors. Motion-Based Recognition. Computational Imaging and Vision. Kluwer Academic Publishers, 1997.

[9] L.B. Shams, M.J. Brady, and S. Schaal. Graph matching vs mutual information maximization for object detection. Neural Networks, 14:345-354, 2001.

[10] R.C. Wilson and E.R. Hancock. A Bayesian compatibility model for graph matching. Pattern Recognition Letters, 17(3):263-276, 1996. 